M. Saffaripour ${ }^{1}$, K.P. Geigle, D.R. Snelling ${ }^{1}$, G.J. Smallwood ${ }^{1}$, K.A. Thomson ${ }^{1}$, Influence of Rapid Laser Heating on the Optical Properties of In-Flame Soot Appl. Phys. B 119 (2015) 621-642.

${ }^{1}$ National Research Council Canada, Ottawa, Canada

The original publication is available at www.springerlink.com

http://dx.doi.org/10.1007/s00340-015-6072-6 


\title{
Influence of Rapid Laser Heating on the Optical Properties of In-Flame Soot
}

\author{
M. Saffaripour ${ }^{1}$, K.-P. Geigle ${ }^{2}$, D.R. Snelling ${ }^{1}$, G.J. Smallwood ${ }^{1}$, K.A. Thomson ${ }^{1, *}$ \\ ${ }^{1}$ National Research Council Canada, 1200 Montreal Road, Ottawa, Canada, K1A OR6 \\ ${ }^{2}$ German Aerospace Centre (DLR), Pfaffenwaldring 38-40, Stuttgart, Germany, 70569
}

\begin{abstract}
To understand the effect of rapid heating on the optical properties of in-flame soot and its potential influence on the laser-induced incandescence (LII) signal, the time-resolved extinction coefficient of soot is measured in diffusion and premixed flames during laser heating. Heating is performed using a 1064$\mathrm{nm}$ pulsed laser with fluences ranging from 0.2 to $6.2 \mathrm{~mJ} / \mathrm{mm}^{2}$. Extinction measurements are carried out using continuous-wave lasers at four different wavelengths. A rapid enhancement of extinction, by up to $10 \%$ in the diffusion flame and $18 \%$ in the premixed flame, occurs during laser heating most likely as a result of temperature-dependent optical properties and laser-induced thermal annealing of soot. The thermal expansion of flame gases causes a gradual decline of soot concentration for about $2 \mu$ s after the laser pulse. Significant loss of soot material by sublimation is observed at fluences as low as 1.03 and $2.06 \mathrm{~mJ} / \mathrm{mm}^{2}$ for the diffusion and premixed flames, respectively. A secondary rise in extinction coefficient is observed from about 50 to $800 \mathrm{~ns}$ after the laser pulse at low monitoring wavelengths, attributed to the formation of light-absorbing gaseous species from the sublimated soot material. These effects may impact the LII signal and should be accounted for in LII analysis.
\end{abstract}

\section{Introduction}

Laser-induced incandescence (LII) is an optical diagnostic technique used to measure the concentration and size of soot particles. This technique uses a laser pulse to rapidly heat the particles to incandescence temperatures and the radiation emission from the soot is measured and analyzed. A key assumption of many LII models is that the internal structure, morphology, and optical properties of soot are not affected by rapid laser heating. However, there is evidence in the literature to suggest that intense laser irradiance typical of 'high fluence' LII leads to significant and irreversible changes in the internal structure of soot particles, sublimation and loss of material from soot, and the formation of new particles from the sublimated material [1,2]. Even for moderate laser fluences (i.e., less than $2 \mathrm{~mJ} / \mathrm{mm}^{2}$ at $1064 \mathrm{~nm}$ ) commonly used for auto-compensating LII (AC-LII) [3], slight but permanent morphological changes have been observed via high resolution transmission electron microscopy (HR-TEM) and by dual-laser pulse LII measurements [4,5]. These permanent transformations occur on a timescale relevant to the LII emission, i.e., the first 1000 ns after heating [6,7]; hence they should be considered in the interpretation of the LII signal.

\footnotetext{
* Corresponding author: kevin.thomson@nrc-cnrc.gc.ca
} 
In addition to the irreversible changes of soot structure, reversible modifications in the light absorption and emission properties of soot particle related to their expansion and varying temperature should be considered because these changes intrinsically happen on a timescale relevant to the LII emission measurements. The time-resolved laser induced incandescence emission is described as:

$$
I_{L I I, \lambda}(t)=N_{\mathrm{p}} C_{\mathrm{abs}, \lambda}^{\mathrm{p}} B_{\lambda}[T(t)] w
$$

where $N_{\mathrm{p}}$ is the number density of primary particles in the aerosol-laden measurement volume, $C_{\mathrm{abs}, \lambda}^{\mathrm{p}}$ is the light absorption cross-section of a primary particle for wavelength $\lambda, B_{\lambda}$ is Planck's function for blackbody emission for wavelength $\lambda, T(t)$ is the instantaneous soot temperature, and $w$ is the depth of the excitation volume. As indicated in Eq. (1), the total light absorption by aggregates is equated to the sum of the light absorption by the individual primary particles, based on Rayleigh-Debye-Gans approximation for fractal-aggregate (RDG-FA) [8,9]. The absorption cross-section of the individual primary particles is described by the Rayleigh limit of Mie theory in which light absorption is proportional to the volume of the primary particles, i.e.

$$
C_{\mathrm{abs}, \lambda}^{\mathrm{p}}=\frac{\pi^{2} d_{\mathrm{p}}{ }^{3} E\left(m_{\lambda}\right)}{\lambda},
$$

where $d_{\mathrm{p}}$ is primary particle diameter, $E\left(m_{\lambda}\right)$ is the soot absorption refractive index function, and $\lambda$ is the wavelength of light.

It is evident that a temporary increase in the volume of soot during laser heating will lead to a proportional increase in its volume fraction. However, it is less certain whether this increase will change the propensity of the soot to absorb and emit light. Michelsen et al. [10] suggested several possible thermal expansion coefficients from which it is estimated that the volume of soot could increase by 4 to $26 \%$ when soot is heated from 1800 to $4000 \mathrm{~K}$. Considering that particle expansion could be significant, particle volume change should be correctly accounted for in the interpretation and modeling of LII emission if related to radiative properties. It is necessary to also consider the influence of a temperature-dependent particle size on the refractive index absorption function, $E\left(m_{\lambda}\right)$. If a particle expands because of heating, the distances between the small scale (i.e., molecular) and the intermediate scale (e.g., planar graphitic microcrystallites) structures in the particle change and it is reasonable to anticipate that $E\left(m_{\lambda}\right)$ will also change. This view is supported by Maxwell-Garnett theory [11], developed to predict the effective electromagnetic properties of inhomogeneous material. This theory can be used to predict the variation of the optical properties of soot caused by a change of soot density:

$$
\left(\frac{m^{2}-1}{m^{2}+2}\right)_{\mathrm{eff}}=\frac{\rho(T)}{\rho\left(T_{o}\right)}\left(\frac{m^{2}-1}{m^{2}+2}\right)
$$

where $m$ is the complex refractive index of soot and $\rho(T)$ is its density at temperature $T[12,13]$. Since $E\left(m_{\lambda}\right)$ is proportional to $\left[\left(m^{2}-1\right) /\left(m^{2}+2\right)\right]_{\mathrm{eff}}$, as the volume of the particle increases because of expansion, $E\left(m_{\lambda}\right)$ would proportionally decrease and no enhancement of light absorption would be expected. In other words, Maxwell-Garnett theory predicts that light absorption by soot aggregates is proportional to the mass rather than the volume of the particles. 
The influence of laser pulse heating on the optical properties of soot has been explored by several researchers. Witze et al. [14] simultaneously performed time-resolved LII using a 532-nm laser pulse, time-resolved elastic light scattering (ELS) generated by the heating pulse, and pulse-integrated light extinction measurements of the heated soot particles in a propane diffusion flame using different laser fluences. The peak of the time-resolved LII signal enhanced with increasing fluence for fluences up to $2.27 \mathrm{~mJ} / \mathrm{mm}^{2}$, after which it monotonically declined because of the onset of sublimation. The cooling rate of soot particles decreased with increasing fluence for fluences below $0.6 \mathrm{~mJ} / \mathrm{mm}^{2}$, which was attributed to thermal-annealing and increased optical emissivity of laser-heated soot particles. On the other hand, a faster cooling was observed for higher fluence levels possibly because of the increased sublimation, reducing the time available for thermal annealing. The scattering coefficient was not affected by the laser pulse for a fluence range of $0.2-1.2 \mathrm{~mJ} / \mathrm{mm}^{2}$. At higher fluences, in particular above $2 \mathrm{~mJ} / \mathrm{mm}^{2}$, a significant decrease of scattering coefficient upon the laser pulse was observed with increasing fluence most likely related to material loss; however, changes in material properties might have also contributed. The time-averaged light extinction coefficient was shown to increase by about $20 \%$ over the unheated soot with increasing fluence for fluence levels below $2 \mathrm{~mJ} / \mathrm{mm}^{2}$. This effect was attributed to either an enhancement in the optical absorptivity by thermal annealing of the laser-heated soot, which is an irreversible effect, or an increase in the temperature-dependent absorptivity, which is elastic. For fluences larger than $2 \mathrm{~mJ} / \mathrm{mm}^{2}$, extinction monotonically decreased with increasing fluence, indicating substantial mass loss by laser-induced sublimation.

To investigate the effect of changes in the internal structure and morphology of in-flame soot upon laser heating on the LII signal, Vander Wal et al. [4] and Vander Wal and Jensen [5] used two 1064-nm laser pulses to heat soot particles twice in rapid succession. The delay between the pulses was $10 \mu \mathrm{s}$, providing enough time for soot particles to cool down to the local gas temperature. The LII signal produced by the second pulse was used to determine the effect of changes in soot structure induced by the first pulse. In addition, TEM images of soot particles heated by a 1064-nm laser pulse at different fluences were analyzed in $[4,1,5]$ to qualify the influence of rapid heating on soot structure. The dual pulse experiments showed that mild thermal annealing, induced by the first laser pulse with fluences below $2 \mathrm{~mJ} / \mathrm{mm}^{2}$, enhanced the intensity of the second LII signal (e.g., by roughly $13 \%$ at $0.9 \mathrm{~mJ} / \mathrm{mm}^{2}$ ). This enhancement is believed to be a permanent effect considering the 10- $\mu$ s delay between the two pulses. However, using fluences higher than $2 \mathrm{~mJ} / \mathrm{mm}^{2}$ resulted in a decrease in the intensity of the second signal. Further experiments [4] looked at the temporal decay of the second signal, which corresponds to particle size, instead of its intensity. It was shown that the size of particles is not affected for fluences below $4.5 \mathrm{~mJ} / \mathrm{mm}^{2}$ [4] $\left(5 \mathrm{~mJ} / \mathrm{mm}^{2}\right.$ in [5]), suggesting that mass loss occurs in considerable amounts only at fluences higher than about $4.5 \mathrm{~mJ} / \mathrm{mm}^{2}$. The lower intensity of the second LII signal for fluences higher than $2 \mathrm{~mJ} / \mathrm{mm}^{2}$ was attributed to changes in the optical properties of soot by the more extensive graphitization that occurs at higher fluences. TEM images of soot particles heated with fluences below $6 \mathrm{~mJ} / \mathrm{mm}^{2}$ showed the formation of hollow shell structures in which the amount of internal material appears less, indicating irreversible changes in soot's underlying structure. These structures are formed mainly by thermal annealing which produces a more ordered structure. TEM images showed that a substantial mass loss, in particular on the surface of soot particles, and significant fragmentation occur only at fluences higher than $6 \mathrm{~mJ} / \mathrm{mm}^{2}$. 
Michelsen et al. [10] coupled LII and time-averaged attenuation measurements at 532 and $1064 \mathrm{~nm}$ to determine the absorption and scattering cross sections of soot in an ethylene laminar diffusion flame. For fluences below $1.4 \mathrm{~mJ} / \mathrm{mm}^{2}$ for $532 \mathrm{~nm}$ and $2.5 \mathrm{~mJ} / \mathrm{mm}^{2}$ for $1064 \mathrm{~nm}$, an increase in light attenuation by up to $3 \%$ and $10 \%$, respectively, was observed with increasing fluence, attributed to an increase in primary particle size. However, the increase in particle size was inconsistent with the decrease observed for the scattering cross-section. Hence, thermal annealing, an increase in the radius of gyration accompanied by a decrease in fractal dimension, and changes in the complex refractive index of soot were proposed as alternative explanations for changes in scattering and absorption crosssections. Similar to the results of Witze et al. [14], it is not clear from the time-averaged measurements whether this increase of attenuation is permanent or reversible. For higher fluence levels, sublimation leads to significant mass loss and decreased attenuation.

Yoder et al. [7] monitored the scattering coefficient of in-flame soot as a function of time and laser fluence to quantify soot particle sublimation as a result of laser heating. This was accomplished by using a 1064-nm Nd:YAG laser to heat particles in a propane diffusion flame and a 532-nm Nd:YAG laser, shifting in time relative to the heating pulse, to generate the time-resolved light scattering signal. These measurements revealed a reduction in soot volume fraction by 80 to $90 \%$ during the laser pulse for fluences in the range of $5 \mathrm{~mJ} / \mathrm{mm}^{2}$. It was shown that sublimation is confined to the laser pulse period ( $25 \mathrm{~ns}$ ), with the majority of it occurring within the first half of the laser pulse waveform. The decline of scattering signal by sublimation was identified for $1.0 \mathrm{~mJ} / \mathrm{mm}^{2}$ and higher fluences. However, the onset of significant material loss was reported to be $1.7 \mathrm{~mJ} / \mathrm{mm}^{2}$, resulting in an $11 \%$ decrease of the scattered signal. No sublimation was detected for laser fluences below $1 \mathrm{~mJ} / \mathrm{mm}^{2}$.

Snelling et al. [15] studied elastic light scattering (ELS) combined with LII, using an excitation wavelength of $532 \mathrm{~nm}$, in an ethylene/air diffusion flame. They noted that the differential volumetric scattering coefficients changed only slightly over a fluence range of 0.1 to $1.63 \mathrm{~mJ} / \mathrm{mm}^{2}$, although the numerical LII models predicted a $35 \%$ loss of soot mass by sublimation.

In another work, Olofsson et al. [16] used a simultaneous light scattering and LII measurement approach to study the fluence threshold of soot sublimation in a premixed ethylene/air flame at various heights, corresponding to different ages of soot. Soot particles were heated by a 1064-nm pulsed laser and the scattering signal was generated with a 532-nm pulse. The results showed that the fluence threshold, the fluence above which the ELS signal drops, is higher for the younger and less graphitic particles at lower flame heights. It was suggested that the main reason for this behavior is the lower $E\left(m_{\lambda}\right)$ for younger soot particles compared to the more graphitized soot at higher heights, although the varying density, specific heat, aggregate size, and refractive index function for scattering, $F\left(m_{\lambda}\right)$, with flame height might have also contributed.

Dasch [17] studied the laser-induced sublimation of soot particles in a premixed flame by time-resolved measurement of scattering and transmittance of continuous 488-nm light while at the same time heating particles with a 532-nm laser pulse. It was shown that particles undergo sublimation, indicated by a sharp decline in the scattering signal and a rapid increase of transmission, at fluences higher than 2 $\mathrm{mJ} / \mathrm{mm}^{2}$. The results indicated that the number of particles remained constant during sublimation, suggesting that no fragmentation occurs. 
Thomson et al. [6] used continuous-wave (CW) lasers at two wavelengths, 405 and $830 \mathrm{~nm}$, to measure the time-resolved extinction coefficient of over-fire, cooled soot while simultaneously heating the aerosol with a 1064-nm laser pulse with fluences typical of LII. Elastic light scattering of the 1064-nm heating pulse was also monitored at 90 degrees. Using low to moderate heating pulses, a reversible increase to the $830-\mathrm{nm}$ light extinction, by up to $7 \%$, observed during the heating period suggested a temperature dependent light absorption refractive index function, $E\left(m_{\lambda}\right)$. At low fluence, a small permanent increase of $E\left(m_{\lambda}\right)$ by $<2 \%$ was also observed, likely related to soot graphitization by laser heating. Measurements done at $405 \mathrm{~nm}$ yielded significantly different results, revealing that the laser heating of soot likely generated 405-nm light absorbing material causing an initial decline of extinction coefficient. It was shown that this sublimated material interacts to form secondary gaseous species, such as $\mathrm{C}_{3}$, with a high propensity to absorb 405-nm light shortly after the laser pulse. The extinction and scattering measurements showed that considerable mass loss occurs at fluences above 1.0 and 1.5 $\mathrm{mJ} / \mathrm{mm}^{2}$, respectively. It was concluded that variations of the optical properties are occurring at the time of LII emission which should be accounted for in time-resolved LII measurement interpretation.

These studies all confirm that laser heating significantly alters the physical nature of soot, thus affecting the scattering, absorption, and incandescence properties, a behavior which is in contrast to the widely used assumption of constant properties during a rapid heating event. The enhancement of absorption and emission properties upon a laser pulse with low fluences is supported by $[14,4,5,10,6]$. A fluence of about $2 \mathrm{~mJ} / \mathrm{mm}^{2}$ is well-established in the literature as the threshold for considerable mass loss by sublimation using both 1064-nm and 532-nm excitation $[4,10,14,17,18,19,7]$. However, the scattering data presented in $[6,14]$, the results of attenuation experiments in [6], and the LII measurements of [20] are inconsistent with other measurements, showing a discernible material loss starting from much lower fluences.

The present work examines the variations in the optical properties of in-flame soot particles during a rapid laser heating event, thus complementing our previous analogous study [6] on the effect of laser heating on the optical properties of cold soot. The same measurement methodology as [6] is applied in this work which provides detailed time-resolved information about the changes in soot absorption properties during laser heating. By varying the intensity of the heating laser pulse, the effect of excitation laser fluence and the fluence threshold for soot sublimation are determined. One of the objectives of this work is to provide a better understanding about the wavelength dependence of the varying optical properties and the possibility of nonsoot interferences from desorbed or sublimated species; therefore, the measurements are conducted at four different wavelengths, $808 \mathrm{~nm}, 633 \mathrm{~nm}$, $488 \mathrm{~nm}$, and $405 \mathrm{~nm}$, better representing the LII emissions measurement spectra. Special emphasis is placed in this work on differentiating the reversible (elastic) and permanent (plastic or irreversible) variations of the soot absorption properties. To study the effect of initial soot temperature on the changes in optical properties upon rapid laser heating, the measured extinction coefficient profiles for in-flame soot are compared to the previous results for cold-soot presented in [6]. The measurements are conducted for soot particles in both premixed and diffusion flames to investigate the effect of age and maturity of soot as well as the effect of light absorbing nonsoot species on the variation in optical properties. 


\section{Methodology}

Light attenuation measurement is a highly convenient tool for the study of soot aerosols because soot strongly absorbs light and weakly scatters it $[21,22,23,24,25]$. Therefore, light attenuation measurements are fairly easily related to the propensity of soot to absorb and emit light despite the complex morphology of soot aggregates. Light attenuation, or extinction, is described by the BeerLambert theory as:

$$
\frac{I_{\lambda}}{I_{\lambda, 0}}=\exp \left(-\int K_{\mathrm{ext}, \lambda} \mathrm{d} x\right)
$$

where $I_{\lambda, 0}$ and $I_{\lambda}$ are the intensities of light before and after transmitting through the soot containing medium, respectively, and $x$ is position along the optical axis. The extinction coefficient, $K_{\text {ext, } \lambda \text {, is equal }}$ to the sum of the absorption coefficient, $K_{\mathrm{abs}, \lambda}$, and the scattering coefficient, $K_{\mathrm{sca}, \lambda}$. The ratio of light scattering to absorption coefficients, $\rho_{s a, \lambda}$, is dependent on soot morphology and wavelength and can reach values as high as 0.3 to 0.4 for large aggregates at ultraviolet wavelengths $[23,24,25]$. For the present measurements in a Gülder co-annular ethylene-air flame at a height of $42 \mathrm{~mm}$ above the burner, the soot morphology has been measured in previous studies from which the $\rho_{s a, \lambda}$ values of 0.11 and 0.06 have been calculated for the wavelengths of 450 and $800 \mathrm{~nm}$, respectively [26]. Measurements for $\rho_{s a, \lambda}$ are available for a McKenna premixed flame with slightly different flow rates [26], showing negligible scattering by particles $\left(\rho_{s a, \lambda}\right.$ is 0.04 at $450 \mathrm{~nm}$ and 0.016 at $800 \mathrm{~nm}$ ). Thus, light absorption dominates attenuation and the measurement of $K_{\text {ext }, \lambda}$ is a good surrogate for measuring $K_{\text {abs }, \lambda \text {. }}$

By monitoring the attenuation of a CW laser beam, caused by a soot aerosol, during the rapid pulsed laser heating of that aerosol, it is possible to observe how the absorptivity and thus emissivity of soot varies as a function of soot temperature and laser fluence. By measuring these changes on timescales relevant to LII emission, it is possible to understand how LII emission is influenced by variations in the optical properties and size of soot particles.

Time-resolved measurement of light attenuation enables the quantification of $\overline{K_{\text {ext }, \lambda}(t)}$, the normalized path-averaged extinction coefficient (normalized by the path-averaged extinction coefficient before the laser pulse at time $t_{0}$ ), and thus monitoring the variations of the extinction and absorption coefficients as a function of time,

$$
\ln \left(I_{\lambda}(t) / I_{\lambda, 0}\right) / \ln \left(I_{\lambda}\left(t_{0}\right) / I_{\lambda, 0}\right)=\overline{K_{\mathrm{ext}, \lambda}(t)} \approx \overline{K_{\mathrm{abs}, \lambda}(t)}
$$

$\overline{K_{a b s, \lambda}(t)}$ is proportional to the absorption cross section of primary particles, $C_{a b s, \lambda}^{p}$, and therefore includes the effects of temperature dependent $E\left(m_{\lambda}\right)$ and $d_{p}$, based on Eq. 2.

\section{Apparatus}

In the present work, soot particles in both premixed and diffusion flames are studied to determine the effect of rapid heating on optical properties of in-flame soot. A Gülder co-annular burner [27] is used to study soot in a laminar, atmospheric pressure, ethylene/air diffusion flame. The burner provided a stable flame with a height of $66 \mathrm{~mm}$ for a fuel flow rate of $194 \mathrm{ccm}$ (cubic centimeters per minute, $21^{\circ} \mathrm{C}$, 
$1 \mathrm{~atm}$ ) and an air flow rate of $284 \mathrm{lpm}$ (liters per minute, $21^{\circ} \mathrm{C}, 1 \mathrm{~atm}$ ). Measurements were performed on the centerline at a height of $42 \mathrm{~mm}$ above the burner because morphological information about soot is available [26] and soot concentration is relatively uniform across the width of the flame [3] at this height. A standard McKenna burner with a brass $60-\mathrm{mm}$ diameter porous-plug is used to study soot in a laminar, atmospheric pressure, premixed ethylene/air flame. To generate higher attenuation levels, an equivalence ratio of 2.7 is used in the present work with a total gas flow rate of $10 \mathrm{slpm}\left(0^{\circ} \mathrm{C}, 1 \mathrm{~atm}\right)$. A nitrogen shroud, with a flow rate of $15 \mathrm{slpm}\left(0^{\circ} \mathrm{C}, 1 \mathrm{~atm}\right)$, is used to protect the flame from air movements in the room. To further enhance flame stability, a stainless steel plate of $60 \mathrm{~mm}$ diameter is placed at a height of $21 \mathrm{~mm}$ above the burner. Measurements are conducted on the centerline at a height of $10 \mathrm{~mm}$ above the burner.

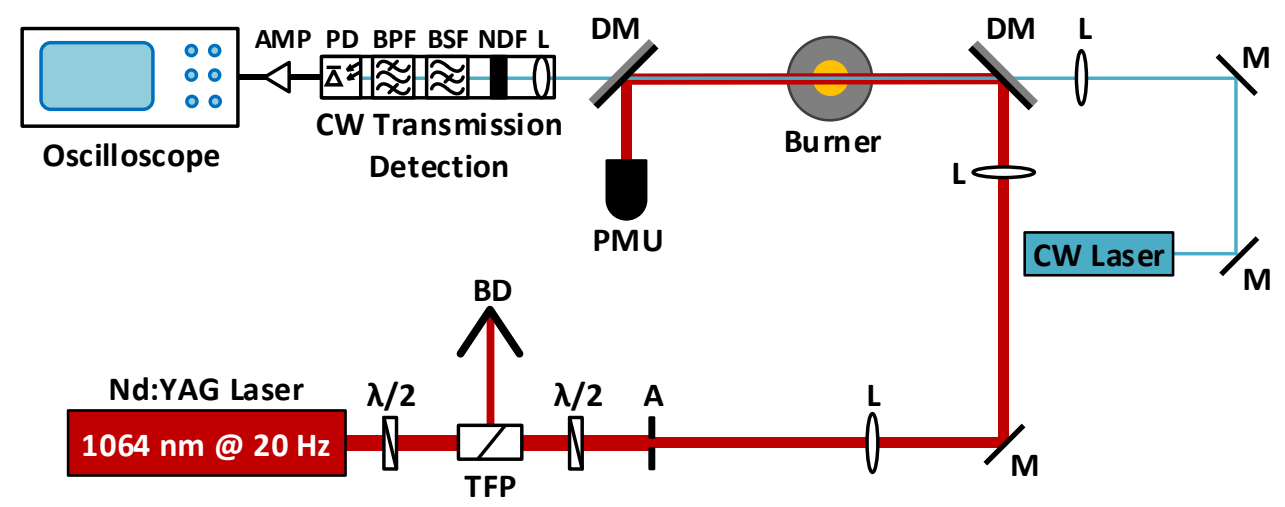

Fig. 1 A schematic of the experimental setup, including an Nd:YAG laser, half-wave plates $(\lambda / 2)$, a thin film polarizer (TFP), a beam dump (BD), an aperture (A), lenses (L), mirrors (M), dichroic mirrors (DM), CW lasers, a power meter unit (PMU), bandstop filters (BSF), bandpass filters (BPF), neutral density filter (NDF), a photodiode (PD), an operational amplifier (AMP), and an oscilloscope.

A schematic of the experimental apparatus, which is similar to the one used in [6], is shown in Fig. 1. Soot particles are heated using a Big Sky Ultra Nd:YAG laser at its fundamental wavelength with a frequency of $20 \mathrm{~Hz}$ and a pulse duration of $6 \mathrm{~ns}$. The laser is operated at full power and the beam energy is controlled by means of a half-wave plate combined with a thin film polarizer. The final polarization direction is tuned to be vertical using a second half wave plate. A pair of metal slits are used to aperture the middle portion of the laser beam which is imaged at the central vertical axis of the burner using a pair of optically conjugate lenses (focal lengths of $500 \mathrm{~mm}$ ) generating a beam with a nearly uniform energy distribution in a $2.2 \mathrm{~mm} \times 2.2 \mathrm{~mm}$ profile at the focal plane. Laser beam powers, ranging from 0.02 to $0.6 \mathrm{~W}$, are monitored using a thermal laser power meter (Scientech Model 365). The size, intensity profile, and fluence of the laser beam, from 0.21 to $6.19 \mathrm{~mJ} / \mathrm{mm}^{2}$, are measured using a LaserCam-HR beam analyzer from Coherent. 

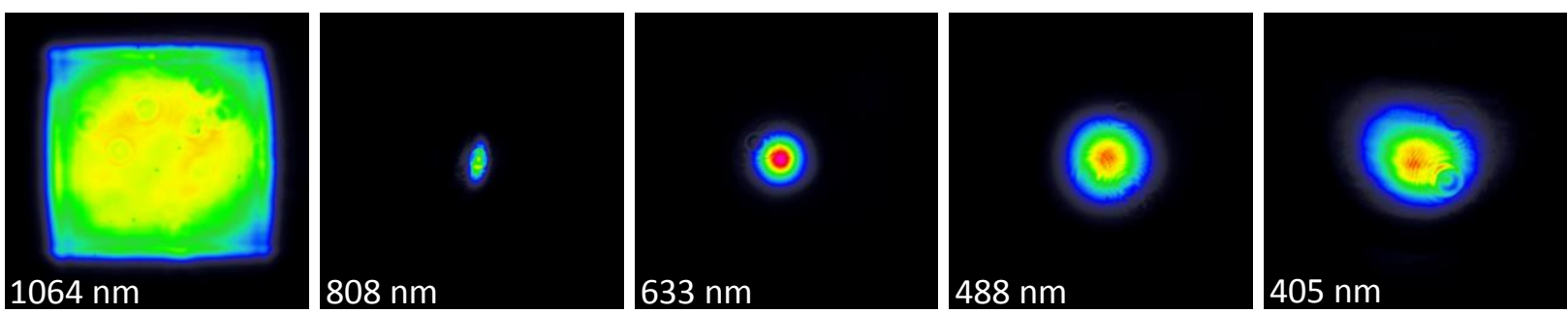

Fig. 2 Profiles of the 1064-nm laser beam used for heating soot and the $C W$ laser beams with $\lambda_{C W}=808 \mathrm{~nm}, \lambda_{c W}=633$ $\mathrm{nm}, \lambda_{C W}=488 \mathrm{~nm}$, and $\lambda_{C W}=405 \mathrm{~nm}$ used for measuring light attenuation.

Time-resolved attenuation measurements through the flames are carried out at $405 \mathrm{~nm}$ using a $16 \mathrm{~mW}$ diode laser, $488 \mathrm{~nm}$ using a $300 \mathrm{~mW}$ krypton-argon laser, $633 \mathrm{~nm}$ with a $17 \mathrm{~mW}$ helium-neon laser, and $808 \mathrm{~nm}$ with a $170 \mathrm{~mW}$ diode laser. These wavelengths are selected to cover a spectrum representative of LII detection wavelengths. The CW laser beams are transmitted along the same optical axis as the 1064-nm pulsed laser and the beam profiles are shaped such that the smaller CW beams pass through the center of the pulsed laser heated chord and only monitor particles heated by the central and most uniform fluence portion of the heating pulse. This guarantees that the $\mathrm{CW}$ lasers only monitor the attenuation of the laser-heated soot. The profiles of the IR and CW beams are included in Fig. 2.

The transmitted CW laser radiation is monitored by a photodiode detector (Thorlabs DET36A, 14-ns rise time) combined with a $400 \mathrm{MHz}$ operational amplifier. A dichroic mirror upstream of the detector deflects the majority of the IR light from the laser heating pulse away from the detector. The detector is fitted with a $190 \mathrm{~mm}$ focal length lens to partially focus the CW laser beam onto the detector, bandpass interference filters for the four CW laser wavelengths, a notch filter for 1064 and 532-nm light, and a KG-3 filter to ensure that only the visible part of the spectrum reaches the photodiode. The $71 \mathrm{~cm}$ distance of the detector from the flame largely eliminates laser induced incandescence as a bias from the attenuation measurement as is validated experimentally using the pulsed laser in the absence of the CW beam. Signal from the photodiode detector is digitized using a LeCroy Waverunner oscilloscope with 400-shot averages acquired for each condition. The signal is recorded with two temporal resolutions, 50 samples per nanosecond and 100 samples per microsecond, to enable the capturing of events with different timescales. To remove the high frequency noise, every 50 and 100 samples are averaged for the high and low temporal resolutions, respectively, in post-processing, resulting in final resolutions of one sample per nanosecond and one sample per microsecond. 


\section{Results and Discussion}

\subsection{The diffusion flame}
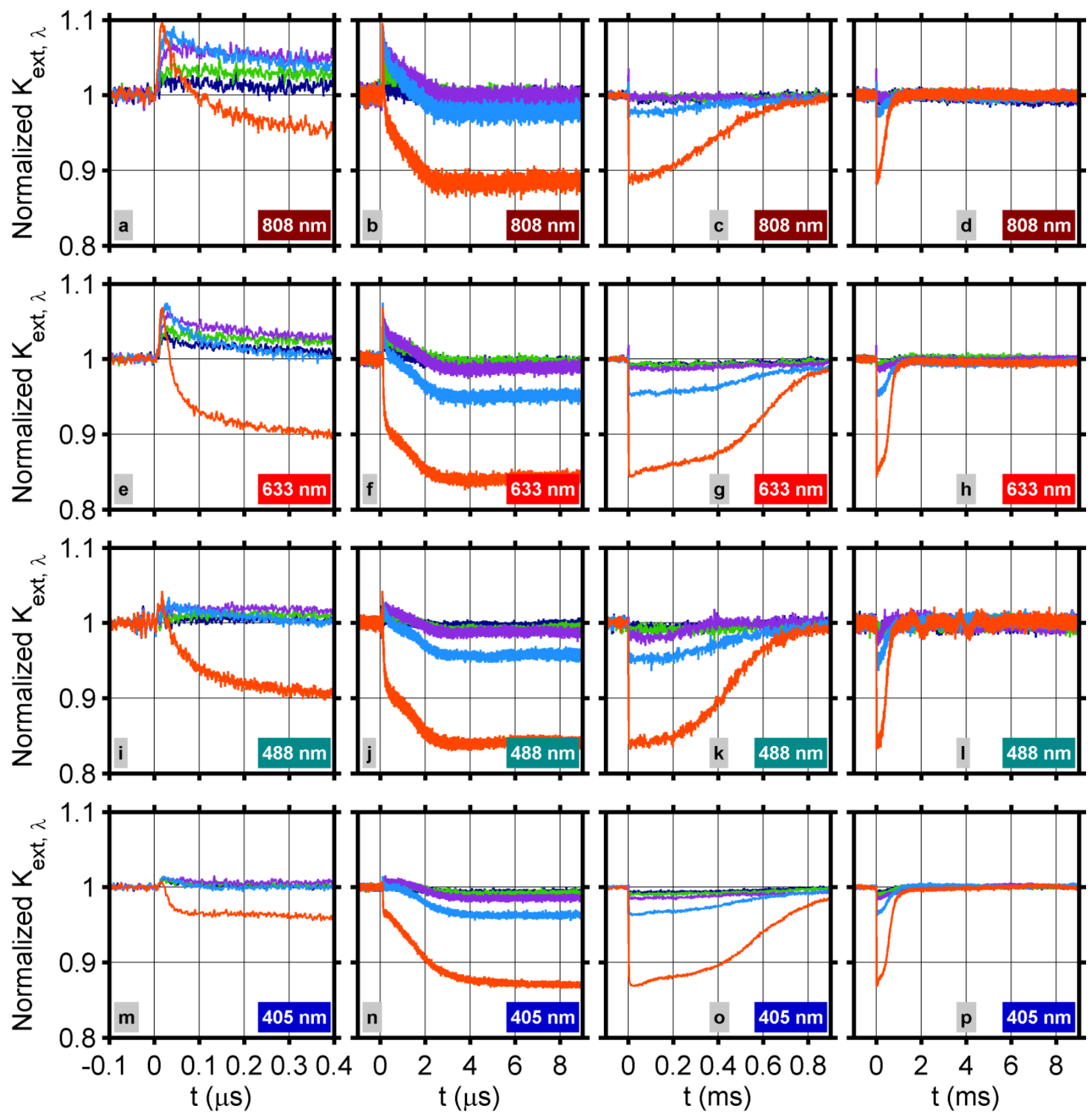

$$
0.21 \mathrm{~mJ} / \mathrm{mm}^{2}-0.41 \mathrm{~mJ} / \mathrm{mm}^{2}-0.62 \mathrm{~mJ} / \mathrm{mm}^{2}-0.82 \mathrm{~mJ} / \mathrm{mm}^{2}-1.24 \mathrm{~mJ} / \mathrm{mm}^{2}
$$

Fig. 3 Comparing the normalized extinction coefficient profiles in the diffusion flame for five IR laser fluences, ranging from 0.21 to $1.24 \mathrm{~mJ} / \mathrm{mm}^{2}$, in four time windows and measured using four $\mathrm{CW}$ laser wavelengths.

As stated in Section 2, time-resolved light attenuation measurements quantify $\overline{K_{\text {ext }, \lambda}}$, the path-averaged extinction coefficient normalized by the path-averaged extinction coefficient before the laser pulse. This 
enables the evaluation of the variations of the optical properties of soot as a function of time. The profiles of $\overline{K_{\text {ext, } \lambda}}$ measured in the diffusion flame for a selection of low laser fluences, from 0.21 to 1.24 $\mathrm{mJ} / \mathrm{mm}^{2}$, are included in Fig. 3 for $\lambda_{c w}=808 \mathrm{~nm}$ (Figs. $3 a-d$ ), $\lambda_{c w}=633 \mathrm{~nm}$ (Figs. 3e-h), $\lambda_{c w}=488 \mathrm{~nm}$ (Figs. $3 \mathrm{i}-\mathrm{I}$ ), and $\lambda_{c w}=405 \mathrm{~nm}$ (Figs. $3 \mathrm{~m}-\mathrm{p}$ ). The data is shown in four time windows to capture the time ranges relevant to LII emission, to the total soot cooling, and for the laser heated soot to flow out of the measurement volume and be replaced with fresh soot. A complete set of profiles, for all twenty fluence levels used in this work, is presented in Figs. S1, S2, S3, and S4 in the supplementary material.

From Fig. 3a, it is observed that $\overline{K_{\text {ext }, \lambda}}$ for the 808 -nm light rapidly increases at the time of laser heating by 2 to $10 \%$ for the range of fluences shown. The amount of this enhancement is close to that observed by Michelsen et al. (about $10 \%$ at $2.5 \mathrm{~mJ} / \mathrm{mm}^{2}$ [10]) and Vander Wal et al. (about $13 \%$ at $0.9 \mathrm{~mJ} / \mathrm{mm}^{2}$ [4]) for a 1064-nm heating pulse. The duration of the increase is about $15 \mathrm{~ns}$ which correlates with the laser pulse duration ( $6 \mathrm{~ns}$ ) and the rise time of the photodiode (14 ns).

The enhancement in Fig. 3a appears to be reversible in nature as $\overline{K_{\text {ext }, \lambda}}$ gradually drops to the pre-laser pulse value of one in about $3 \mu \mathrm{s}$ for fluences below $0.82 \mathrm{~mJ} / \mathrm{mm}^{2}$, as shown in Fig. 3b. A similar reversible increase of $\overline{K_{\text {ext }, \lambda}}$, observed in [6], was attributed to a temperature dependent $E\left(m_{\lambda}\right)$ which is also supported by the findings of Charalampopoulos et al. [28] showing that the imaginary part of the complex refractive index is a function of temperature. However, this explanation is not in accordance with the Maxwell-Garnett theory (see Section 1.2), predicting that the effect of changes in $E\left(m_{\lambda}\right)$ with temperature is offset by a proportional change in the volume of particles, thereby keeping light absorption constant. The enhancement shown in Fig. 3a may also be attributable to an irreversible increase in $E\left(m_{\lambda}\right)$ by laser-induced thermal annealing, permanently changing the microstructure and optical properties of soot. The findings of [4] confirm that moderate levels of thermal annealing induced by laser fluences below $2 \mathrm{~mJ} / \mathrm{mm}^{2}$ cause irreversible and long-standing changes in $E\left(m_{\lambda}\right)$. But, thermal annealing of soot does not explain the decline of $\overline{K_{\text {ext }, \lambda}}$ immediately after the enhancement.

The enhancement of $\overline{K_{\text {ext }, \lambda}}$ gets stronger with increasing IR laser fluence (an $\sim 8 \%$ increase in enhancement for a $1-\mathrm{mJ} / \mathrm{mm}^{2}$ increase in fluence) because of the higher soot temperatures achieved with higher fluence levels. Enhancement of extinction during the laser pulse is observed in Figs. 3e, 3i, and $3 \mathrm{~m}$ for the 633-nm, 488-nm, and 405-nm light, respectively; however, the degree of enhancement is observed to decrease with decreasing wavelengths.

The sharp rise in $\overline{K_{\text {ext, } \lambda}}$ suggests the enhancement of the soot absorption propensity, and thus the efficiency of laser light absorption, coupled with the rapid temperature rise during soot heating. This would alter the peak incandescence signal and the peak temperature which occur in short timescales after the laser pulse and should be considered for LII analysis. This increase is also likely to affect the cooling rate of the particles considerably.

For the three lowest fluences, $\overline{K_{\text {ext }, \lambda}}$ decays slowly after the initial enhancement as shown in Figs. 3a, 3e, $3 \mathrm{i}$, and $3 \mathrm{~m}$. However, extinction decreases more rapidly for higher fluences, in particular for 1.24 $\mathrm{mJ} / \mathrm{mm}^{2}$. For the $1.24-\mathrm{mJ} / \mathrm{mm}^{2}$ fluence, $\overline{K_{\text {ext }, \lambda}}$ declines rapidly for about 50 to $200 \mathrm{~ns}$, depending on wavelength, followed by a secondary decay comparable in rate to those for the four lower fluences. The rapid decay is attributed to the loss of light absorbing soot material by sublimation. Indication for a 
significant decline of extinction is noted for fluences as low as $1.24 \mathrm{~mJ} / \mathrm{mm}^{2}$ for the $808 \mathrm{~nm}$ light and $1.03 \mathrm{~mJ} / \mathrm{mm}^{2}$ for the 633,488 , and $405 \mathrm{~nm}$ light, as shown in Fig. S1 in the supplementary material. A significant decline of extinction is considered to occur when $\overline{K_{\text {ext, } \lambda}}$ drops to values below 1 within the first $100 \mathrm{~ns}$ after the laser pulse, i.e. after $\mathrm{t}=0 \mathrm{~ns}$. This fluence threshold for soot sublimation is substantially lower than 2.0 to $2.5 \mathrm{~mJ} / \mathrm{mm}^{2}$ observed in $[10,14,7,17]$ and 4.5 to $5 \mathrm{~mJ} / \mathrm{mm}^{2}$ recommended in $[4,5]$, both for 1064-nm light. However, this threshold is in excellent agreement with experimental results of [6] and the value predicted by the LII model of [29], $0.5 \mathrm{~mJ} / \mathrm{mm}^{2}$ for $532-\mathrm{nm}$ excitation or $1.0 \mathrm{~mJ} / \mathrm{mm}^{2}$ for 1064-nm excitation. Vander Wal et al. [4] have shown that the decline of extinction may as well be a result of more extensive levels of thermal annealing which lower the light absorption propensity of heated soot. Therefore, the soot sublimation threshold might be higher than the value suggested by the present measurements.

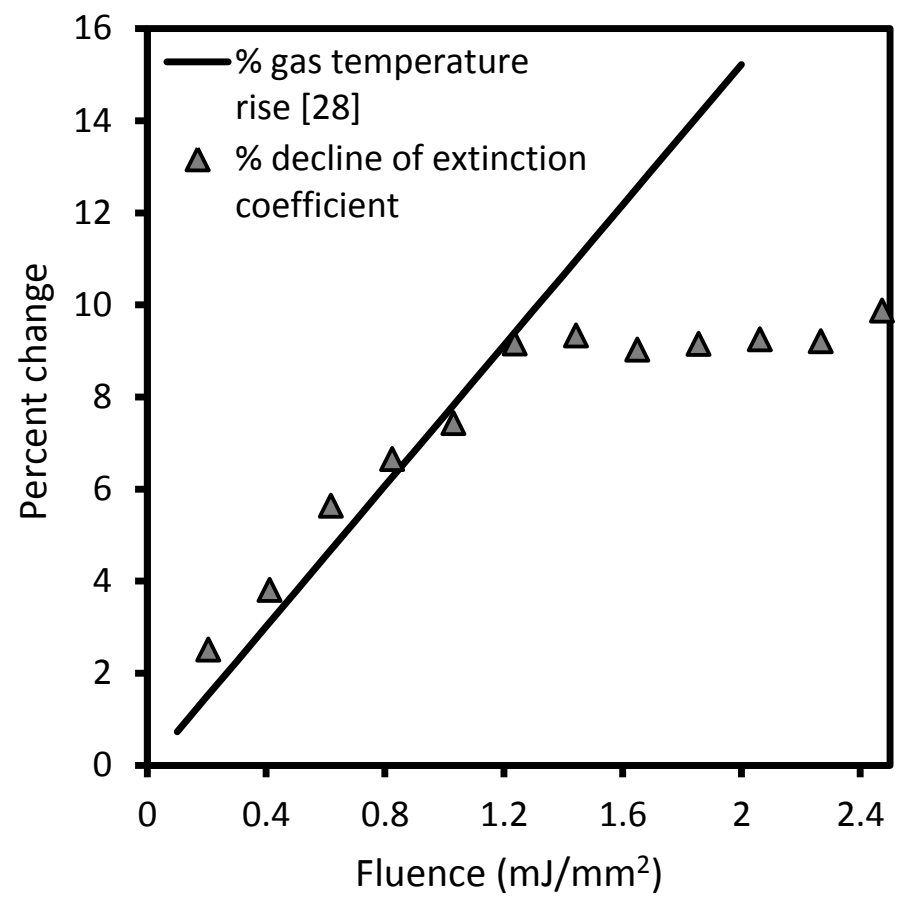

Fig. $4 \mathrm{~A}$ comparison between the estimated rise in the temperature of the gases surrounding the laser-heated soot [29] and the measured decline of $\overline{K_{\text {ext }}}$ at $808 \mathrm{~nm}$ (only secondary decline for fluences higher than $1 \mathrm{~mJ} / \mathrm{mm}^{2}$ ).

From Figs. 3b, 3f, 3j, and 3n, the gradual decay of extinction for fluences below $1.24 \mathrm{~mJ} / \mathrm{mm}^{2}$ and the secondary decay observed at $1.24 \mathrm{~mJ} / \mathrm{mm}^{2}$ extend to about $3 \mu \mathrm{s}$, roughly the time period for soot temperature to completely equilibrate with the gas temperature. This point strongly supports the argument that the principal cause for these gradual decays of $\overline{K_{\text {ext }, \lambda}}$ is not in fact a reversible variation of the optical property of the soot because of a temperature dependent $E\left(m_{\lambda}\right)$, but rather a decrease in soot concentration induced by the expansion of the surrounding gas which is heated by the cooling soot particles. Snelling et al. [29] estimated the local gas temperature rise for 532-nm laser excitation at this same measurement location in the diffusion flame. For 1064-nm excitation, the rate of temperature rise approximately halves, assuming an absorption coefficient inversely proportional to $\lambda$. The local gas 
temperature rise is proportional to the increase in the volume of the gas and the decrease in the volume fraction of soot. Figure 4 compares the linear fit to the data of [29] for gas temperature rise with the decline of $\overline{K_{\text {ext }, \lambda}}$ measured in the present work. It is evident that the decline of extinction for fluences below $1.24 \mathrm{~mJ} / \mathrm{mm}^{2}$ and the secondary decay of $\overline{K_{\text {ext }, \lambda}}$ at $1.24 \mathrm{~mJ} / \mathrm{mm}^{2}$ are mainly a consequence of gas expansion. This explanation for the decline of extinction immediately after the initial enhancement at low fluences supports the hypothesis that a permanent change in $E\left(m_{\lambda}\right)$ by moderate thermal annealing can cause the initial enhancements depicted in Figs. $3 a, 3 e, 3 i$, and $3 \mathrm{~m}$. It is possible that the decay is also influenced by a reversible temperature dependent $E\left(m_{\lambda}\right)$, which would decrease $\overline{K_{\text {ext }, \lambda}}$ as the soot cools; however, it would be difficult to ascertain this in the presence of strong local gas heating and expansion.

From Figs. $3 b, 3 f, 3 j$, and 30 it is confirmed that the minimum $\overline{K_{\text {ext }, \lambda}}$ occurs at $\sim 3 \mu$ for $\lambda_{c w}=808 \mathrm{~nm}$, $\lambda_{c W}=633 \mathrm{~nm}$, and $\lambda_{c w}=488 \mathrm{~nm}$, and at $\sim 20 \mu \mathrm{s}$ for $\lambda_{c w}=405 \mathrm{~nm}$. As shown in Figs. $3 \mathrm{c}, 3 \mathrm{~g}, 3 \mathrm{k}$, and 30 , the soot refreshes completely in 0.8 to $1 \mathrm{~ms}$, i.e., $\overline{K_{\text {ext }, \lambda}}$ returns to one, which is a sufficiently short time to prevent exposure of soot to more than one laser pulse (50-ms delay between pulses with a frequency of $20 \mathrm{~Hz}$ ). The slight wavelength dependence of soot refresh time is due to the different sizes of the CW laser beams shown in Fig. 2.

The results presented in Figs. 3 clearly show that the assumption of $\overline{K_{\text {ext }, \lambda}}=1$ throughout the heating and cooling process, in the absence of sublimation, is not valid. In fact, $\overline{K_{\text {ext }, \lambda}}$ and soot optical properties vary considerably in timescales relevant to LII emission which should be accounted for in LII models. 

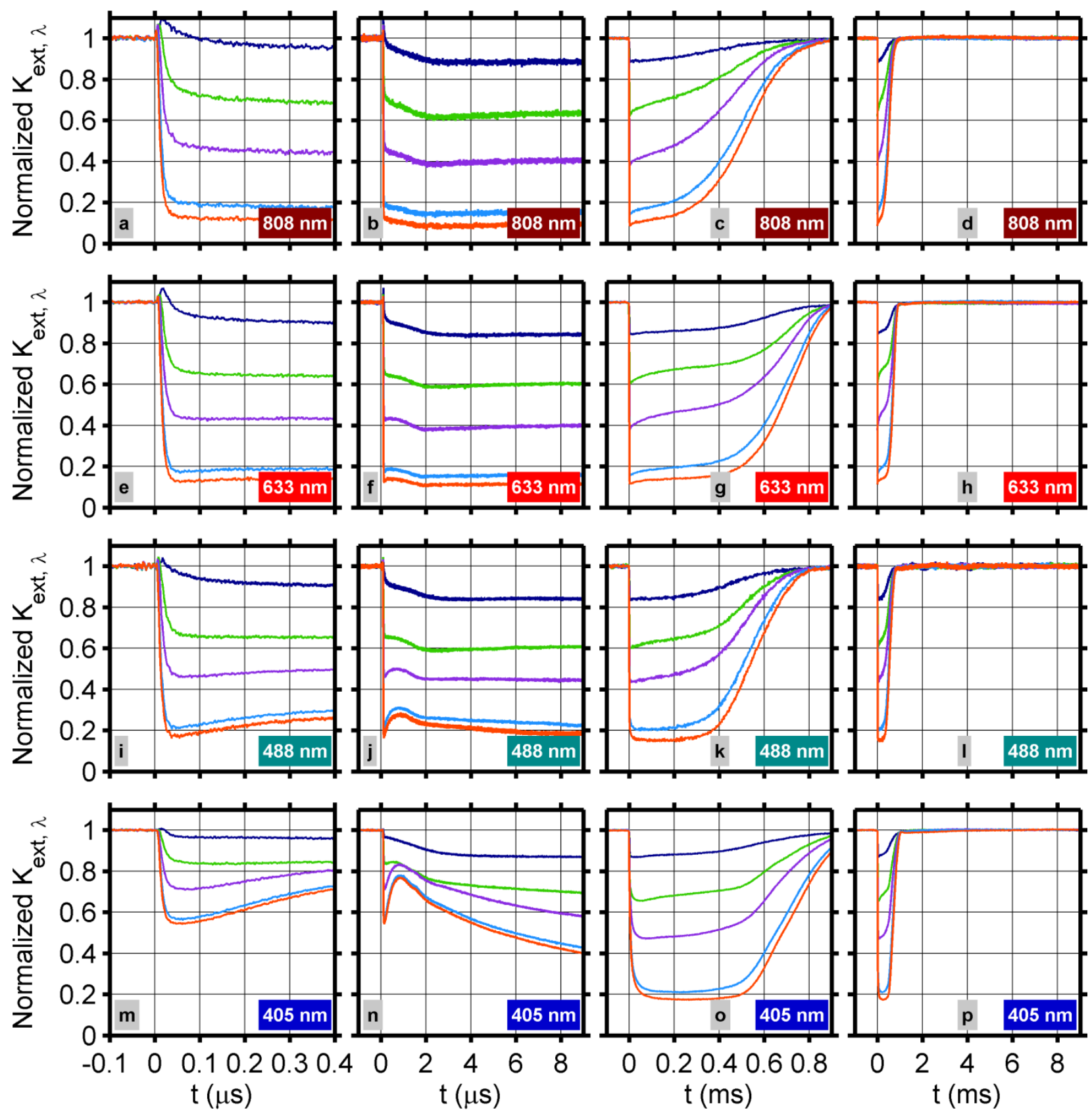

$1.24 \mathrm{~mJ} / \mathrm{mm}^{2}$

$2.47 \mathrm{~mJ} / \mathrm{mm}^{2}$

$3.51 \mathrm{~mJ} / \mathrm{mm}^{2}$

$5.15 \mathrm{~mJ} / \mathrm{mm}^{2}$

$6.19 \mathrm{~mJ} / \mathrm{mm}^{2}$

Fig. 5 Comparing normalaized extinction coefficient profiles in the diffusion flame for five different high fluence leveles, from 1.24 to $6.19 \mathrm{~mJ} / \mathrm{mm}^{2}$, in four time windows and measured with four different wavelengths.

Figure 5 compares the $\overline{K_{\text {ext }, \lambda}}$ profiles measured in the diffusion flame with high laser fluences, ranging from 1.24 to $6.19 \mathrm{~mJ} / \mathrm{mm}^{2}$ (see Figs. S1, S2, S3, and S4 for the complete dataset). From Figs. 5a-d and Figs. 5e-h, it is observed that the high fluence profiles for the 808-nm and 633-nm light are qualitatively similar to the $1.24-\mathrm{mJ} / \mathrm{mm}^{2}$ data, which was also presented in Fig. 3, but with a more significant decline of soot attenuation occurring in the first 15 to $30 \mathrm{~ns}$ after the start of the laser pulse. The initial enhancement of extinction becomes less significant as the fluence of the IR laser is increased. However, 
this does not imply that the processes responsible for the enhancement of extinction, such as modifications to the internal structure of soot by annealing, do not exist at higher fluences. These processes are probably getting stronger with increasing fluence but their effect is being masked by the growing sublimation effect. The limitations of the detection system, in particular the low temporal resolution of the photodiode (14-ns rise time) and the frequency of the amplifier, may also contribute to the diminishing initial enhancements in Fig. 5 at high laser fluences. With increasing fluence, the heatup phase starts earlier and becomes shorter because of a more rapid loss of material; therefore, the low temporal resolution of the detection system might filter out the enhancement of $\overline{K_{\text {ext }, \lambda}}$. The high fluence profiles presented in Figs. 5a-d and Figs.5e-h, for 808-nm and 633-nm light, are thus summarized as an initial rapid increase of $\overline{K_{\text {ext, } \lambda}}$ because of temperature induced changes (up to $\sim 15 \mathrm{~ns}$ ), decrease of $\overline{K_{\text {ext, }, \lambda}}$ by sublimation (up to $\sim 30 \mathrm{~ns}$ ), a secondary decrease caused by gas heating (from 30 to $\sim 2500 \mathrm{~ns}$ ), and then a stable value (from $\sim 2$ to $200 \mu \mathrm{s}$ ) until the soot begins to refresh in the measurement volume $(200-1000 \mu \mathrm{s})$.

The decline of extinction by sublimation for the 488 and $405-\mathrm{nm}$ light lasts for up to $50 \mathrm{~ns}$. However, $\overline{K_{\text {ext }, \lambda}}$ increases again between 50 and $800 \mathrm{~ns}$ for fluences higher than $1.24 \mathrm{~mJ} / \mathrm{mm}^{2}$. This increase, shown in Figs. $5 \mathrm{j}$ and $5 \mathrm{n}$, is about $12 \%$ for the 488 -nm light and $22 \%$ for the $405-\mathrm{nm}$ light at the highest fluence relative to $\overline{K_{\text {ext }, \lambda}}$ prior to the laser pulse. In Fig. $5 f$ a small increase in $\overline{K_{\text {ext }, \lambda}}$ (by about $2 \%$ ) is also observed for the 633-nm light at the highest laser fluences. The reason for this secondary increase will be addressed in the following.

The decline of $\overline{K_{\text {ext }, \lambda}}$ by material loss is detected with all four wavelengths during and immediately after the laser pulse when soot is at elevated temperatures. Hence, it can reduce the intensity and accelerate the decay of the LII signal, thereby affecting soot volume fraction and particle sizing analysis. It is recommended to avoid high fluences for particle sizing, because it is difficult to interpret the LII signal at the presence of cooling by sublimation, and for soot volume fraction measurements by the autocompensating time-resolved LII, since the material that makes up the signal is being sublimated. 
(a) $0.21 \mathrm{~mJ} / \mathrm{mm}^{2}$

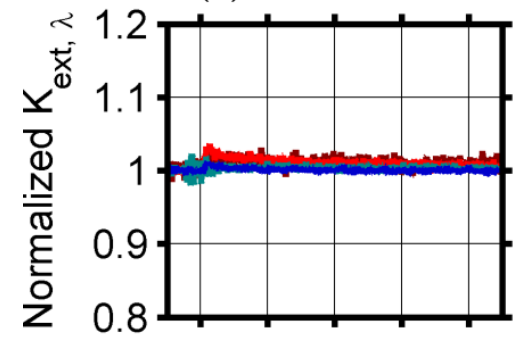

(e) $1.03 \mathrm{~mJ} / \mathrm{mm}^{2}$

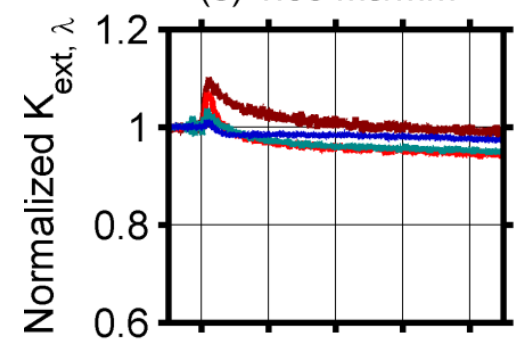

(i) $1.86 \mathrm{~mJ} / \mathrm{mm}^{2}$

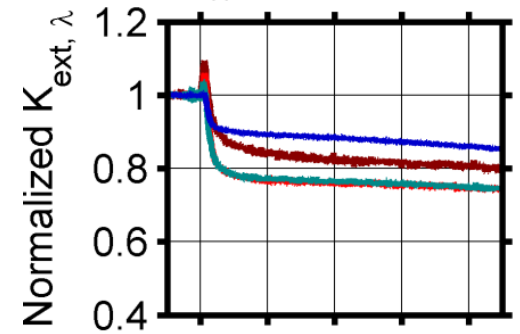

(m) $2.68 \mathrm{~mJ} / \mathrm{mm}^{2}$

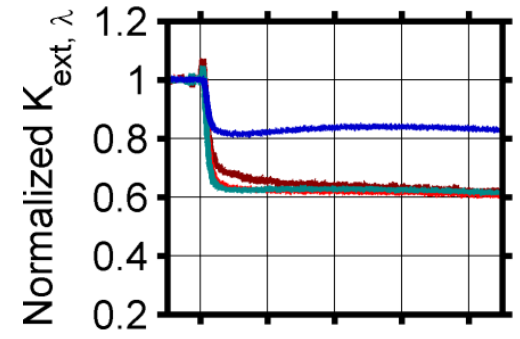

(q) $3.51 \mathrm{~mJ} / \mathrm{mm}^{2}$

몽 (b) $0.41 \mathrm{~mJ} / \mathrm{mm}^{2}$

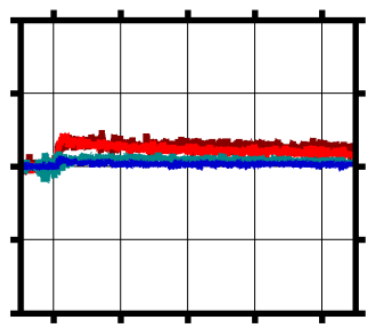

(f) $1.24 \mathrm{~mJ} / \mathrm{mm}^{2}$

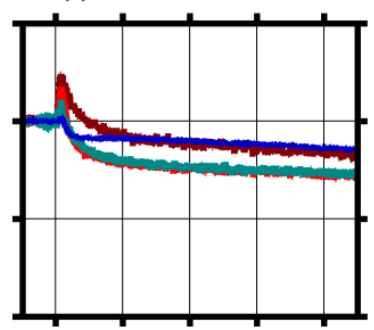

(j) $2.06 \mathrm{~mJ} / \mathrm{mm}^{2}$

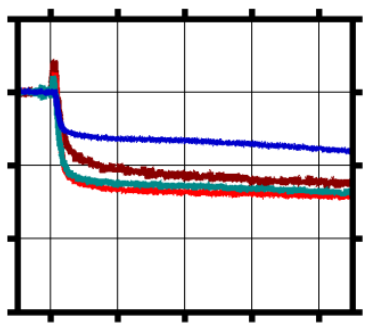

(n) $2.89 \mathrm{~mJ} / \mathrm{mm}^{2}$

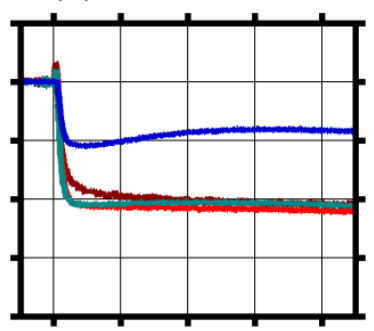

(r) $4.12 \mathrm{~mJ} / \mathrm{mm}^{2}$

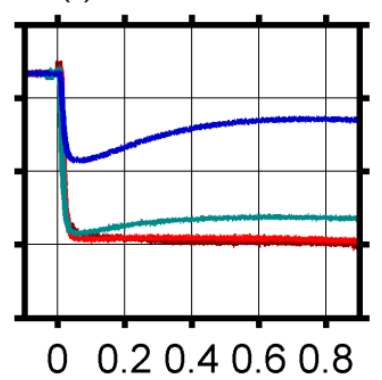

$\mathrm{t}(\mu \mathrm{s})$

$\mathrm{t}(\mu \mathrm{s})$ (c) $0.62 \mathrm{~mJ} / \mathrm{mm}^{2}$

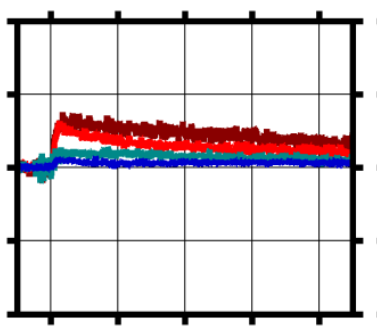

(g) $1.44 \mathrm{~mJ} / \mathrm{mm}^{2}$

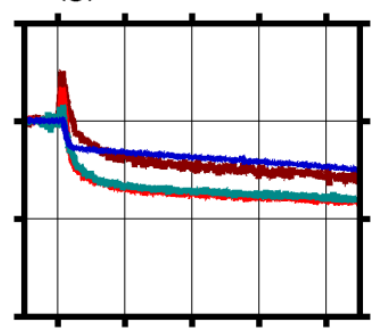

(k) $2.27 \mathrm{~mJ} / \mathrm{mm}^{2}$

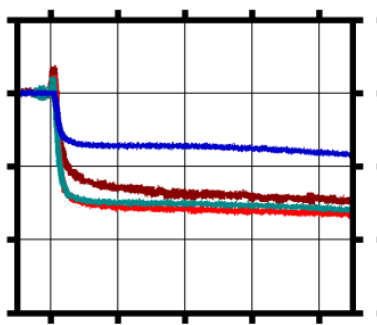

(o) $3.09 \mathrm{~mJ} / \mathrm{mm}^{2}$

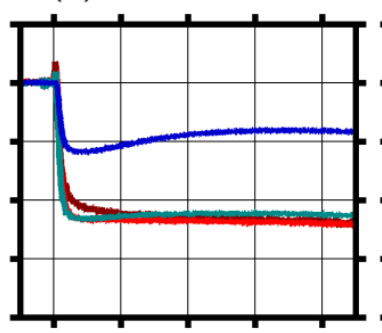

(s) $5.15 \mathrm{~mJ} / \mathrm{mm}^{2}$

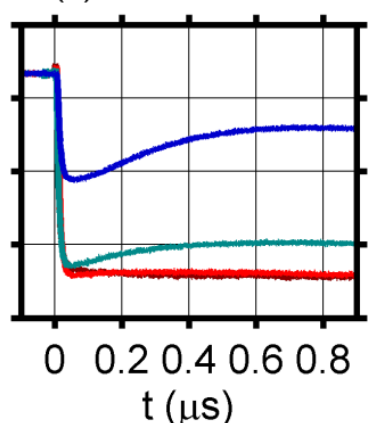

(d) $0.82 \mathrm{~mJ} / \mathrm{mm}^{2}$

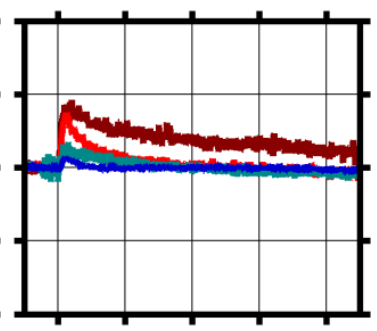

(h) $1.65 \mathrm{~mJ} / \mathrm{mm}^{2}$

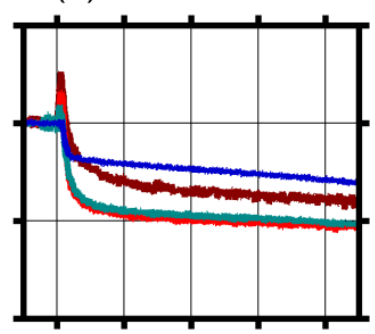

(I) $2.47 \mathrm{~mJ} / \mathrm{mm}^{2}$

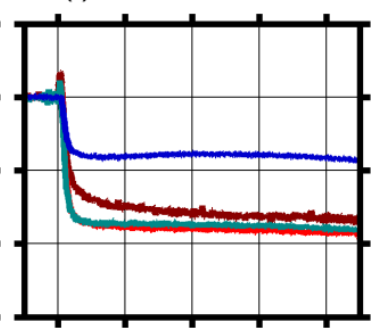

(p) $3.3 \mathrm{~mJ} / \mathrm{mm}^{2}$

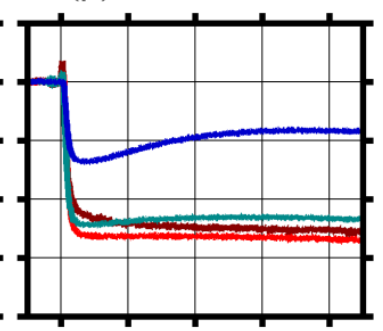

(t) $6.19 \mathrm{~mJ} / \mathrm{mm}^{2}$

$$
-608 \mathrm{~nm}=488 \mathrm{~nm}=405 \mathrm{~nm}
$$

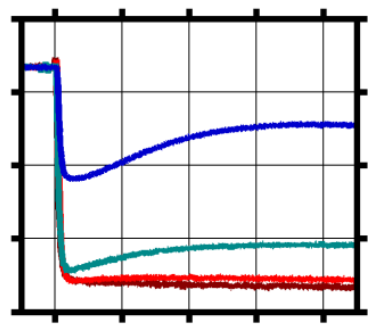

Fig. $6 \mathrm{~A}$ comparison between the $\overline{K_{\text {ext }, \lambda}}$ profiles measured in the diffusion flame with four different wavelengths, $\lambda_{C W}=808 \mathrm{~nm}, \lambda_{C W}=633 \mathrm{~nm}, \lambda_{C W}=488 \mathrm{~nm}$, and $\lambda_{c W}=405 \mathrm{~nm}$, over a wide range of fluence levels. 
To explore the dependence of the variations in soot optical properties on wavelength, Fig. 6 compares the $\overline{K_{\text {ext, } \lambda}}$ profiles measured at $808 \mathrm{~nm}, 633 \mathrm{~nm}, 488 \mathrm{~nm}$, and $405 \mathrm{~nm}$ in short timescales (comparisons in longer timescales are included in Figs. $\mathrm{S} 5$ and $\mathrm{S6}$ ). Figures $6 \mathrm{a}$ to $6 \mathrm{~d}$ compare the profiles measured with fluences below $1 \mathrm{~mJ} / \mathrm{mm}^{2}$. It is shown that the rapid enhancement of $\overline{K_{\text {ext }, \lambda}}$ gets stronger with increasing wavelength over the first $\sim 800 \mathrm{~ns}$ after the laser pulse. This spectral dependence of the initial enhancement suggests that the enhancement most probably stems from the $E\left(m_{\lambda}\right)$ variations with temperature rather than a particle size dependence which is expected to be independent of wavelength. One explanation for this wavelength dependence is that a surface coating of volatile material, such as large polycyclic aromatic hydrocarbons (PAH) which enhance light absorption at shorter wavelengths, is desorbed during laser heating, counterbalancing any enhancement of $\overline{K_{\text {ext }, \lambda}}$ at lower wavelengths. Another plausible reason for the spectral dependence is the increasing contribution of large gaseous molecules and radicals, which are insensitive to infrared irradiation, to light attenuation with shortening the wavelength, thereby reducing the relative variations of $\overline{K_{\mathrm{ext}, \lambda}}$. The $E\left(m_{\lambda}\right)$ of nascent and lessmature particles present in the flame also increases with decreasing wavelength (see $[26,30,31]$ and Section 4.3) which may reduce the variations of $\overline{K_{\text {ext }, \lambda}}$ for mature particles. Hence, it is expected to see a greater enhancement of extinction, relative to the pre-laser pulse levels, at longer wavelengths as the soot anneals.

Because this enhancement is occurring on timescales relevant to LII emission and has a spectral dependence, it affects the peak temperatures determined by two-color pyrometry as well as soot volume fractions and particle sizes; therefore, it should be accounted for in LII models. However, the temperature and wavelength dependence of $E\left(m_{\lambda}\right)$ variations add complication to the interpretation of LII measurements. For the highest non-sublimating fluence of $0.82 \mathrm{~mJ} / \mathrm{mm}^{2}, E\left(m_{\lambda}\right)$ increases by $9 \%$ at $808 \mathrm{~nm}, 7.5 \%$ at $633 \mathrm{~nm}, 3.5 \%$ at $488 \mathrm{~nm}$, and $1.5 \%$ at $405 \mathrm{~nm}$. From two-color pyrometry theory and a soot temperature of $3500 \mathrm{~K}$, not accounting for these change to $E\left(m_{\lambda}\right)$ in LII emission analysis would lead to a $1.5 \%$ underestimation of the soot temperature and a $18.5 \%$ overprediction of the soot volume fraction [32].

Figures 6e-t present the comparisons at fluences higher than $1 \mathrm{~mJ} / \mathrm{mm}^{2}$ and show a rapid decline of $\overline{K_{\text {ext }, \lambda}}$, caused by soot sublimation, after the initial enhancement for all wavelengths. However the minimum $\overline{K_{\text {ext }, \lambda}}$ values reached at $405 \mathrm{~nm}$ are generally higher than the minimum values for the other three wavelengths. For fluences above $2.27 \mathrm{~mJ} / \mathrm{mm}^{2}, \overline{K_{\text {ext }, \lambda}}$ at $405 \mathrm{~nm}$ comes to a minimum between about 50 and $100 \mathrm{~ns}$ after the laser pulse and increases again following this minimum. The profiles measured at $488 \mathrm{~nm}$ with fluences above $2.9 \mathrm{~mJ} / \mathrm{mm}^{2}$ exhibit a similar minimum and a subsequent secondary enhancement of extinction. It is believed that the secondary rise in extinction at 405 and 488 $\mathrm{nm}$ and the significantly higher minimum values for $\overline{K_{\mathrm{ext}, \lambda}}$ at $405 \mathrm{~nm}$ are due to the formation of secondary gaseous species that absorb light strongly at 405 and $488 \mathrm{~nm}$ from the sublimated soot material. The secondary enhancement is also apparent in Figs. $5 \mathrm{j}$ and $5 \mathrm{n}$ as a 'bump' from about $50 \mathrm{~ns}$ to about $2 \mu \mathrm{s}$ after the laser pulse which is increasingly pronounced with increasing fluence. The small bumps observed between 150 and 2000 ns for the 633-nm data, presented in Fig. 5f, might be similar in nature. 
There is strong evidence in the literature to support this explanation for the secondary enhancement of light attenuation. A major product of the laser-induced sublimation of carbon is $C_{3}[33,34,35,36,37]$ which has strong Swings bands absorption near $405 \mathrm{~nm}[38,39,40]$ and can explain the secondary enhancement observed in the present work at $405 \mathrm{~nm}$. Swan band absorption of $\mathrm{C}_{2}$ radicals, formed in substantial amounts upon sublimation of soot $[41,42,43,36,44]$, has a peak near $474 \mathrm{~nm}$ and may contribute to the secondary enhancement of 488-nm light attenuation observed in the present work. Sasaki et al. [36] measured the temporal distribution of $C_{2}$ and $C_{3}$ radicals in carbon plumes by measuring the laser-induced fluorescence from $C_{2}$, excited at $516.52 \mathrm{~nm}$, and $C_{3}$, excited with 405.13-nm light. Nemes et al. [45] measured the laser-induced optical breakdown spectra in laser generated carbon plasma, using an Nd:YAG laser at its fundamental wavelength with high laser intensities (on the order of $\mathrm{GW} / \mathrm{cm}^{2}$ ) and observed the $C_{2}$ Swan band system in the spectrum, centered at 474, 517, and $564 \mathrm{~nm}$. A continuum at approximately $400 \mathrm{~nm}$ ( 380 to $430 \mathrm{~nm}$ ) was attributed to $C_{3}$, supported by spectral simulation calculations of the high temperature Swings bands. In a similar work, Nemes et al. [46] measured the emission spectra following laser-induced breakdown on graphite and in a gaseous allene-helium mixture, using a 1064-nm Nd:YAG laser with a fluence of $400 \mathrm{GW} / \mathrm{cm} 2$. The emission spectra from the allene-helium mixture were dominated by atomic lines of ionized carbon at 426.7 and $596.6 \mathrm{~nm}$, hydrogen Balmer beta line centered at $486.1 \mathrm{~nm}$, and $C_{2}$ Swan band between 450 and 570 $\mathrm{nm}$. Strong emissions from neutral and ionized carbon atoms and from $\mathrm{C}_{2}$ Swan band were observed for the solid graphite. Bengtsson and Aldén [44] generated $C_{2}$ molecules by the laser-induced sublimation of soot, using high fluence beams, in a premixed flame and detected laser-induced emissions from $C_{2}$ Swan band (with a peaks at 473,516, and $573 \mathrm{~nm}$ ) for all incident wavelengths between 485 and $540 \mathrm{~nm}$ (including 488). Goulay et al. [43] conducted spectrally and temporally resolved LII emission measurements from soot in a diffusion flame, using the second harmonic of a nanosecond $\mathrm{Nd}$ :YAG laser to heat the soot over a wide range of fluences. The spectra recorded at fluences greater than $2 \mathrm{~mJ} / \mathrm{mm}^{2}$ show several features in the 380 to $680-\mathrm{nm}$ wavelength region attributed to $\mathrm{C}_{2}$ Swan band (with peaks at 467.2, 516.1, 544.7, and $577.0 \mathrm{~nm}$ ), $C_{3}$ Swings bands (a broadband signal from 360 to $440 \mathrm{~nm}$ ), singly charged carbon atoms and $C_{5}$ vibrational transitions (sharp features at $458.3,492.3$, and $503.9 \mathrm{~nm}$ ), and other exited molecules, such as PAHs and larger carbon clusters. These studies show that absorption of light by carbon atoms and linear carbon chains with more than 3 carbons, such as $C_{5}$, as well as the broadband absorption by large PAH molecules, all generated by laser sublimation of soot, might also contribute to the secondary enhancement detected in the present work.

The secondary species are forming in about 15 to $800 \mathrm{~ns}$ after the laser pulse which is the period relevant to LII emission analysis. To avoid the production of these species in sooting flames and the associated interferences with LII emission, it is recommended to keep the fluence below $2 \mathrm{~mJ} / \mathrm{mm}^{2}$. The results of the present work, similar to those of [Migliorini et al. [26], Zerbs et al. [21], Goulay et al. [43]], suggest avoiding wavelengths at which significant emission from non-soot species is expected, such as $405 \mathrm{~nm}$, for Lll emissions detection.

In Fig. 6, the rates of the decline of extinction by material loss measured at 405 and $488 \mathrm{~nm}$ are very similar during the first 15 to $20 \mathrm{~ns}$ after the laser pulse. However, the secondary rise in extinction by the formation of secondary species starts earlier for the 405-nm data compared to 488-nm data. For example, this delay is roughly $10 \mathrm{~ns}$ for a fluence of $6.19 \mathrm{~mJ} / \mathrm{mm}^{2}$, causing the minimum extinction at 
$405 \mathrm{~nm}$ to be more than three times higher than that at $488 \mathrm{~nm}$. The most likely reason is that the secondary species that absorb light at $488 \mathrm{~nm}$ (e.g., $C_{2}$ and $C_{5}$ ) form later than species that absorb at 405 $\mathrm{nm}$ (mainly $\mathrm{C}_{3}$ ), thus more time is available for extinction to decline at $488 \mathrm{~nm}$. This speculation is supported by the results of Sasaki et al. [36] showing the sequential growth of clusters by the direct formation of $C_{2}$ from laser heated graphite particles followed by the formation of $C_{3}$ and heavier clusters by chemical reactions in the gas phase. However, Leider et al. [35] and Goulay et al. [43] have shown that $C_{3}$ is most likely the first species to sublime, followed by $C, C_{2}, C_{4}$, and $C_{5}$.

A tertiary decay of $\overline{K_{\text {ext }, \lambda}}$ after the formation of secondary species, shown in Fig. 5 for the $405-\mathrm{nm}$ and 488-nm data, begins at about $800 \mathrm{~ns}$. This decay possibly results from the complete transformation of sublimated material, the oxidation or recombination of the newly formed carbon species that absorb light at shorter wavelengths, and the diffusion of material to regions of lower concentration out of the laser probe region. The increasing duration and magnitude of this decay with increasing fluence can be explained by the slower oxidation of an increasingly high concentration of light absorbing species.
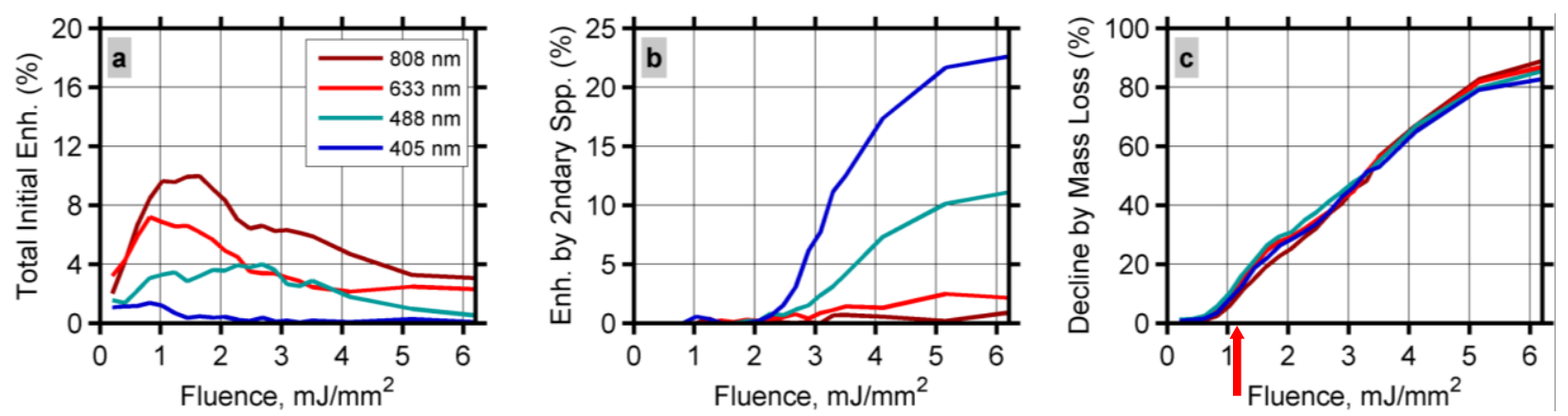

Fig. 7 Comparison of (a) the initial enhancement of $\overline{K_{\text {ext, }, \lambda}}$ caused by a temperature dependent $E\left(m_{\lambda}\right)$, (b) the enhancement of $\overline{K_{\text {ext }, \lambda}}$ by the formation secondary species, and (c) the decline of $\overline{K_{\text {ext, }}}$ by soot sublimation, measured at four different wavelengths in the diffusion flame as a function of IR laser fluence. The fluence threshold for soot sublimation in the diffusion flame is indicted by a red arrow in Fig. c.

Figure 7 summarizes the wavelength dependence of the initial enhancement of $\overline{K_{\text {ext }, \lambda}}$ (Fig. 7a), enhancement by the formation secondary species (Fig. 7b), and the decline of $\overline{K_{\text {ext, } \lambda}}$ by soot sublimation (Fig. 7c), as a function of IR laser fluence. Figure 7a depicts the increase of the prompt extinction enhancement by increasing the wavelength of the $\mathrm{CW}$ laser, calculated by subtracting peak $\overline{K_{\text {ext }, \lambda}}$ in the first $100 \mathrm{~ns}$ after the laser pulse from one. Initially, increasing the fluence levels increases the enhancement of light extinction, but as the effect of material loss by sublimation gradually gets stronger and starts earlier, it seems to overwhelm the enhancement causing the peak enhancement to decrease with increasing fluence for fluences higher than $\sim 1 \mathrm{~mJ} / \mathrm{mm}^{2}$. The low temporal resolution of the detection system is also likely to contribute to the decreasing enhancements at high fluences. Figure $7 \mathrm{~b}$ shows the effect of secondary species formation determined by subtracting the minimum of $\overline{K_{\text {ext }, \lambda}}$ in the first $200 \mathrm{~ns}$ after the laser pulse from the peak that occurs between $t=300 \mathrm{~ns}$ and $\mathrm{t}=2000 \mathrm{~ns}$. Secondary enhancement occurs only for fluences higher than $2 \mathrm{~mJ} / \mathrm{mm}^{2}$ and gets stronger with reducing wavelength, because the secondary species absorb light more strongly at shorter wavelengths. The decline of $\overline{K_{\text {ext, }, \lambda}}$ by material loss, shown in Fig. $7 c$, is calculated by subtracting the minimum of $\overline{K_{\text {ext, } \lambda}}$ occurring during the first millisecond after the laser pulse from one. This decline is due to a loss of light 
absorbing material by sublimation and is nearly independent of wavelength, because the effect of the formation of secondary species is negligible for this longer time period. Figure 7c, as well as Fig. 3, shows that significant mass loss occurs at roughly $1.1 \mathrm{~mJ} / \mathrm{mm}^{2}$ (indicated with a red arrow) and higher fluences, considerably lower than the sublimation fluence thresholds observed in the literature. It should be noted that processes responsible for the enhancement or reduction of light absorption by soot particles are occurring simultaneously, therefore the results presented in Fig. 7 and the rest of the figures in this paper exhibit the net effect or outcome of these effects. 


\subsection{The premixed flame}
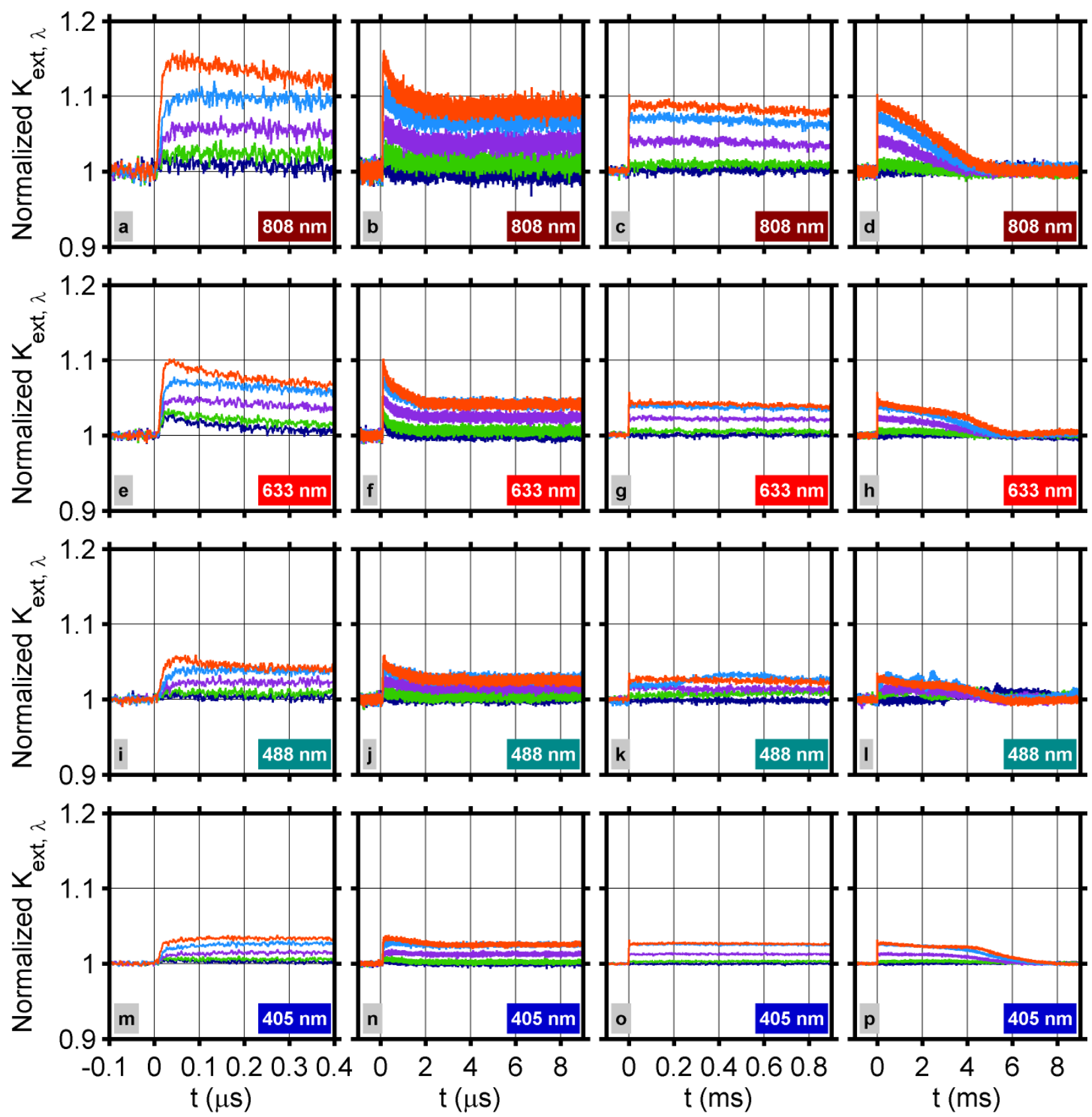

$0.21 \mathrm{~mJ} / \mathrm{mm}^{2}$

$0.41 \mathrm{~mJ} / \mathrm{mm}^{2}$

$0.62 \mathrm{~mJ} / \mathrm{mm}^{2}$

$0.82 \mathrm{~mJ} / \mathrm{mm}^{2}$

$1.24 \mathrm{~mJ} / \mathrm{mm}^{2}$

Fig. 8 Comparing the normalized extinction coefficient profiles in the premixed flame for five IR laser fluences, ranging from 0.21 to $1.24 \mathrm{~mJ} / \mathrm{mm}^{2}$, in four time windows and measured using four CW laser wavelengths.

The profiles of $\overline{K_{\text {ext }, \lambda}}$ measured in the premixed flame using low laser fluences, from $0.21 \mathrm{~mJ} / \mathrm{mm}^{2}$ to $1.24 \mathrm{~mJ} / \mathrm{mm}^{2}$, are included in Fig. 8 for $\lambda_{c w}=808 \mathrm{~nm}$ (Figs. 8a-d), $\lambda_{c w}=633 \mathrm{~nm}$ (Figs. 8e-h), $\lambda_{c w}=488 \mathrm{~nm}$ (Figs. 8i-I), and $\lambda_{c W}=405 \mathrm{~nm}$ (Figs. $8 \mathrm{~m}-\mathrm{p}$ ). Similar to Figs. 3 and 5 , the data is shown in four time 
windows. Profiles for all twenty fluence levels are presented in Figs. S7, S8, S9, and S10 in the supplementary material.

Figure 8a demonstrates enhanced light absorption for the 808-nm light during soot heating by about 2.5 to $15 \%$, for the range of fluences shown. The rise period is about $17 \mathrm{~ns}$, consistent with the laser pulse duration ( $6 \mathrm{~ns}$ ) and photodiode's rise-time (14 ns). Figure $8 \mathrm{~b}$ shows that $\overline{K_{\text {ext }, \lambda}}$ loses about one-third of its peak value by $t \approx 4 \mu \mathrm{s}$. However, as shown by Fig. $8 \mathrm{c}$, and in contrast to Fig. 3 for the diffusion flame, about two-thirds of the peak value is retained by $\sim 700 \mu$ s after the laser pulse which is well beyond the time needed for the temperatures of soot and surrounding gas to equilibrate. This suggests a significant enhancement of soot absorption as a result of an irreversible increase in $E\left(m_{\lambda}\right)$ by laser-induced thermal annealing and graphitization, reorganizing the microstructure of soot and permanently modifying the optical properties. The magnitude of initial enhancement is a strong function of the fluence of the IR laser, increasing from about 2 to $15 \%$ by a $1.03 \mathrm{~mJ} / \mathrm{mm}^{2}$ increase in fluence, because of the higher peak temperatures.

Similar enhancements (with smaller quantity, discussed in a later section) also occur for $\overline{K_{\text {ext }, \lambda}}$ measured at $633 \mathrm{~nm}, 488 \mathrm{~nm}$, and $405 \mathrm{~nm}$ as shown in Figs. 8e, 8i, and 8m, respectively. New soot replaces laserheated soot in the measurement volume in 6 to 7 milliseconds and $\overline{K_{\text {ext }, \lambda}}$ returns to a value of one, as depicted in Figs. 8d, 8h, 8l, and 8p. This is longer compared to the diffusion flame because of the slower flow velocities in the premixed flame.

The increase of $\overline{K_{\text {ext, } \lambda}}$ suggests an initial enhancement of the soot emissivity, affecting the LII signal and thus particle sizes measured by signal decay. A major part of the increase in $\overline{K_{\text {ext }, \lambda}}$, which is attributed to thermal annealing of the laser-heated soot, is permanent. Therefore, it is likely to decrease the rate of LII signal decay after reaching peak intensity which also impacts particle size analysis. 


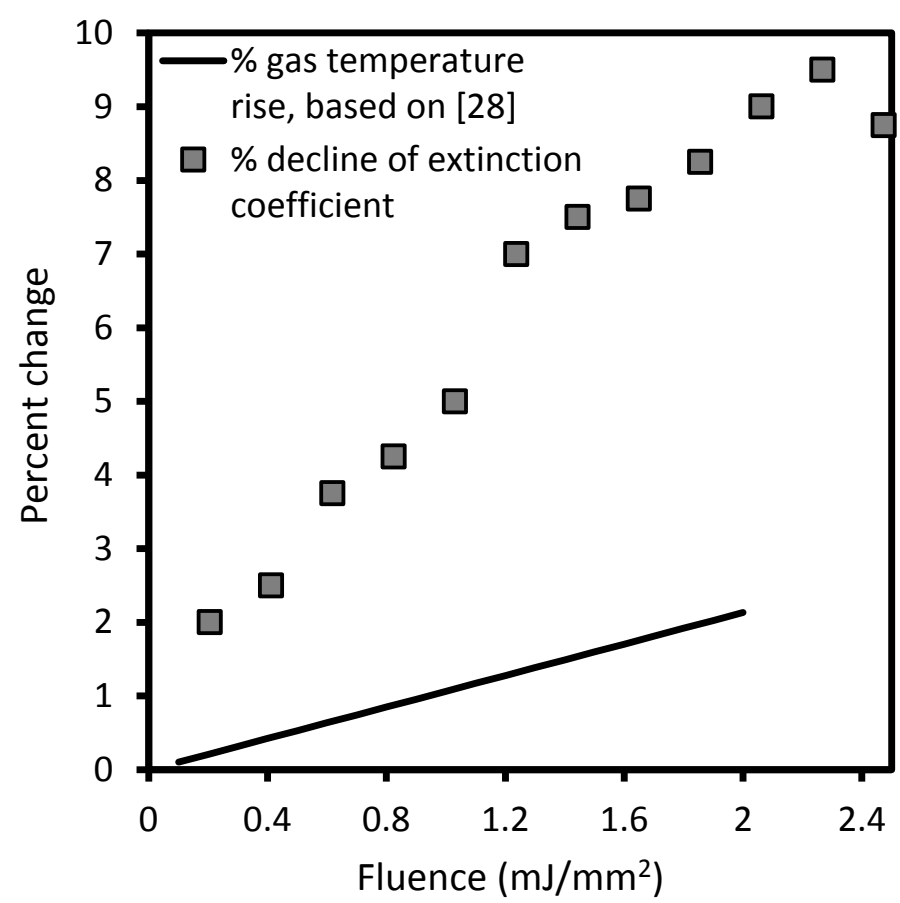

Fig. 9 A comparison between the estimated rise in the temperature of the gases surrounding the laser-heated soot in the premixed flame (based on [29]) and the measured decline of $\overline{K_{\text {ext }}}$ at $808 \mathrm{~nm}$ (only secondary decline for fluences higher than $1 \mathrm{~mJ} / \mathrm{mm}^{2}$ ).

Figure $8 \mathrm{~b}$ displays the decline of $\overline{K_{\text {ext, } \lambda}}$ for about $2 \mu$ s after the initial enhancement. To show the contribution of the gas expansion to this decline, an estimate of the increase in the temperature of gases upon the laser pulse is required. Measurements for local gas temperature increase are not available in the literature for the premixed flame under study in the present work. Therefore, the temperature rise, assumed to be proportional to $f_{v} \cdot E(m)$, is estimated based on the data provided in [29] for the diffusion flame and by comparing the measured attenuations of the $808 \mathrm{~nm}$ light through the diffusion and premixed flames for estimating $f_{v}$. The length of the beam path through the diffusion and premixed flames are about $0.8 \mathrm{~cm}$ and $6 \mathrm{~cm}$, respectively. Figure 9 compares the estimated rise of gas temperature with the decline of $\overline{K_{\text {ext }, \lambda}}$ measured in the present work. In contrast to the diffusion flame (Fig. 4), expansion of heated gases can explain only a fraction of the decline in $\overline{K_{\text {ext }} \lambda}$. Thus, the elastic variations of $E\left(m_{\lambda}\right)$ with temperature seem to be the dominant reason for the reversible behavior of $\overline{K_{\mathrm{ext}, \lambda}}$. 

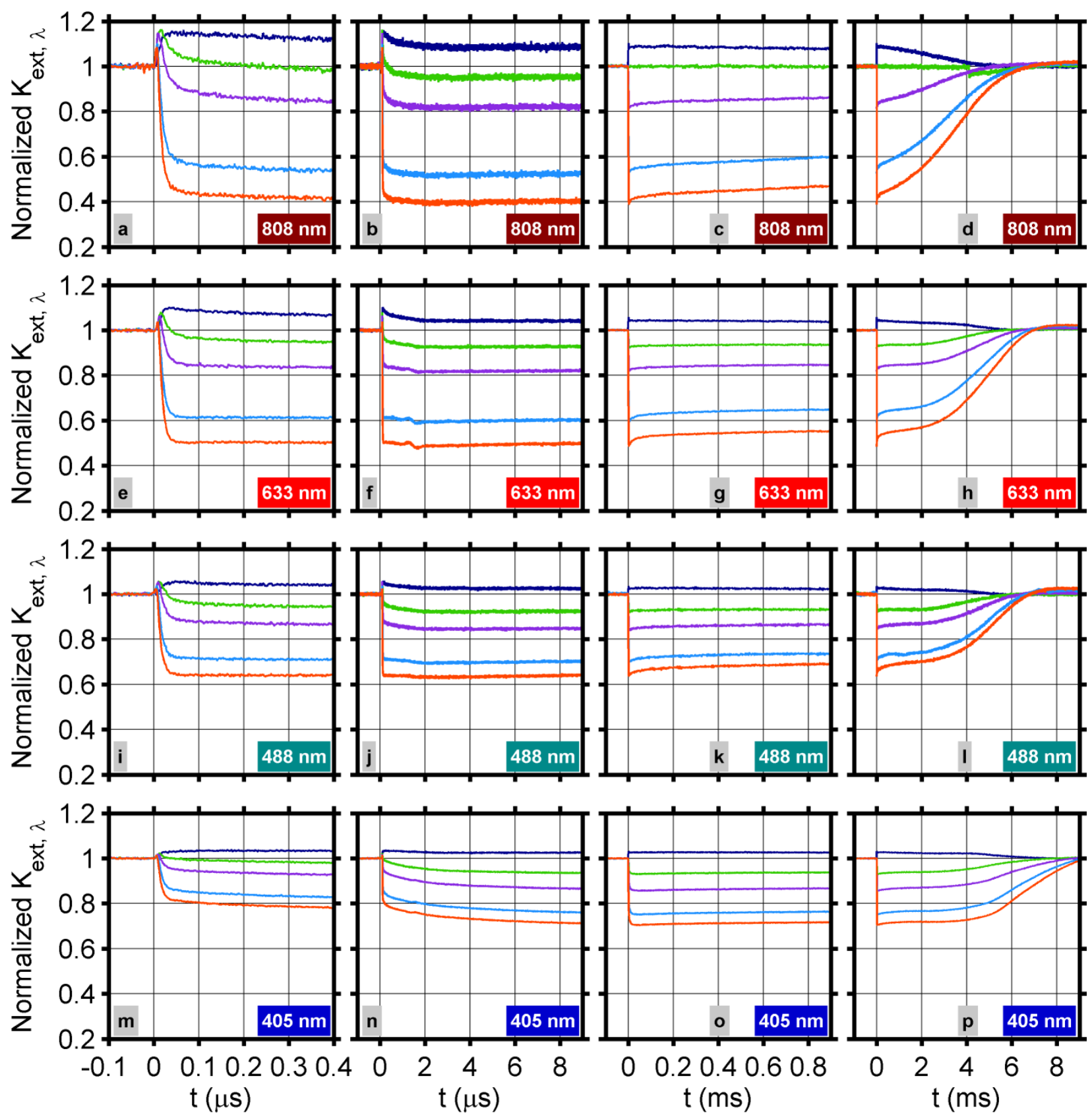

$1.24 \mathrm{~mJ} / \mathrm{mm}^{2}-2.47 \mathrm{~mJ} / \mathrm{mm}^{2}-3.51 \mathrm{~mJ} / \mathrm{mm}^{2}$

$5.15 \mathrm{~mJ} / \mathrm{mm}^{2}$

$6.19 \mathrm{~mJ} / \mathrm{mm}^{2}$

Fig. 10 Comparing the normalaized extinction coefficient profiles in the premixed flame for five high fluence leveles, from 1.24 to $6.19 \mathrm{~mJ} / \mathrm{mm}^{2}$, in four time windows and measured at four different wavelengths.

Comparisons between the $\overline{K_{\text {ext }, \lambda}}$ profiles measured in the premixed flame with high IR laser fluences, 1.24 to $6.19 \mathrm{~mJ} / \mathrm{mm}^{2}$, are included in Fig. 10. Based on Figs. 10a, 10e, 10i, and 10m, light extinction declines gradually for the fluence of $1.24 \mathrm{~mJ} / \mathrm{mm}^{2}$; however, a rapid decline by mass loss and extinction coefficients smaller than one occur at higher fluences. The more detailed profiles, presented in Figs. S8 and S9, show that a significant loss of material by sublimation, indicated by $\overline{K_{\text {ext, } \lambda}}$ dropping to values below 1 in the first $100 \mathrm{~ns}$ after the laser pulse, occurs using laser fluences higher than $2.68 \mathrm{~mJ} / \mathrm{mm}^{2}$ at 
$808 \mathrm{~nm}, 2.27 \mathrm{~mJ} / \mathrm{mm}^{2}$ at $633 \mathrm{~nm}, 2.06 \mathrm{~mJ} / \mathrm{mm}^{2}$ at 488 , and $2.47 \mathrm{~mJ} / \mathrm{mm}^{2}$ for the $405-\mathrm{nm}$ light. These fluence thresholds for soot sublimation are closer to the values observed frequently in the literature $[4,10,14,7,17]$. More significant sublimation and mass loss occurs at higher temperatures, therefore the magnitude of the decline increases with increasing laser fluence.

A secondary decay of $\overline{K_{\text {ext }, \lambda}}$, extending to $\mathrm{t} \approx 2 \mu \mathrm{s}$, is seen in Figs. $10 \mathrm{~b}, 10 \mathrm{f}$, and $10 \mathrm{j}$ for $\lambda_{c w}=808 \mathrm{~nm}$, $\lambda_{c W}=633 \mathrm{~nm}$, and $\lambda_{c W}=488 \mathrm{~nm}$, respectively, attributed to a decrease in soot volume fraction by the expansion of surrounding gases. Figures $10 \mathrm{n}$ and $10 \mathrm{o}$ show that the secondary decay lasts longer for $\overline{K_{\text {ext }, \lambda}}$ measured at $405 \mathrm{~nm}$, by up to about $25 \mu \mathrm{s}$ at a fluence of $6.19 \mathrm{~mJ} / \mathrm{mm}^{2}$. The formation of small quantities of species that absorb light at $405 \mathrm{~nm}$ from sublimated soot material may contribute to the more persistent decay of extinction at this wavelength. Fresh soot enters the measurement volume in 7 to $9 \mathrm{~ms}$, shown in Figs. 10d, 10h, $10 \mathrm{l}$, and 10p, and $\overline{K_{\text {ext }, \lambda}}$ returns to its pre-laser pulse value of one. 
(a) $0.21 \mathrm{~mJ} / \mathrm{mm}^{2}$

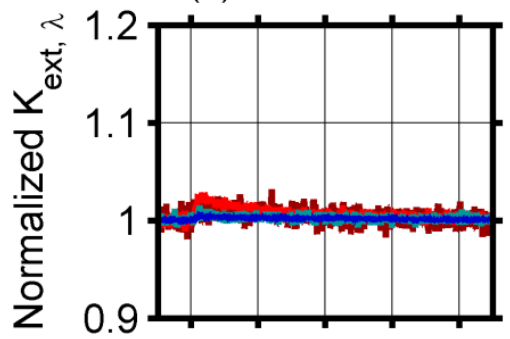

(e) $1.03 \mathrm{~mJ} / \mathrm{mm}^{2}$

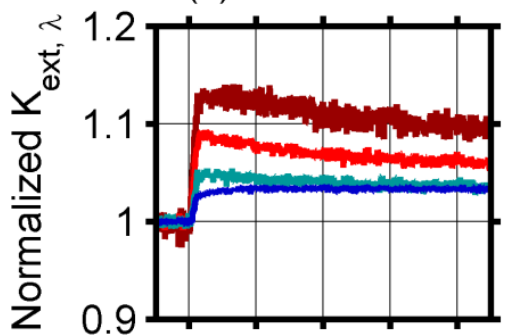

(i) $1.86 \mathrm{~mJ} / \mathrm{mm}^{2}$

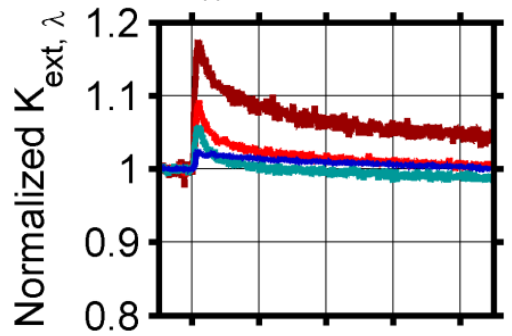

(m) $2.68 \mathrm{~mJ} / \mathrm{mm}^{2}$

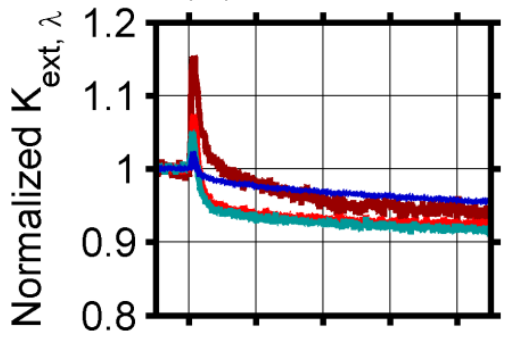

(q) $3.51 \mathrm{~mJ} / \mathrm{mm}^{2}$

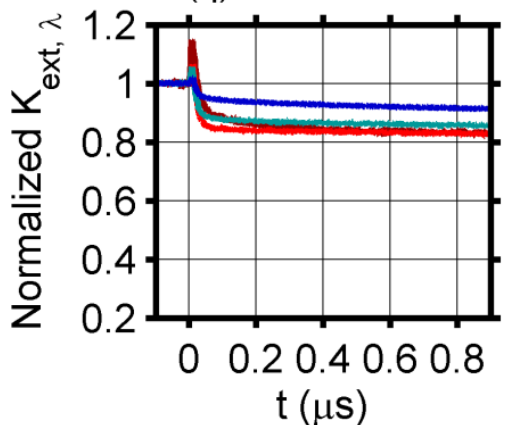

(b) $0.41 \mathrm{~mJ} / \mathrm{mm}^{2}$

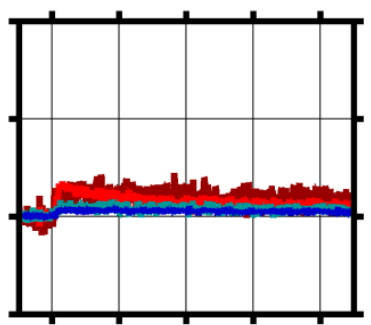

(f) $1.24 \mathrm{~mJ} / \mathrm{mm}^{2}$

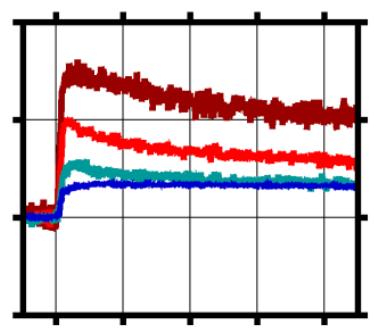

(j) $2.06 \mathrm{~mJ} / \mathrm{mm}^{2}$

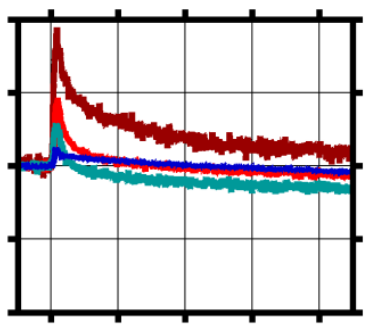

(n) $2.89 \mathrm{~mJ} / \mathrm{mm}^{2}$

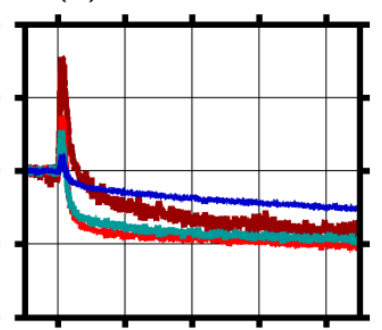

(r) $4.12 \mathrm{~mJ} / \mathrm{mm}^{2}$

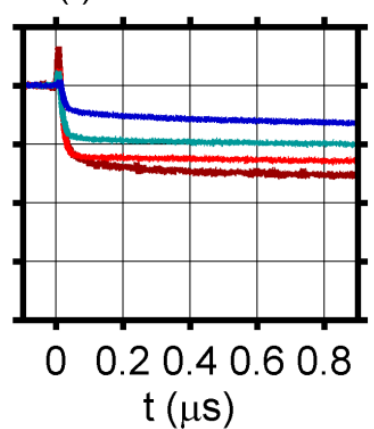

$808 \mathrm{~nm}$ (c) $0.62 \mathrm{~mJ} / \mathrm{mm}^{2}$

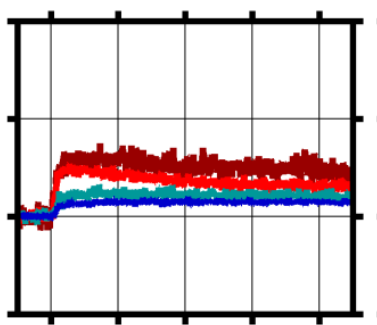

(g) $1.44 \mathrm{~mJ} / \mathrm{mm}^{2}$

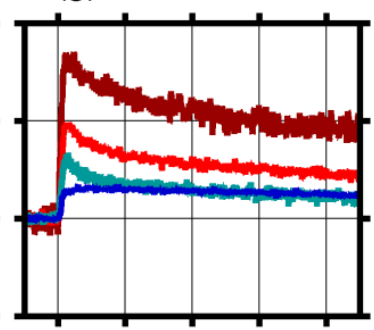

(k) $2.27 \mathrm{~mJ} / \mathrm{mm}^{2}$

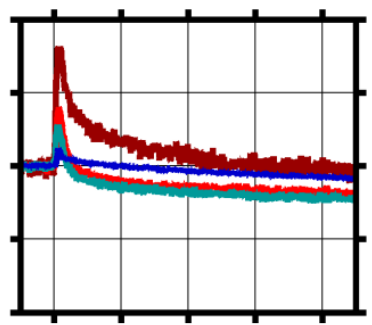

(o) $3.09 \mathrm{~mJ} / \mathrm{mm}^{2}$

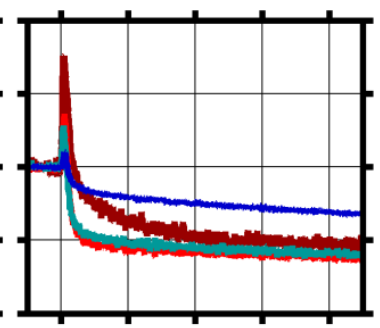

(s) $5.15 \mathrm{~mJ} / \mathrm{mm}^{2}$

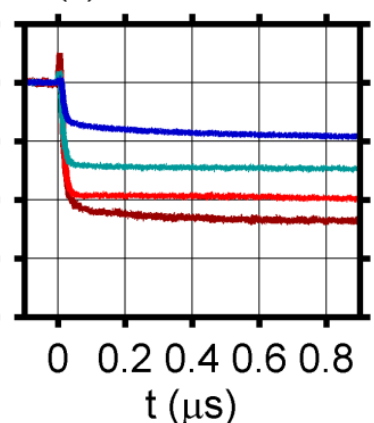

(d) $0.82 \mathrm{~mJ} / \mathrm{mm}^{2}$

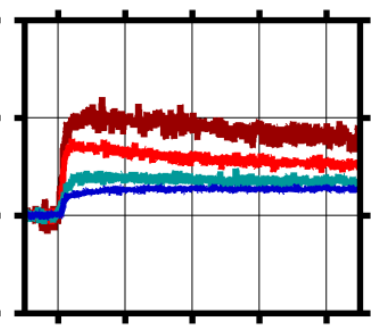

(h) $1.65 \mathrm{~mJ} / \mathrm{mm}^{2}$

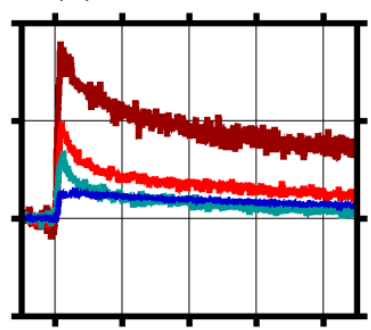

(I) $2.47 \mathrm{~mJ} / \mathrm{mm}^{2}$

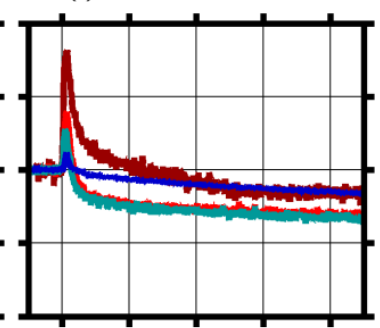

(p) $3.3 \mathrm{~mJ} / \mathrm{mm}^{2}$

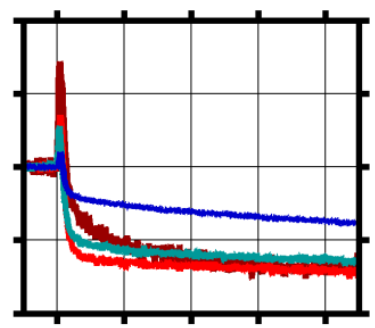

(t) $6.19 \mathrm{~mJ} / \mathrm{mm}^{2}$

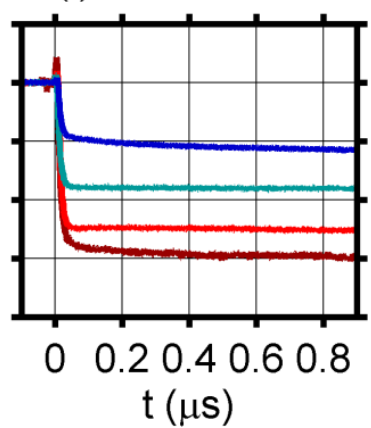

$405 \mathrm{~nm}$

Fig. $11 \mathrm{~A}$ comparison between $\overline{K_{\text {ext }, \lambda}}$ profiles measured in the premixed flame using four different wavelengths, $\lambda_{C W}=808 \mathrm{~nm}, \lambda_{C W}=633 \mathrm{~nm}, \lambda_{C W}=488 \mathrm{~nm}$, and $\lambda_{c W}=405 \mathrm{~nm}$, over a wide range of fluence levels. 
Figure 11 compares the $\overline{K_{\text {ext, } \lambda}}$ profiles measured for the premixed flame with four different wavelengths and for twenty laser fluences in short timescales. The data on longer timescales are included in Figs. S11 and S12. For fluences up to $1.65 \mathrm{~mJ} / \mathrm{mm}^{2}$, shown in Figs. $11 \mathrm{a}-\mathrm{h}$, a significant enhancement of $\overline{K_{\text {ext, } \lambda}}$ occurs which gets stronger with increasing $\mathrm{CW}$ laser wavelength. For example for a fluence of 1.65 $\mathrm{mJ} / \mathrm{mm}^{2}$, enhancements of 3\%,7\%,10\%, and $18 \%$ occur at $405 \mathrm{~nm}, 488 \mathrm{~nm}, 633 \mathrm{~nm}$, and $808 \mathrm{~nm}$, respectively. Figure S11 in the supplementary material presents similar comparisons for a longer timescale, up to $9 \mu \mathrm{s}$ after the laser pulse, and more clearly shows the permanent component of enhancement, from $4 \mu \mathrm{s}$ to $9 \mu \mathrm{s}$. This permanent enhancement, mainly caused by changes in the internal structure of soot particles by laser heating and a permanent increase in $E\left(m_{\lambda}\right)$, also shows a strong spectral dependence and increases with wavelength up to a fluence of $1.24 \mathrm{~mJ} / \mathrm{mm}^{2}$. The permanent enhancement is in particular very strong at $808 \mathrm{~nm}$ compared to the other three wavelengths. The spectral dependence of the enhancement of $E\left(m_{\lambda}\right)$ by graphitization has also been demonstrated in the literature. Migliorini et al. [26] determined the $E\left(m_{\lambda}\right)$ of soot in premixed and non-premixed flames at various height above the burner by measuring the extinction of light at various wavelengths. The amount of increase in $E\left(m_{\lambda}\right)$ with height, caused by the graphitization and aging of soot, was shown to depend strongly on the wavelength of the laser used for extinction measurements. The evaporation of the potentially light-absorbing volatile material by laser heating and also the increasing contribution of the gaseous species present in the flame, in particular large PAH molecules, to attenuation with shortening the wavelength might also partly mask the initial enhancement at shorter wavelengths.

At high fluences, the effect of mass loss by sublimation overwhelms the effect of $E\left(m_{\lambda}\right)$ increase, hence the enhancement of extinction gets weaker and $\overline{K_{\text {ext }, \lambda}}$ goes below unity for fluences equal to and higher than $1.86 \mathrm{~mJ} / \mathrm{mm}^{2}$ based on $488-\mathrm{nm}$ profiles, presented in Figs. $11 \mathrm{i}$ and $\mathrm{S} 11 \mathrm{i}$. The low temporal resolution of the photodiode likely contributes to this decreasing enhancement. After the start of soot sublimation, $\overline{K_{\text {ext }, \lambda}}$ measured at $808 \mathrm{~nm}$ is higher than the extinction coefficients measured at shorter wavelengths for fluence below $2.47 \mathrm{~mJ} / \mathrm{mm}^{2}$ because of the strong enhancement of $E\left(m_{\lambda}\right)$ at $808 \mathrm{~nm}$. However, as the fluence of the IR laser increases, $\overline{K_{\text {ext, }, \lambda}}$ at shorter wavelengths rapidly goes up with increasing fluence possibly because of the formation of secondary species from sublimated soot material which absorb strongly at shorter wavelengths. The increasing contribution of light absorbing molecules, present in the flame gases, to attenuation with shortening wavelength can also explain the spectral dependence of the decline of $\overline{K_{\text {ext }, \lambda}}$.
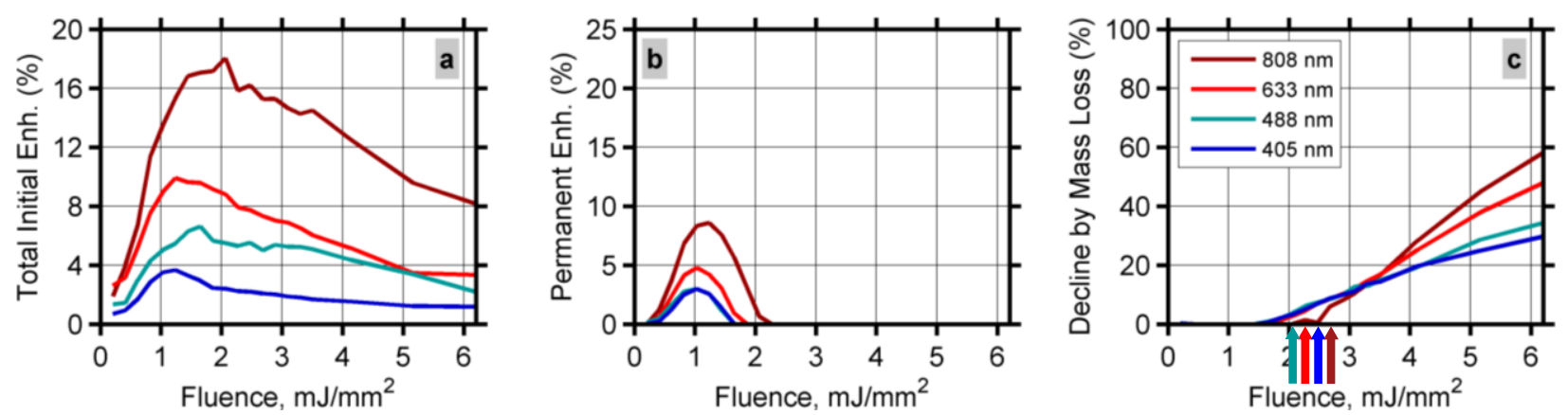

Fig. 12 Comparing (a) total initial enhancement of $\overline{K_{\text {ext }, \lambda}}$, (b) the permanent component of $\overline{K_{\text {ext, }, \lambda}}$ enhancement by laser-induced thermal annealing, and (c) and the decline of extinction by soot sublimation, measured with four CW wavelengths in the premixed flame as a function of IR laser fluence. The wavelength-dependent fluence 
thresholds for soot sublimation are shown in Fig. c.

The key distinctions between $\overline{K_{\text {ext }, \lambda}}$ profiles measured with different wavelengths in the premixed flame are outlined in Fig. 12. The total initial enhancement of $\overline{K_{\text {ext }, \lambda}}$, shown in Fig. 12a, gets stronger with $\lambda_{c w}$. The peak values of this enhancement measured at $808,633,488$, and $405 \mathrm{~nm}$ are $18 \%, 10 \%, 7 \%$, and $4 \%$, respectively. The permanent component of this enhancement, calculated by averaging the enhancement between 4 and $9 \mu \mathrm{s}$, follows a similar trend as shown in Fig. 12b, indicating a strong dependence of the increase in $E\left(m_{\lambda}\right)$ on wavelength. The decline of $\overline{K_{\text {ext }, \lambda}}$ by sublimation, depicted in Fig. 12c, is lower at $808 \mathrm{~nm}$ for fluences below $\sim 3.5 \mathrm{~mJ} / \mathrm{mm}^{2}$, mostly likely because of the significant enhancement of $E\left(m_{\lambda}\right)$ at this wavelength. However, at higher fluences, the effect of nonsoot light absorbing species becomes dominant, reducing the decline of extinction by mass loss measured at 633 , 488 , and $405 \mathrm{~nm}$. These results specify that the magnitude of the decline in $\overline{K_{\text {ext }, \lambda}}$ is not a reliable indicator of the amount of sublimated soot mass because this decline is influenced strongly by the formation of light absorbing secondary species, contributions from nonsoot elements to attenuation, and changes in soot optical properties by laser heating. 


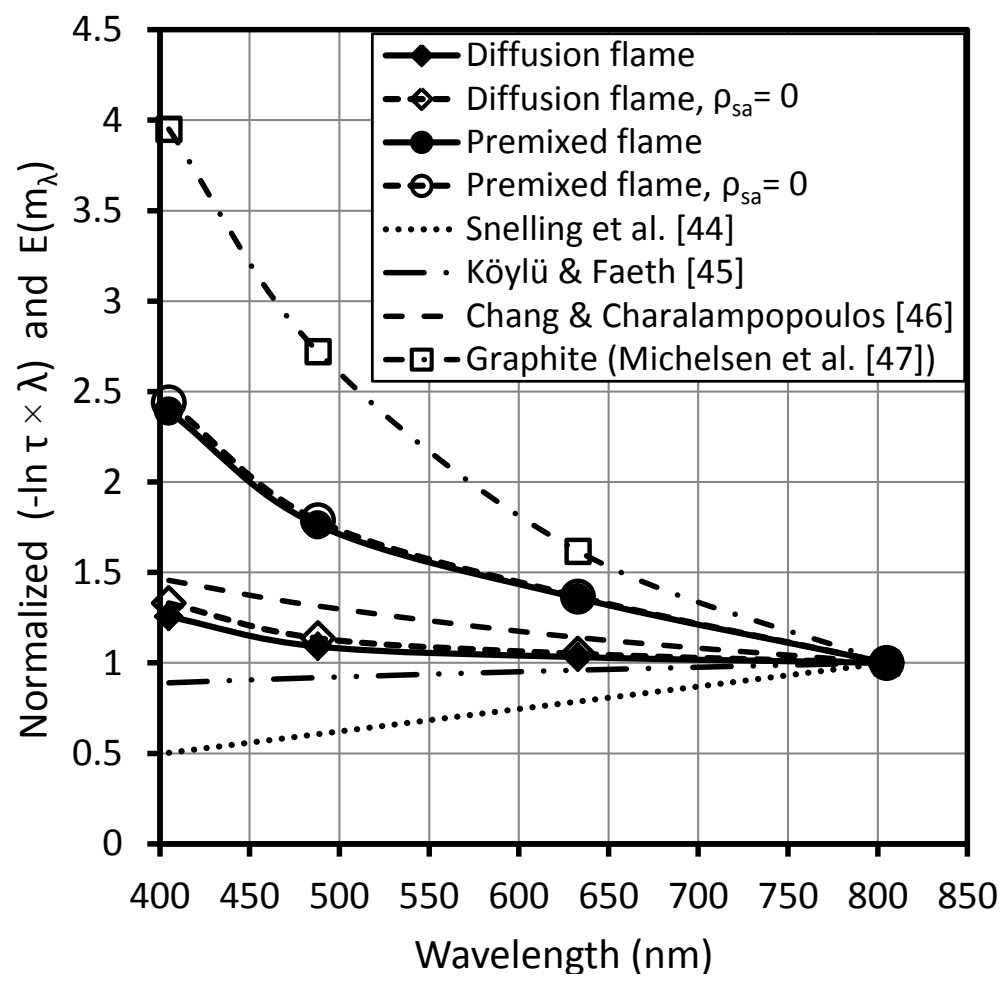

Fig. $13 \mathrm{~A}$ comparison between the normalized $(-\ln (\tau) \cdot \lambda)$ which is proportional to $E\left(m_{\lambda}\right)$, measured in the diffusion and premixed flames with and without considering the effect of light scattering, and the relationships for the wavelength dependence of $E\left(m_{\lambda}\right)$ reported by Snelling et al. [47], Köylü and Faeth [48], Chang and Charalampopoulos [49] for flame soot, and Michelsen et al. [50] for graphite.

The measured transmissivities of the CW laser beams at each wavelength, $\tau_{\lambda}$, in the absence of infrared laser pulse are used to calculate $\left(-\ln \left(\tau_{\lambda}\right) \cdot \lambda_{C W}\right)$ for the premixed and diffusion flames as a function of $\lambda_{c W}$. Based on the RDG-FA approximation [51], $\left(-\ln \left(\tau_{\lambda}\right) \cdot \lambda_{C W}\right)$ is proportional to $E\left(m_{\lambda}\right)$,

$-\ln \left(\tau_{\lambda}\right) \cdot \lambda_{C W}=6 \pi L f_{v}\left(1+\rho_{s a, \lambda}\right) E\left(m_{\lambda}\right)$

where $L$ is the length of laser beam path through the flames, $f_{v}$ is the path-integrated soot volume fraction whose value does not vary with wavelength for each burner, and $\rho_{s a, \lambda}$ is the ratio of light scattering to light absorption coefficients at wavelength $\lambda$.

Migliorini et al. [26] estimated $\rho_{s a, \lambda}$ for the Gülder diffusion flame, at the same measurement position and for the same flow rates used in the present work, as a function of wavelength (e.g., $12 \%$ and $6 \%$ for the 405 and 808-nm light, respectively). For the McKenna premixed flame, $\rho_{s a, \lambda}$ is also adopted from [26] which calculated the ratio for the same measurement position used in the present work but for a flame with an equivalence ratio of 2.1 (as opposed to 2.7 in the present work). 
The wavelength dependence of $\left(-\ln \left(\tau_{\lambda}\right) \cdot \lambda_{C W}\right)$ for the premixed and diffusion flames are shown in Fig. 13 , normalized at $\lambda_{c W}=808 \mathrm{~nm}$. These profiles can be used to compare the relative variations of $E\left(m_{\lambda}\right)$ with wavelength for the two flames. To show the impact of neglecting laser scattering, the data calculated with the assumption of $\rho_{s a, \lambda}=0$ is also included in Fig. 13.

For both flames, Fig. 13 shows an increase in $E\left(m_{\lambda}\right)$ with shortening the wavelength. The variations of $E\left(m_{\lambda}\right)$ in the diffusion flame, specifically for $\lambda \geq 633 \mathrm{~nm}$, are relatively small (within $3 \%$ ) confirming that $E\left(m_{\lambda}\right)$ is nearly independent of wavelength at the upper visible region of the spectrum. However, the variability of $E\left(m_{\lambda}\right)$ in the premixed flame is more than one order of magnitude higher than the variability in the diffusion flame (e.g., $36 \%$ at $633 \mathrm{~nm}$ ).

A similar behavior was observed by other researchers in premixed and diffusion flames. For example, Michelsen et al. [10] determined the wavelength and temperature dependence of soot absorption and scattering cross-sections by LII and attenuation measurements at 532 and $1064 \mathrm{~nm}$ in a laminar diffusion flame. Measurements were carried out for mature soot at locations with minimum PAH concentrations to avoid nonsoot interferences. The emissivity of soot deviated from the $1 / \lambda$ dependence, predicted by the RDG-FA approximation, implying that $E\left(m_{\lambda}\right)$ is wavelength dependent. López-Yglesias et al. [20] measured the time-resolved LII signal using laser wavelengths of $532 \mathrm{~nm}$ and $1064 \mathrm{~nm}$ at the edge and center of diffusion flames. It was shown that the 532 to $1064 \mathrm{~nm}$ absorption cross-section ratio increases with increasing hydrogen content and decreasing soot maturity. In another work, Migliorini et al. [26] measured $E\left(m_{\lambda}\right)$ for the Gülder diffusion flame and a McKenna premixed flame at different heights above the burners. $E\left(m_{\lambda}\right)$ was shown to have a very strong spectral dependence for wavelengths below $700 \mathrm{~nm}$. For longer wavelengths, the variations of $E\left(m_{\lambda}\right)$ with wavelength were negligible in both flames and for all measurements heights. Olofsson et al. [16] measured the fluence threshold for sublimation of soot in a premixed flame and showed that the threshold is higher for the younger and less graphitic particles at lower flame heights. It was suggested that the main reason for this behavior is the lower $E\left(m_{\lambda}\right)$ for younger soot particles compared to the more graphitic soot at higher heights.

The spectral dependence of $E\left(m_{\lambda}\right)$ is most likely caused by the increasing contribution of the liquid-like and semi-transparent soot precursors, the newly-formed and less-graphitized soot particles, and also the large PAH molecules in the gas phase to light attenuation $[26,16,52,20,30]$. The stronger variability of $E\left(m_{\lambda}\right)$ in the premixed flame might be a result of different residence times and temperature/gas composition histories leading to the formation of less graphitized soot under these conditions [52,53], as well as the effect of burner type on flame structure and soot formation processes [54]. Higher concentrations of nonsoot species, such as PAH molecules and nanoparticles made of condensed large PAHs $[55,56]$, in the premixed flame may also contribute to the observed differences between the two flames.

Figure 13 also compares the data measured for the flames to the results of a few relationships, suggested in [10], describing the wavelength dependence of $E\left(m_{\lambda}\right)$. There is a good agreement between the measured data and the relationship proposed by Chang and Charalampopoulos [49]. However, the relationship developed for graphite overpredicts the variability of $E\left(m_{\lambda}\right)$ and even the signs of the slopes of the measured curves do not match the relationships proposed by Snelling et al. [47], based on the experimental data of [23], and Köylü and Faeth [48]. 

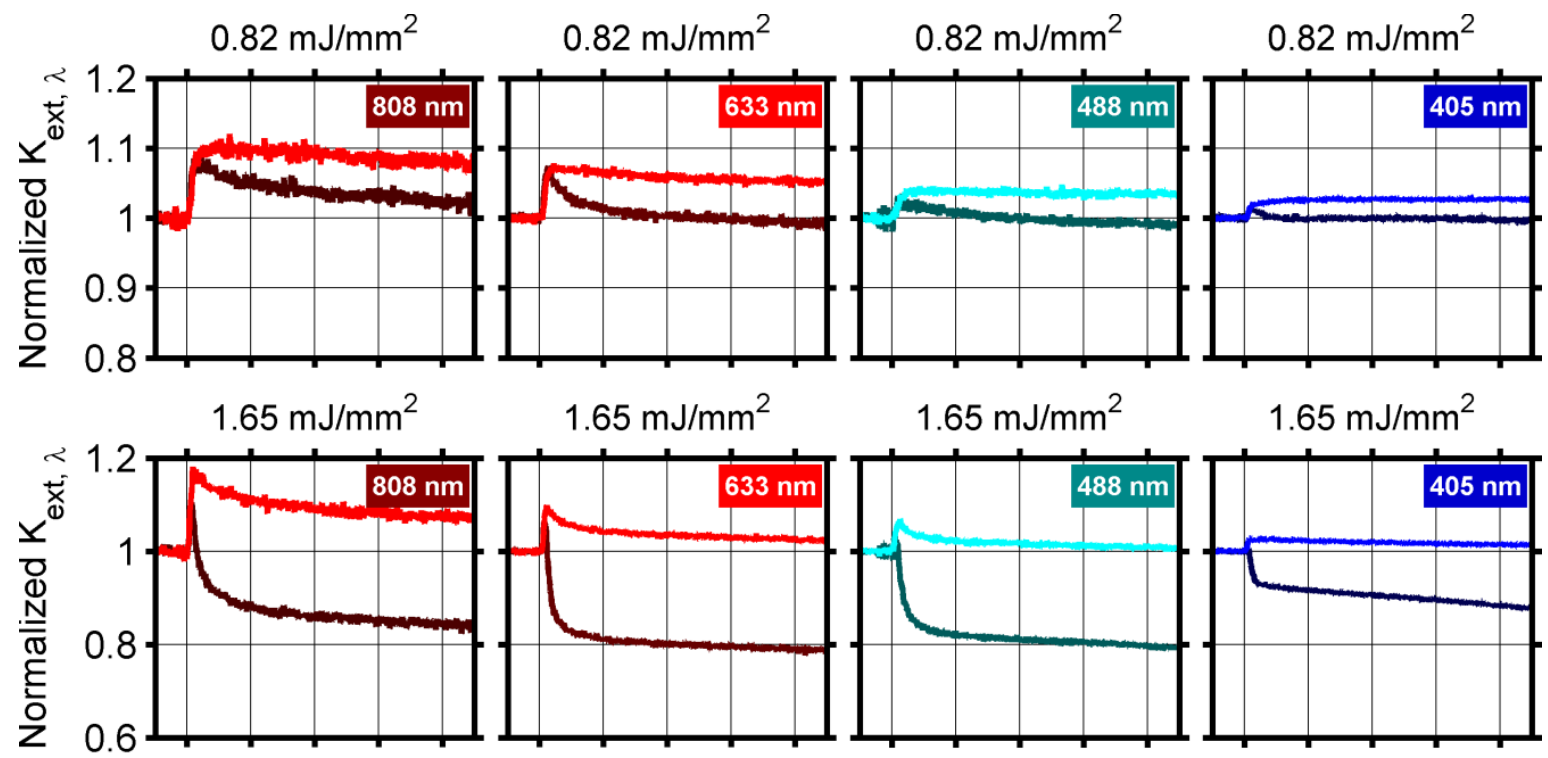

$1.65 \mathrm{~mJ} / \mathrm{mm}^{2}$
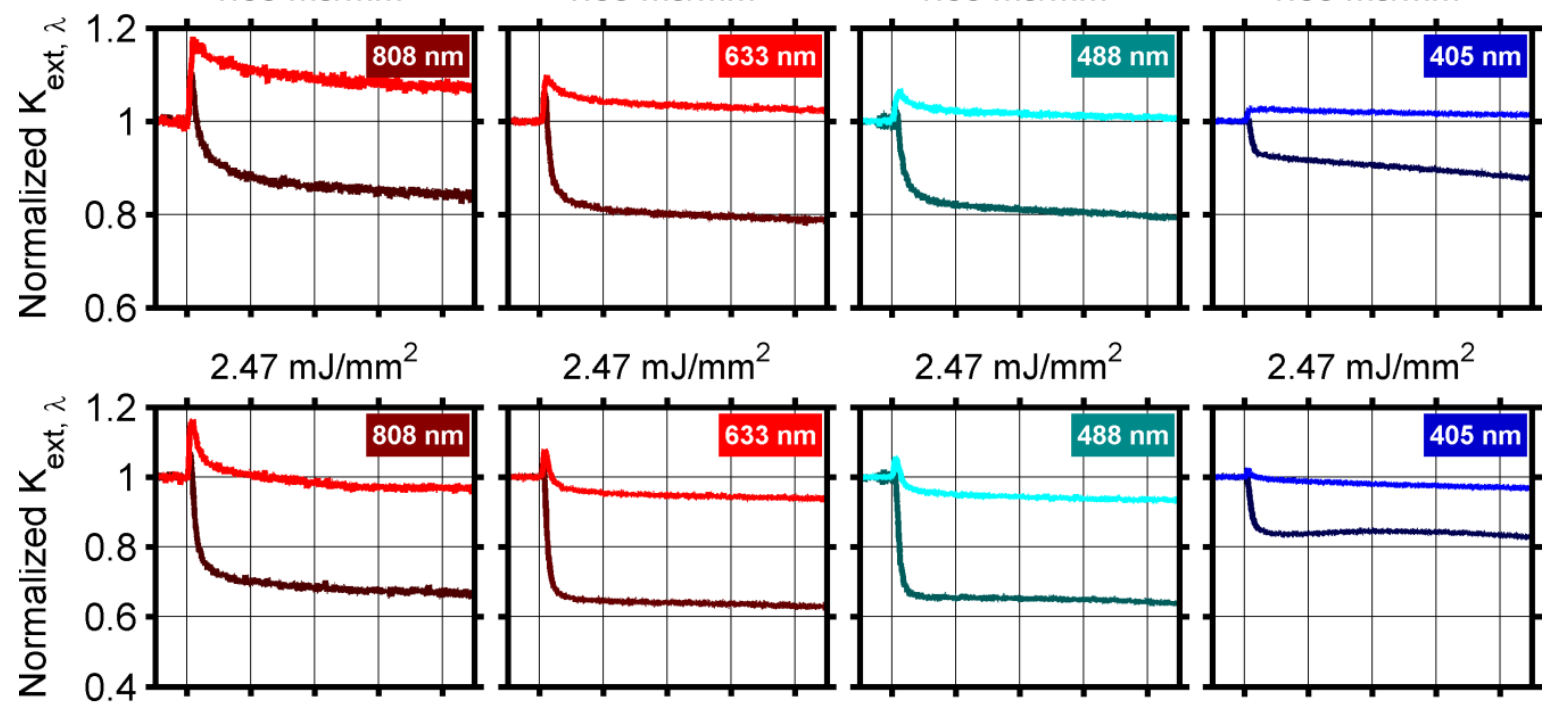

$2.47 \mathrm{~mJ} / \mathrm{mm}^{2}$

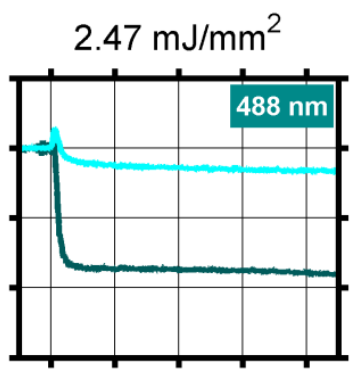

$2.47 \mathrm{~mJ} / \mathrm{mm}^{2}$
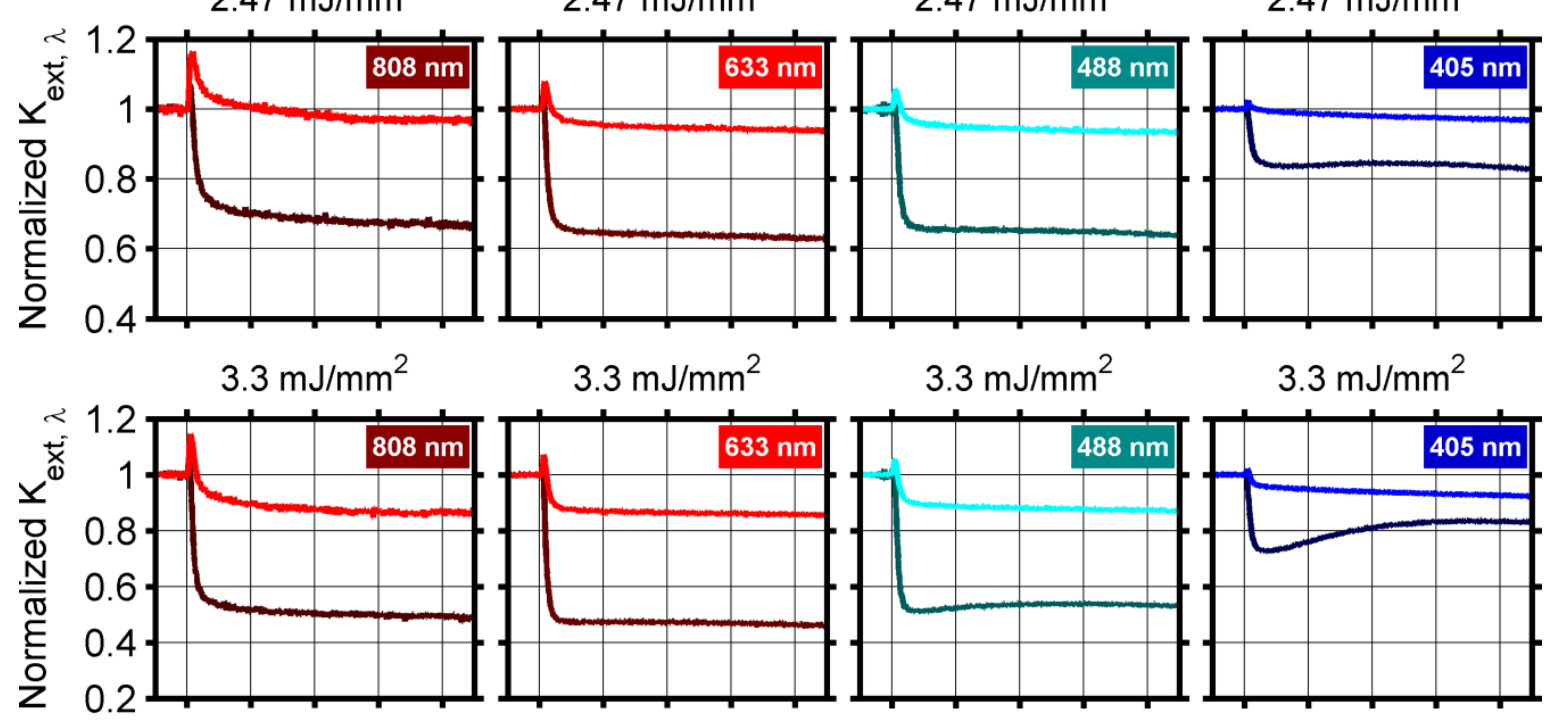

$3.3 \mathrm{~mJ} / \mathrm{mm}^{2}$

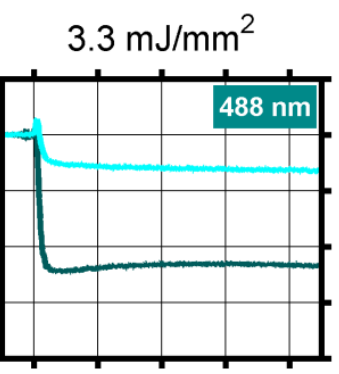

$3.3 \mathrm{~mJ} / \mathrm{mm}^{2}$

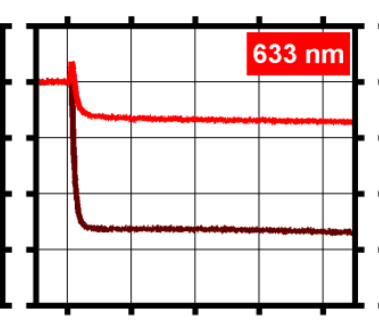

$6.19 \mathrm{~mJ} / \mathrm{mm}^{2}$

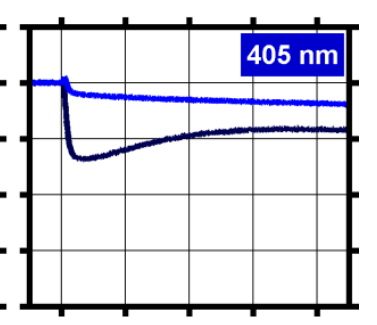

$6.19 \mathrm{~mJ} / \mathrm{mm}^{2}$

$6.19 \mathrm{~mJ} / \mathrm{mm}^{2}$
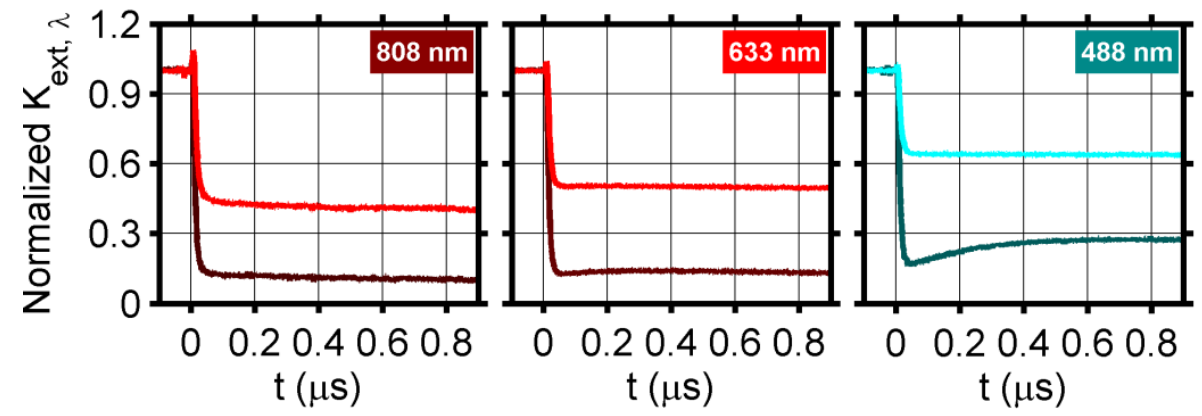

$6.19 \mathrm{~mJ} / \mathrm{mm}^{2}$

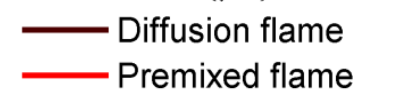

Diffusion flame

Diffusion flame

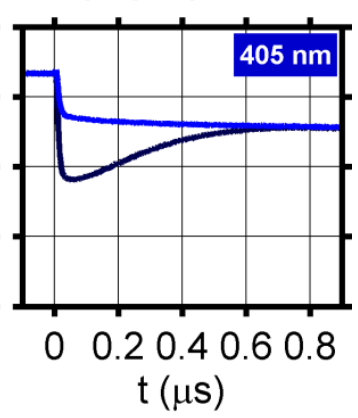

Premixed flame

Fig. 14 Comparing the normalized extinction coefficient profiles in the diffusion and premixed flames, at four wavelengths and five fluence levels. The profiles measured in the diffusion flame are shown with darker colors and the profiles measured in the premixed flame are shown with brighter colors. 
Figure 14 compares the profiles of $\overline{K_{\text {ext, } \lambda}}$ measured in the diffusion and premixed flames with four wavelengths and for five fluence levels, from 0.82 to $6.19 \mathrm{~mJ} / \mathrm{mm}^{2}$, in a short timescale. Comparisons for all 20 fluences as well as comparisons in longer timescales are demonstrated in Figs. S13 to S17 in the supplementary material.

The amount of enhancement during the laser pulse is consistently higher for the premixed flame at all wavelengths and fluences, e.g., $10 \%$ in the diffusion fame compared to $17 \%$ in the premixed flame for $1.65 \mathrm{~mJ} / \mathrm{mm}^{2}$. The different ages and temperature histories of soot particles in the two flames, potentially causing dissimilar optical and physical properties of soot, can explain the more significant enhancement in the absorption cross section for soot particles in the diffusion flame.

Figure 14 and Figs. S13 to S16 show that $\overline{K_{\text {ext }, \lambda}}$ drops to the pre-laser pulse values within a short time after the laser-pulse for fluences of $1.03-1.24 \mathrm{~mJ} / \mathrm{mm}^{2}$ for the diffusion flame and $2.06-2.68 \mathrm{~mJ} / \mathrm{mm}^{2}$ for the premixed flame, demonstrating that substantially higher laser energies are required for sublimating soot in the premixed flame. The stronger enhancement of the light absorption coefficient for soot in the premixed flame, partly masking the decline of extinction by material loss, can explain the higher sublimation threshold in the premixed flame. A more graphitic structure of soot in the diffusion flame, i.e., a higher $E\left(m_{\lambda}\right)$, causing a stronger absorption of infrared light and as a result a higher temperature rise, may also contribute to the lower sublimation threshold in the diffusion flame.

The amount of soot sublimation, as crudely estimated by the minimum of $\overline{K_{\text {ext }, \lambda}}$, decreases significantly with decreasing wavelength for the premixed flame at high fluences, as shown in Fig. 12c. This is in contradiction with the behavior of soot in the diffusion flame (Fig. 7c) showing soot sublimation to be nearly independent of wavelength. Considering that the amount of material loss by sublimation is only a function of the properties of the heating laser (1064-nm Nd:YAG laser in the present work), it is not expected to change with the $\mathrm{CW}$ laser wavelength. This suggests a strong contribution to attenuation from nonsoot elements which are not influenced by the IR laser heating, most likely PAH molecules, thereby reducing the amount variations in $\overline{K_{\text {ext, } \lambda}}$ by soot sublimation relative to total attenuation.

A substantial amount of secondary light absorbing species form in the diffusion flame at high fluences, causing a secondary enhancement of extinction after $\mathrm{t} \approx 50 \mathrm{~ns}$ at 405 and $488 \mathrm{~nm}$ (Fig. 6). However, secondary species apparently form in very small amounts in the premixed flame, only causing a sharper leveling out of the curves after the decline of extinction by material loss has ended. This can be explained by the considerably smaller quantities of soot sublimation in the premixed flame and a possibly higher contribution from nonsoot species to attenuation. 


\subsection{Comparing the Behaviors of In-Flame and Cold Soot}

Thomson et al. [6] carried out a similar time-resolved attenuation study for soot particles at ambient temperature, emitted from a quenched diffusion flame, with $\lambda_{c w}=830 \mathrm{~nm}$ and $405 \mathrm{~nm}$. For lower laser fluences at $830 \mathrm{~nm}$, an initial rise of the extinction coefficient was observed followed by a gradual decrease towards the pre-laser pulse extinction coefficient. At the highest laser fluences, the initial

increase of $\overline{K_{\text {ext }, \lambda}}$ was suppressed as it was overtaken by a rapid decrease of light absorption related to material loss from soot by sublimation. These trends are exactly similar to those shown in Figs. 3 and 5 in the present work for soot particles in the diffusion flame, measured with $\lambda_{C W}=808 \mathrm{~nm}$, demonstrating identical behavior of (mature) soot particles during rapid heating and cooling, regardless of their initial temperature.

The extinction coefficients measured in [6] with the 405-nm light were dramatically different from those measured at $830 \mathrm{~nm}$. For all fluence levels, an initial decline of the extinction coefficient was observed during the laser heating period, which was completely opposite to the enhancement of extinction coefficient at $830 \mathrm{~nm}$, followed by a substantial increase in extinction coefficient. Thomson et al. [6] explained the fall and then rise in the extinction coefficient by the evaporation of a coating of adsorbed volatile species, with strong absorption at shorter wavelengths, upon laser heating at low laser fluences. These species leaving the soot surface are less effective absorbers in the gas phase, thus the initial drop of the extinction coefficient. However, these released species interact or relax chemically to form others with a higher propensity to absorb radiation at $405 \mathrm{~nm}$ causing an increase of $\overline{K_{\text {ext }, \lambda}}$ to values higher than the pre-laser pulse value of one. The strong effect of the evaporation of desorbed volatiles outweighed the initial enhancement of soot extinction coefficient, attributable to thermal annealing and/or a temperature dependent $E\left(m_{\lambda}\right)$. This type of behavior, i.e., the initial drop of $\overline{K_{\text {ext }, \lambda}}$ by the evaporation of volatile material followed by a substantial secondary rise at fluences as low as 0.28 $\mathrm{mJ} / \mathrm{mm}^{2}$, is not seen for the in-flame soot particles, neither in the diffusion flame nor in the premixed flame. The reason for this dissimilarity at $405 \mathrm{~nm}$ could be the large differences between the initial temperatures of soot particles. For example, high-temperature soot particles within the flame require less energy to exhibit strong variations in optical properties, such as enhanced light absorption. In other words, in-flame soot particles are already closer to the temperatures required for enhancement before the laser pulse. Moreover, the absorption lines of the secondary and other gaseous species broaden at high flame temperatures, an effect that possibly changes light absorption by these species compared to the measurements for cold soot. 


\section{Conclusions}

To investigate the influence of variations in the optical properties of in-flame soot by rapid laser heating on the LII signals and to determine if these changes follow the same trends as identified for cold soot [6], the present study measured the time-resolved extinction coefficient of soot in laminar diffusion and premixed flames during a rapid laser heating event using four different wavelengths. The significant results of these measurements along with the important lessons learned from this study are summarized here:

1. A rapid enhancement of $\overline{K_{\text {ext }, \lambda}}$ occurs at the time of laser heating, suggesting an increase in soot emission propensity. The spectral dependence of the enhancement indicates that the main reason for the enhancement is an increase in $E\left(m_{\lambda}\right)$, most likely by laser induced thermal annealing and the restructuring of soot's crystalline material, rather than particle size variations. The amount of prompt enhancement is higher for the premixed flame at all wavelengths and for the whole range of laser fluences because of the different ages and temperature/gas composition histories of soot in the two flames. The reversible variations of $\overline{K_{\text {ext }, \lambda}}$ in the diffusion flame, attributed in the literature to a temperature dependent $E\left(m_{\lambda}\right)$, is shown to be most likely caused by a reduction in the volume fraction of soot by the expansion of the gas surrounding heated soot particles. For the premixed flame, gas expansion is only partly responsible for the reversible variations in $\overline{K_{\text {ext }, \lambda}}$.

2. The experimentally observed enhancement of $\overline{K_{\text {ext }, \lambda}}$ shows that the widely used assumption of a temperature invariant $E\left(m_{\lambda}\right)$ could lead to errors in LII analysis. The cooling rate of soot particles and therefore the calculated particle sizes will be affected by the permanent enhancement of the soot absorption coefficient. The strong spectral dependence of enhancement will influence the accuracy of temperature measurement by two-color pyrometry and in turn the soot volume fraction evaluations, and should be correctly accounted for in LII calculations.

3. A rapid decay of $\overline{K_{\text {ext }, \lambda}}$ is observed after the initial enhancement at high fluences, caused most likely by the loss of light absorbing material and shrinking size of particles through sublimation. Evidence for significant loss of soot mass was seen at fluences as low as $1.03 \mathrm{~mJ} / \mathrm{mm}^{2}$ and 2.06 $\mathrm{mJ} / \mathrm{mm}^{2}$ for the diffusion and premixed flames, respectively, consistent with the predictions of LII models. The decline of soot absorption by mass loss starts at lower fluences and is more substantial for the diffusion flame as a result of a stronger permanent enhancement of $E\left(m_{\lambda}\right)$ in the premixed flame, a stronger IR light absorption by the more graphitized soot in the diffusion flame, and a more substantial contribution from gaseous species to attenuation in the premixed flame.

4. Heating and expansion of gases, observed over a $\sim 2-\mu$ s time window for both flames, results in a gradual decline in soot volume fraction and thereby further reduction of $\overline{K_{\text {ext }, \lambda}}$ after the rapid decay by mass loss. This effect might impact the interpretation of LII signal decay for particle sizing, depending on the timescale of the measurement and the volume fraction of soot, and should be incorporated into the models that use intensity decay.

5. A secondary rise in $\overline{K_{\text {ext }, \lambda}}$ was observed after the start of mass loss by sublimation in the diffusion flame for $\lambda_{c w}=405 \mathrm{~nm}, \lambda_{c w}=488 \mathrm{~nm}$, and slightly for $\lambda_{c w}=633 \mathrm{~nm}$, possibly related to 
the formation of secondary gaseous species that absorb light strongly at these wavelengths from the sublimated soot material, such as carbon molecules $\left(C_{n}\right)$ and PAH species. The secondary enhancement of extinction occurs only for fluences higher than $\sim 2 \mathrm{~mJ} / \mathrm{mm}^{2}$. The secondary enhancement of $\overline{K_{\text {ext }, \lambda}}$ is largely inhibited in the premixed flame by the lower quantities of sublimated soot species and the strong contribution of nonsoot compounds to light extinction.

6. The secondary species are forming in about 50 to $800 \mathrm{~ns}$ after the laser pulse which is the period relevant to LII emission analysis. These species may cause measurement interferences, in particular for emission measurements near the UV, either by attenuating LII emission or possibly by contributing a nonsoot emission. Therefore, it is necessary to avoid interference signals, at wavelengths such as $405 \mathrm{~nm}$, for LII emission measurements and to use low laser fluences to minimize the formation of these species.

7. The fundamental processes that occur during heating and cooling of soot particles, such as the initial enhancement of extinction, the decline of attenuation by gas expansion and sublimation, and the formation of secondary light-absorbing species, are the same for the diffusion and premixed flames. However, there are minor differences due to stronger graphitization of soot by the laser pulse in the premixed flame, higher contribution of gas phase species capable of attenuating visible light in the premixed flame, and a more graphitic soot in the diffusion flame

which results in higher levels of infrared light absorption and higher temperature rise compared to soot particles in the premised flame.

8. A comparison between the results of the present work for in-flame soot and our previous study for cold soot [6] shows differences in the variations of soot optical properties detected at shorter wavelengths. The dissimilarities can be explained by the stronger contribution of the gas phase species present in the flame to light attenuation and by the significant differences between the initial temperatures of particles and the temperatures of the surrounding gases.

\section{Acknowledgements}

The authors acknowledge the support of a Helmholtz/NRC collaborative partnership which made this research possible.

\section{Bibliography}

[1] R. L. Vander Wal and M. Y. Choi, Carbon, vol. 37, p. 231, 1999.

[2] H. A. Michelsen, et al., Appl. Optics, vol. 46, p. 959, 2007.

[3] D. R. Snelling, G. J. Smallwood, F. Liu, O. L. Gülder, and W. D. Bachalo, Appl. Optics, vol. 44, p. 6773, 2005. 
[4] R. L. Vander Wal, T. M. Ticich, and A. B. Stephens, Appl. Phys. B, vol. 67, p. 115, 1998.

[5] R. L. Vander Wal and K. A. Jensen, Appl. Optics, vol. 37, p. 1607, 1998.

[6] K. A. Thomson, K. P. Geigle, M. Köhler, G. J. Smallwood, and D. R. Snelling, Appl. Phys. B, vol. 104, p. 307, 2011.

[7] G. D. Yoder, P. K. Diwakar, and D. W. Hahn, Appl. Optics, vol. 44, p. 4211, 2005.

[8] T. L. Farias, Ü. Ö. Köylü, and M. G. Carvalho, Appl. Optics, vol. 35, p. 6560, 1996.

[9] F. Liu, in Proceedings of the 40th Thermophysics Conference, American Institute for Aeronautics and Astronautics, p.1160, Seattle, Washington, 2008.

[10] H. A. Michelsen, P. E. Schrader, and F. Goulay, Carbon, vol. 48, p. 2175, 2010.

[11] J. C. Maxwell Garnett, Philos. T. R. Soc. Lond., vol. 203, p. 385, 1904.

[12] C. F. Bohren and D. R. Huffman, Absorption and Scattering of Light by Small Particles. New York: John Wiley \& Sons Inc., 1983.

[13] C. M. Sorensen, Aerosol Sci. Tech., vol. 35, p. 648, 2001.

[14] P. O. Witze, S. Hochgreb, D. Kayes, H. A. Michelsen, and C. R. Shaddix, Appl. Optics, vol. 40, p. 2443, 2001.

[15] D. R. Snelling, O. Link, K. A. Thomson, and G. J. Smallwood, Appl. Phys. B, vol. 104, p. 385, 2011.

[16] N. .-E. Olofsson, J. Johnsson, H. Bladh, and P. .-E. Bengtsson, Appl. Phys. B, vol. 112, p. 333, 2013.

[17] C. J. Dasch, Appl. Optics, vol. 23, p. 2209, 1984.

[18] H. A. Michelsen, P. O. Witze, D. Kayes, and S. Hochgreb, Appl. Optics, vol. 42, p. 5577, 2003.

[19] T. Ni, J. A. Pinson, S. Gupta, and R. J. Santoro, Appl. Optics, vol. 34, p. 7083, 1995.

[20] X. López-Yglesias, P. E. Schrader, and H. A. Michelsen, J. Aerosol Sci., vol. 75, p. 43, 2014.

[21] J. Zerbs, et al., Appl. Phys. B, vol. 96, p. 683, 2009.

[22] Ü. Ö. Köylü, Combust. Flame, vol. 109, p. 488, 1997.

[23] S. S. Krishnan, K. Lin, and G. M. Faeth, J. Heat Transf., vol. 123, p. 331, 2001. 
[24] S. S. Krishnan, K. .-C. Lin, and G. M. Faeth, J. Heat Transf., vol. 122, p. 517, 2000.

[25] A. R. Coderre, K. A. Thomson, D. R. Snelling, and M. R. Johnson, Appl. Phys. B, vol. 104, p. 175, 2011.

[26] F. Migliorini, K. A. Thomson, and G. J. Smallwood, Appl. Phys. B, vol. 104, p. 273, 2011.

[27] O. L. Gülder, D. R. Snelling, and R. A. Sawchuk, Symp. (Int.) Combust., vol. 26 , p. 2351, 1996.

[28] T. T. Charalampopoulos, H. Chang, and B. Stagg, Fuel, vol. 68, p. 1173, 1989.

[29] D. R. Snelling, K. A. Thomson, F. Liu, and G. J. Smallwood, Appl. Phys. B, vol. 96, p. 657, 2009.

[30] P. Minutolo, G. Gambi, and A. D’Alessio, Symp. (Int.) Combust., vol. 26, p. 951, 1996.

[31] Z. G. Habib and P. Vervisch, Combust. Sci. Tech., vol. 59, p. 261, 1988.

[32] B. M. Crosland, M. R. Johnson, and K. A. Thomson, Appl. Phys. B, vol. 102, p. 173, 2011.

[33] H. .-H. Grotheer, K. Wolf, and K. Hoffmann, Appl. Phys. B, vol. 104, p. 367, 2011.

[34] R. T. Meyer, A. W. Lynch, and J. M. Freese, J. Phys. Chem., vol. 77, p. 1083, 1973.

[35] H. R. Leider, O. H. Krikorian, and D. A. Young, Carbon, vol. 11, p. 555, 1973.

[36] K. Sasaki, T. Wakasaki, S. Matsui, and K. Kadota, J. Appl. Phys., vol. 91, p. 4033, 2002.

[37] F. Goulay, L. Nemes, P. E. Schrader, and H. A. Michelsen, Mol. Phys., vol. 108, p. 1013, 2010.

[38] L. Gausset, G. Herzberg, A. Lagerqvist, and B. Rosen, Astrophys. J., vol. 142, p. 45, 1965.

[39] A. E. Douglas, Astrophys. J., vol. 114, p. 467, 1951.

[40] A. J. Merer, Can. J. Phys., vol. 45, p. 4103, 1967.

[41] E. A. Rohlfing, J. Chem. Phys., vol. 89, p. 6103, 1988.

[42] F. Beretta, A. D'Alessio, A. D'Orsi, and P. Minutolo, Combust. Sci. Technol., vol. 85, p. 455, 1992.

[43] F. Goulay, P. E. Schrader, L. Nemes, M. A. Dansson, and H. A. Michelsen, P. Combust. Inst., vol. 32, p. 963, 2009.

[44] P. .-E. Bengtsson and M. Aldén, Combust. Sci. Technol., vol. 77, p. 307, 1991.

[45] L. Nemes, A. M. Keszler, J. O. Hornkohl, and C. G. Parigger, Appl. Optics, vol. 44, p. 4032, 2007. 
[46] L. Nemes, et al., Appl. Optics, vol. 46, p. 4032, 2007.

[47] D. R. Snelling, F. Liu, G. J. Smallwood, and O. L. Gülder, Combust. Flame, vol. 136, p. 180, 2004.

[48] Ü. Ö. Köylü and G. M. Faeth, J. Heat Transf., vol. 118, p. 415, 1996.

[49] H. Chang and T. T. Charalampopoulos, Proc. R. Soc. London, A, vol. 430, p. 577, 1990.

[50] H. A. Michelsen, J. Chem. Phys., vol. 118, p. 7012, 2003.

[51] C. M. Sorensen, Aerosol Sci. Tech., vol. 35, p. 648, 2001.

[52] M. Kholghy, M. Saffaripour, C. Yip, and M. J. Thomson, Combust. Flame, vol. 160, p. 2119, 2013.

[53] M. Alfé, et al., Proc. Combust. Inst., vol. 32, p. 697, 2009.

[54] T. C. Williams, C. R. Shaddix, K. A. Jensen, and J. M. Suo-Anttila, J. Heat Mass Transf., vol. 50, p. 1616, 2007.

[55] A. D'Alessio, et al., Symp. (Int.) Combust., vol. 24, p. 973, 1992.

[56] R. A. Dobbins, R. A. Fletcher, and W. Lu, Combust. Flame, vol. 1995, p. 301, 100.

[57] R. L. Vander Wal, Appl. Optics, vol. 35, p. 6548, 1996.

[58] Ü. Ö. Köylü, Combust. Flame, vol. 109, p. 488, 1996.

[59] B. McCall, R. N. Casaes, M. Ádámkovics, and R. J. Saykally, Chem. Phys. Lett., vol. 374, p. 583, 2003.

[60] S. C. Lee and C. L. Tien, Symposium (Int.) on Combustion, vol. 18, p. 1159, 1981.

[61] X. López-Yglesias, P. E. Schrader, and H. A. Michelsen, J. Aerosol Sci., vol. 75, pp. 43-64, 2014. 


\section{Supplementary Material}

Fig. S1 Comparing the normalized extinction coefficient profiles in the diffusion flame for five IR laser fluences, from 0.21 to $1.03 \mathrm{~mJ} / \mathrm{mm}^{2}$, presented in four time windows and measured with four CW laser wavelengths.

Fig. S2 Comparing the normalized extinction coefficient profiles in the diffusion flame for five IR laser fluences, from 1.24 to $2.06 \mathrm{~mJ} / \mathrm{mm}^{2}$, presented in four time windows and measured with four CW laser wavelengths.

Fig. S3 Comparing the normalized extinction coefficient profiles in the diffusion flame for five IR laser fluences, from 2.27 to $3.09 \mathrm{~mJ} / \mathrm{mm}^{2}$, presented in four time windows and measured with four CW laser wavelengths.

Fig. S4 Comparing the normalized extinction coefficient profiles in the diffusion flame for five IR laser fluences, from 3.30 to $6.19 \mathrm{~mJ} / \mathrm{mm}^{2}$, presented in four time windows and measured with four CW laser wavelengths.

Fig. S5 Comparing the extinction profiles measured for the diffusion flame with four different wavelengths, $\lambda_{C W}=808 \mathrm{~nm}, \lambda_{C W}=633 \mathrm{~nm}, \lambda_{C W}=488 \mathrm{~nm}$, and $\lambda_{C W}=405 \mathrm{~nm}$, from $1 \mu \mathrm{s}$ before to $9 \mu \mathrm{s}$ after the laser pulse.

Fig. S6 Comparing the extinction profiles measured for the diffusion flame with four different wavelengths, $\lambda_{C W}=808 \mathrm{~nm}, \lambda_{C W}=633 \mathrm{~nm}, \lambda_{c W}=488 \mathrm{~nm}$, and $\lambda_{C W}=405 \mathrm{~nm}$, from $0.1 \mathrm{~ms}$ before to $0.9 \mathrm{~ms}$ after the laser pulse.

Fig. S7 Comparing the normalaized extinction coefficient profiles in the premixed flame for five different fluence leveles ranging from, $0.21 \mathrm{~mJ} / \mathrm{mm}^{2}$ to $1.03 \mathrm{~mJ} / \mathrm{mm}^{2}$, at four wavelengths and in four time windows.

Fig. $\mathbf{8 8}$ Comparing the normalaized extinction coefficient profiles in the premixed flame for five different fluence leveles ranging from, $1.24 \mathrm{~mJ} / \mathrm{mm}^{2}$ to $2.06 \mathrm{~mJ} / \mathrm{mm}^{2}$, at four wavelengths and in four time windows.

Fig. S9 Comparing the normalaized extinction coefficient profiles in the premixed flame for five different fluence leveles ranging from, $2.27 \mathrm{~mJ} / \mathrm{mm}^{2}$ to $3.09 \mathrm{~mJ} / \mathrm{mm}^{2}$, at four wavelengths and in four time windows.

Fig. S10 Comparing the normalaized extinction coefficient profiles in the premixed flame for five different fluence leveles ranging from, $3.30 \mathrm{~mJ} / \mathrm{mm}^{2}$ to $6.19 \mathrm{~mJ} / \mathrm{mm}^{2}$, at four wavelengths and in four time windows.

Fig. S11 Comparing extinction profiles for the premixed flame at four different wavelengths from $t=-1$ to $t=9 \mu \mathrm{s}$.

Fig. S12 Comparing extinction profiles for the premixed flame at four different wavelengths from $t=-1$ to $t=9$ ms.

Fig. S13 Comparing extinction profiles in the diffusion and premixed flames, at four wavelengths and for fluence ranging from 0.21 to $1.03 \mathrm{~mJ} / \mathrm{mm}^{2}$, up to $\mathrm{t}=0.9 \mu \mathrm{s}$. The profiles measured in the diffusion flame are shown with darker lines and the results measured in the premixed flame are shown with the brighter lines.

Fig. S14 Comparing extinction profiles in the diffusion and premixed flames, at four wavelengths and for fluence ranging from 1.24 to $2.06 \mathrm{~mJ} / \mathrm{mm}^{2}$, up to $\mathrm{t}=0.9 \mu \mathrm{s}$. The profiles measured in the diffusion flame are shown with darker lines and the results measured in the premixed flame are shown with the brighter lines.

Fig. S15 Comparing extinction profiles in the diffusion and premixed flames, at four wavelengths and for fluence ranging from 2.27 to $3.09 \mathrm{~mJ} / \mathrm{mm}^{2}$, up to $\mathrm{t}=0.9 \mu \mathrm{s}$. The profiles measured in the diffusion flame are shown with darker lines and the results measured in the premixed flame are shown with the brighter lines.

Fig. S16 Comparing extinction profiles in the diffusion and premixed flames, at four wavelengths and for fluence ranging from 3.30 to $6.19 \mathrm{~mJ} / \mathrm{mm}^{2}$, up to $\mathrm{t}=0.9 \mu \mathrm{s}$. The profiles measured in the diffusion flame are shown with darker lines and the results measured in the premixed flame are shown with the brighter lines.

Fig. S17 Comparing extinction profiles in the diffusion and premixed flames, at four wavelengths and for fluence ranging from 0.21 to $1.03 \mathrm{~mJ} / \mathrm{mm}^{2}$, up to $\mathrm{t}=9 \mu \mathrm{s}$. The profiles measured in the diffusion flame are shown with darker lines and the results measured in the premixed flame are shown with the brighter lines.

Fig. S18 Comparing extinction profiles in the diffusion and premixed flames, at four wavelengths and for fluence ranging from 1.24 to $2.06 \mathrm{~mJ} / \mathrm{mm}^{2}$, up to $\mathrm{t}=9 \mu \mathrm{s}$. The profiles measured in the diffusion flame are shown with darker lines and the results measured in the premixed flame are shown with the brighter lines.

Fig. S19 Comparing extinction profiles in the diffusion and premixed flames, at four wavelengths and for fluence ranging from 2.27 to $3.09 \mathrm{~mJ} / \mathrm{mm}^{2}$, up to $\mathrm{t}=9 \mu \mathrm{s}$. The profiles measured in the diffusion flame are shown with darker lines and the results measured in the premixed flame are shown with the brighter lines.

Fig. S20 Comparing extinction profiles in the diffusion and premixed flames, at four wavelengths and for fluence ranging from 3.30 to $6.19 \mathrm{~mJ} / \mathrm{mm}^{2}$, up to $\mathrm{t}=9 \mu \mathrm{s}$. The profiles measured in the diffusion flame are shown with darker lines and the results measured in the premixed flame are shown with the brighter lines.

Fig. S21 Comparing extinction profiles in the diffusion and premixed flames at four wavelengths and five fluence levels, from $1 \mathrm{~ms}$ before to $9 \mathrm{~ms}$ after the laser pulse. The profiles measured in the diffusion flame are shown with darker lines and the results measured in the premixed flame are shown with the brighter lines. 

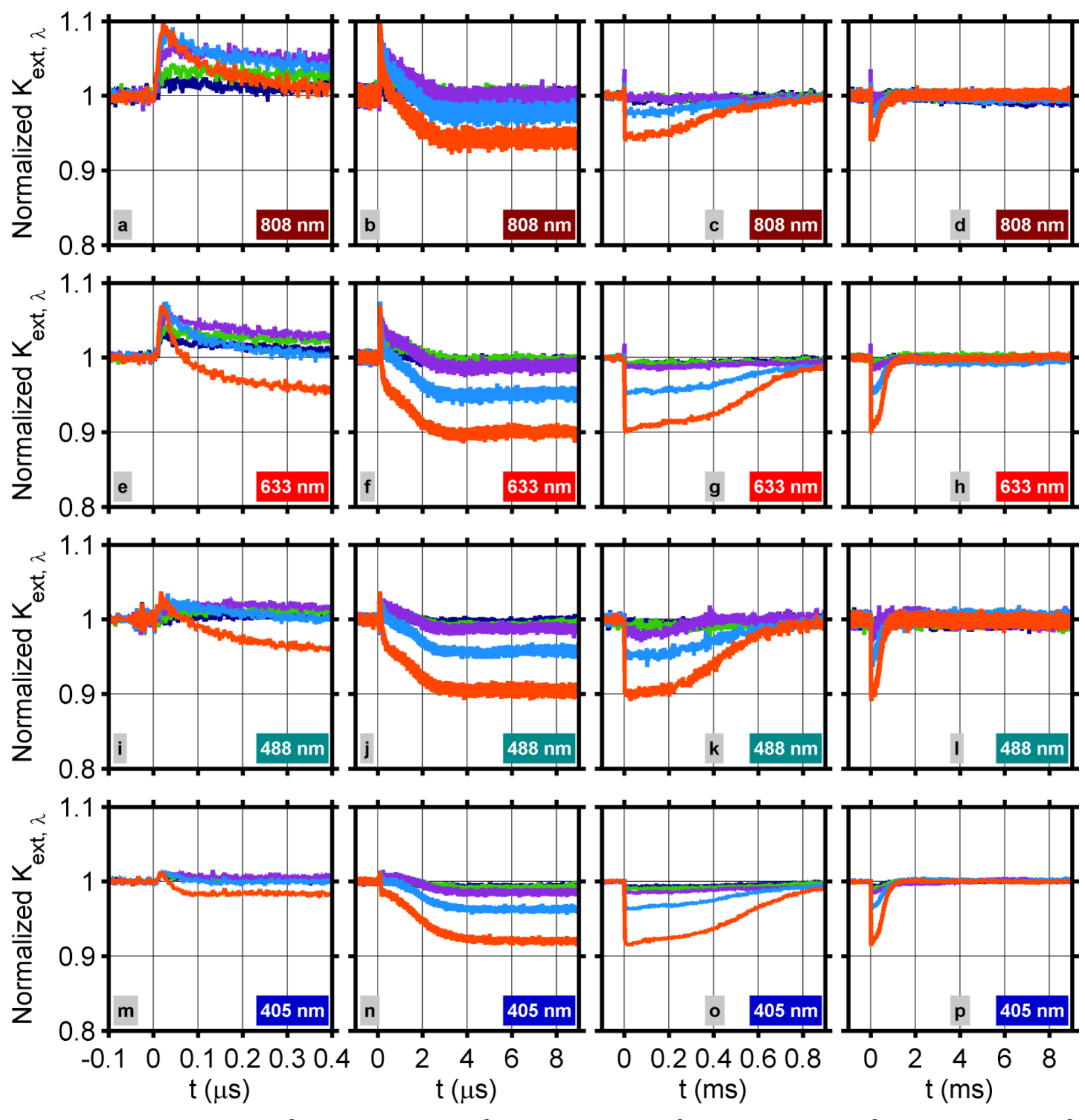

$-0.21 \mathrm{~mJ} / \mathrm{mm}^{2}-0.41 \mathrm{~mJ} / \mathrm{mm}^{2}-0.62 \mathrm{~mJ} / \mathrm{mm}^{2}-0.82 \mathrm{~mJ} / \mathrm{mm}^{2}-1.03 \mathrm{~mJ} / \mathrm{mm}^{2}$

Fig. S1 Comparing the normalized extinction coefficient profiles in the diffusion flame for five IR laser fluences, from 0.21 to $1.03 \mathrm{~mJ} / \mathrm{mm}^{2}$, presented in four time windows and measured with four $\mathrm{CW}$ laser wavelengths. 

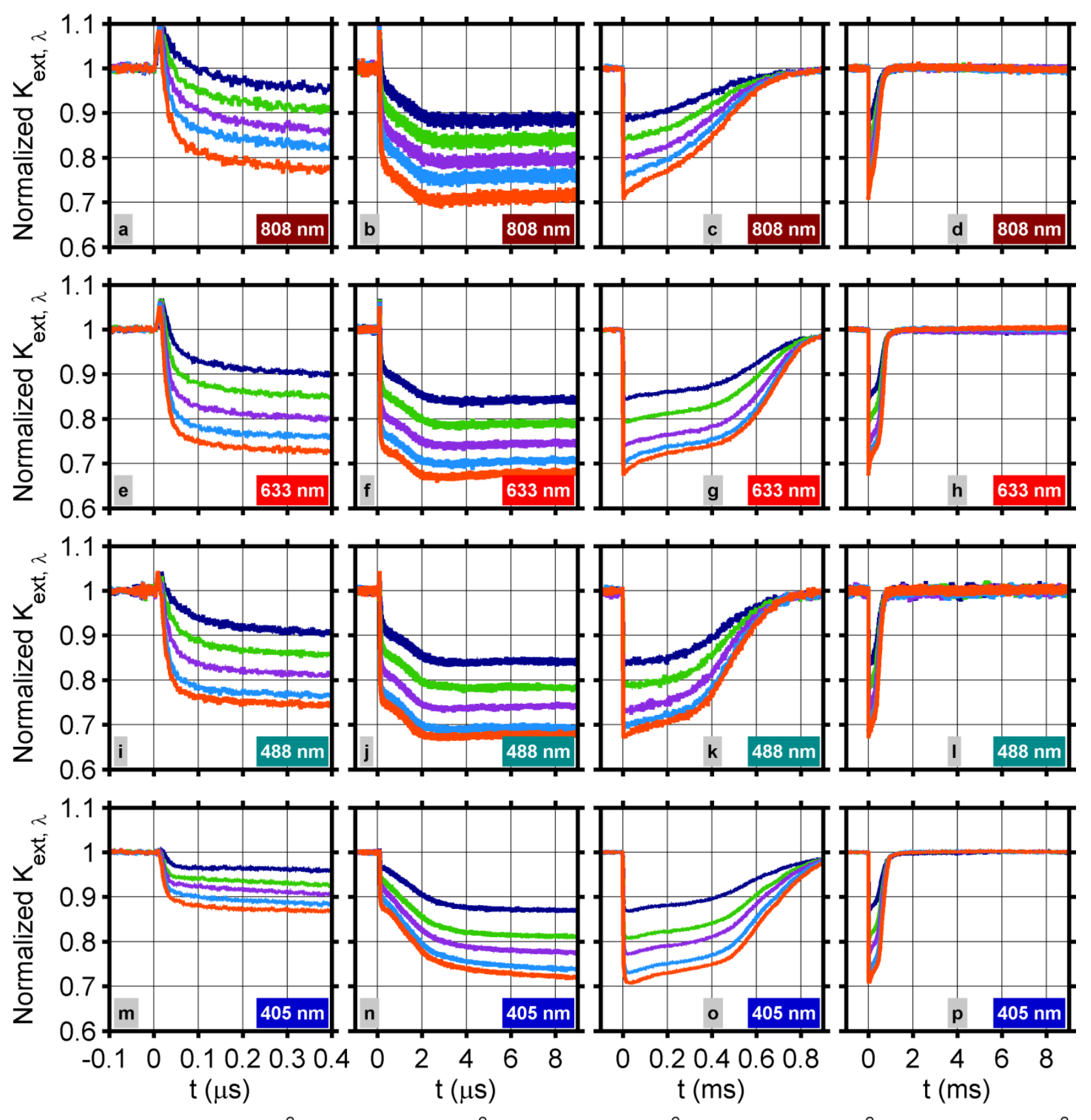

$-1.24 \mathrm{~mJ} / \mathrm{mm}^{2} \longrightarrow 1.44 \mathrm{~mJ} / \mathrm{mm}^{2}-1.65 \mathrm{~mJ} / \mathrm{mm}^{2}-1.86 \mathrm{~mJ} / \mathrm{mm}^{2}-2.06 \mathrm{~mJ} / \mathrm{mm}^{2}$

Fig. S2 Comparing the normalized extinction coefficient profiles in the diffusion flame for five IR laser fluences, from 1.24 to $2.06 \mathrm{~mJ} / \mathrm{mm}^{2}$, presented in four time windows and measured with four CW laser wavelengths. 

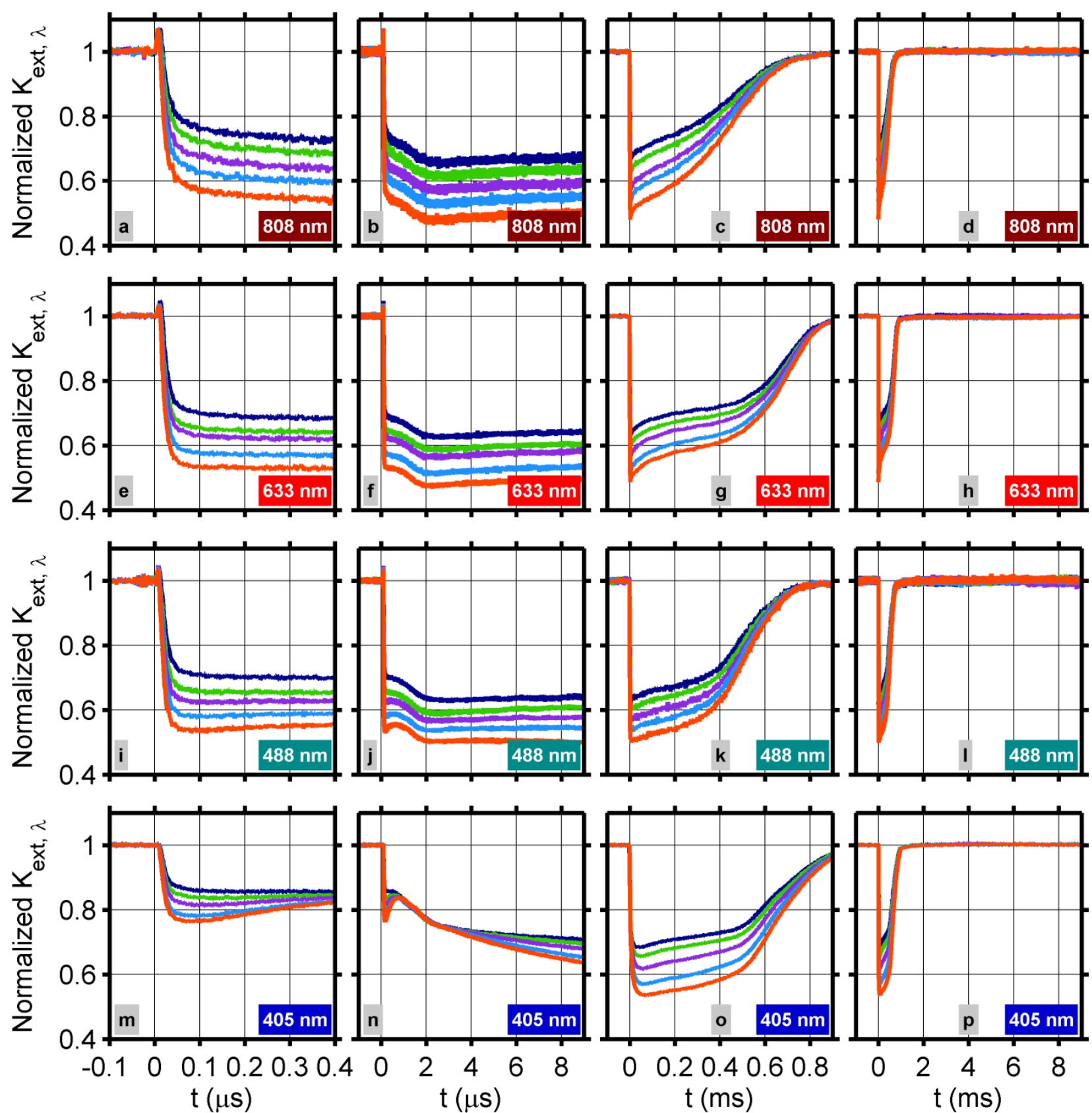

$-2.27 \mathrm{~mJ} / \mathrm{mm}^{2}-2.47 \mathrm{~mJ} / \mathrm{mm}^{2} \longrightarrow 2.68 \mathrm{~mJ} / \mathrm{mm}^{2}-2.89 \mathrm{~mJ} / \mathrm{mm}^{2}-3.09 \mathrm{~mJ} / \mathrm{mm}^{2}$

Fig. S3 Comparing the normalized extinction coefficient profiles in the diffusion flame for five IR laser fluences, from 2.27 to $3.09 \mathrm{~mJ} / \mathrm{mm}^{2}$, presented in four time windows and measured with four CW laser wavelengths. 

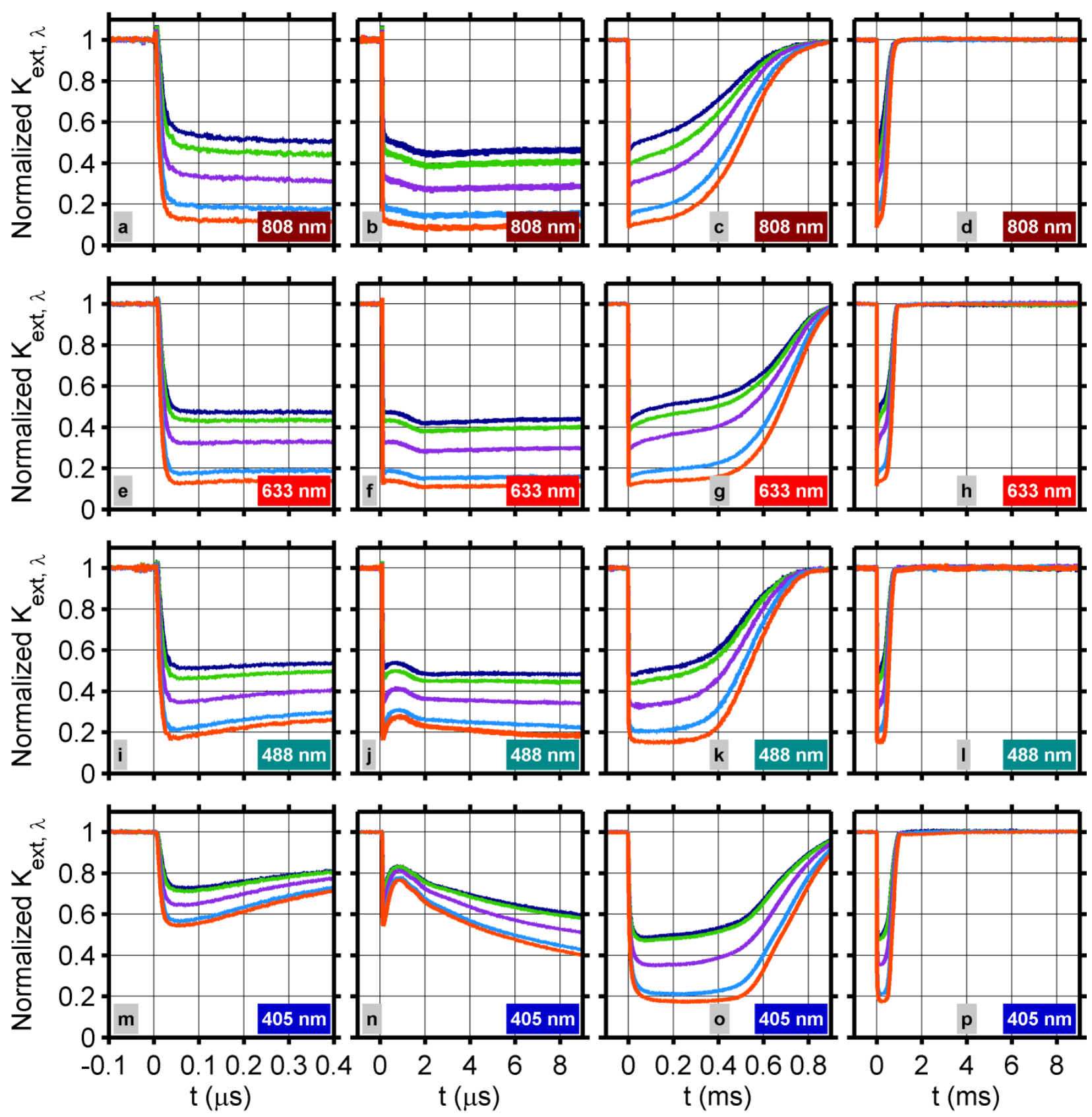

\footnotetext{
$-3.3 \mathrm{~mJ} / \mathrm{mm}^{2}$
}

$3.51 \mathrm{~mJ} / \mathrm{mm}^{2}$

$4.12 \mathrm{~mJ} / \mathrm{mm}^{2}-5.15 \mathrm{~mJ} / \mathrm{mm}^{2}$

$6.19 \mathrm{~mJ} / \mathrm{mm}^{2}$

Fig. S4 Comparing the normalized extinction coefficient profiles in the diffusion flame for five IR laser fluences, from 3.30 to $6.19 \mathrm{~mJ} / \mathrm{mm}^{2}$, presented in four time windows and measured with four CW laser wavelengths. 

(a) $0.21 \mathrm{~mJ} / \mathrm{mm}^{2}$
(b) $0.41 \mathrm{~mJ} / \mathrm{mm}^{2}$
(c) $0.62 \mathrm{~mJ} / \mathrm{mm}^{2}$
(d) $0.82 \mathrm{~mJ} / \mathrm{mm}^{2}$
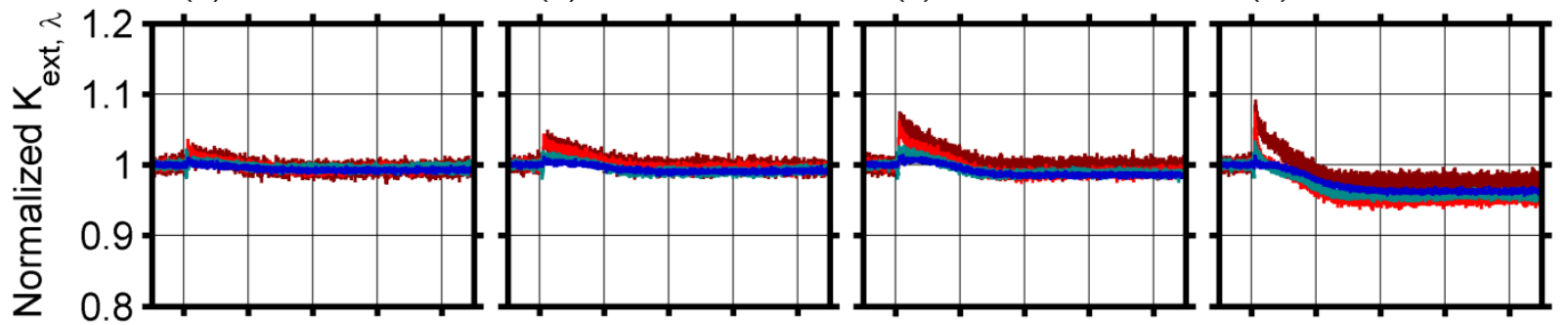

(e) $1.03 \mathrm{~mJ} / \mathrm{mm}^{2}$

(f) $1.24 \mathrm{~mJ} / \mathrm{mm}^{2}$

(g) $1.44 \mathrm{~mJ} / \mathrm{mm}^{2}$

(h) $1.65 \mathrm{~mJ} / \mathrm{mm}^{2}$
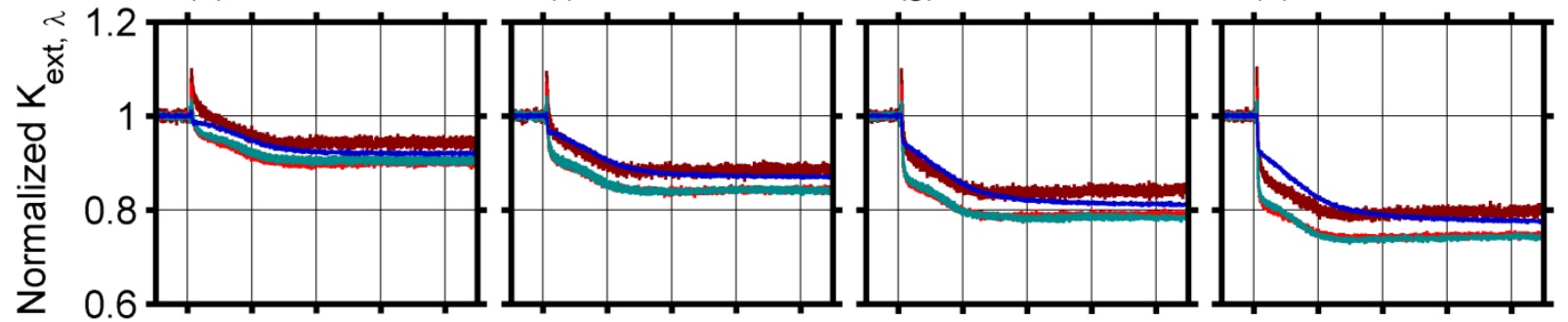

(i) $1.86 \mathrm{~mJ} / \mathrm{mm}^{2}$

(j) $2.06 \mathrm{~mJ} / \mathrm{mm}^{2}$
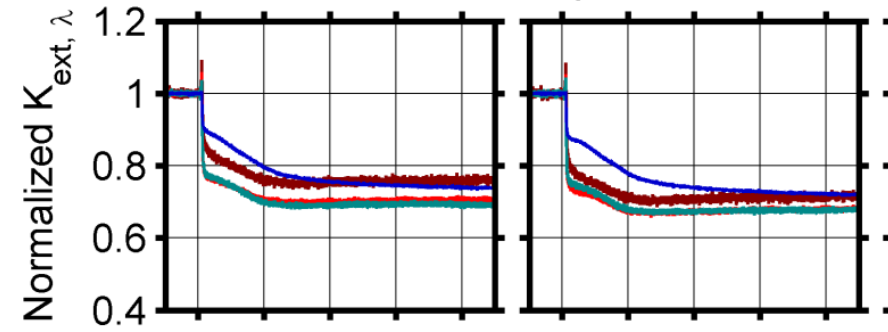

(k) $2.27 \mathrm{~mJ} / \mathrm{mm}^{2}$

(I) $2.47 \mathrm{~mJ} / \mathrm{mm}^{2}$

(m) $2.68 \mathrm{~mJ} / \mathrm{mm}^{2}$

(n) $2.89 \mathrm{~mJ} / \mathrm{mm}^{2}$
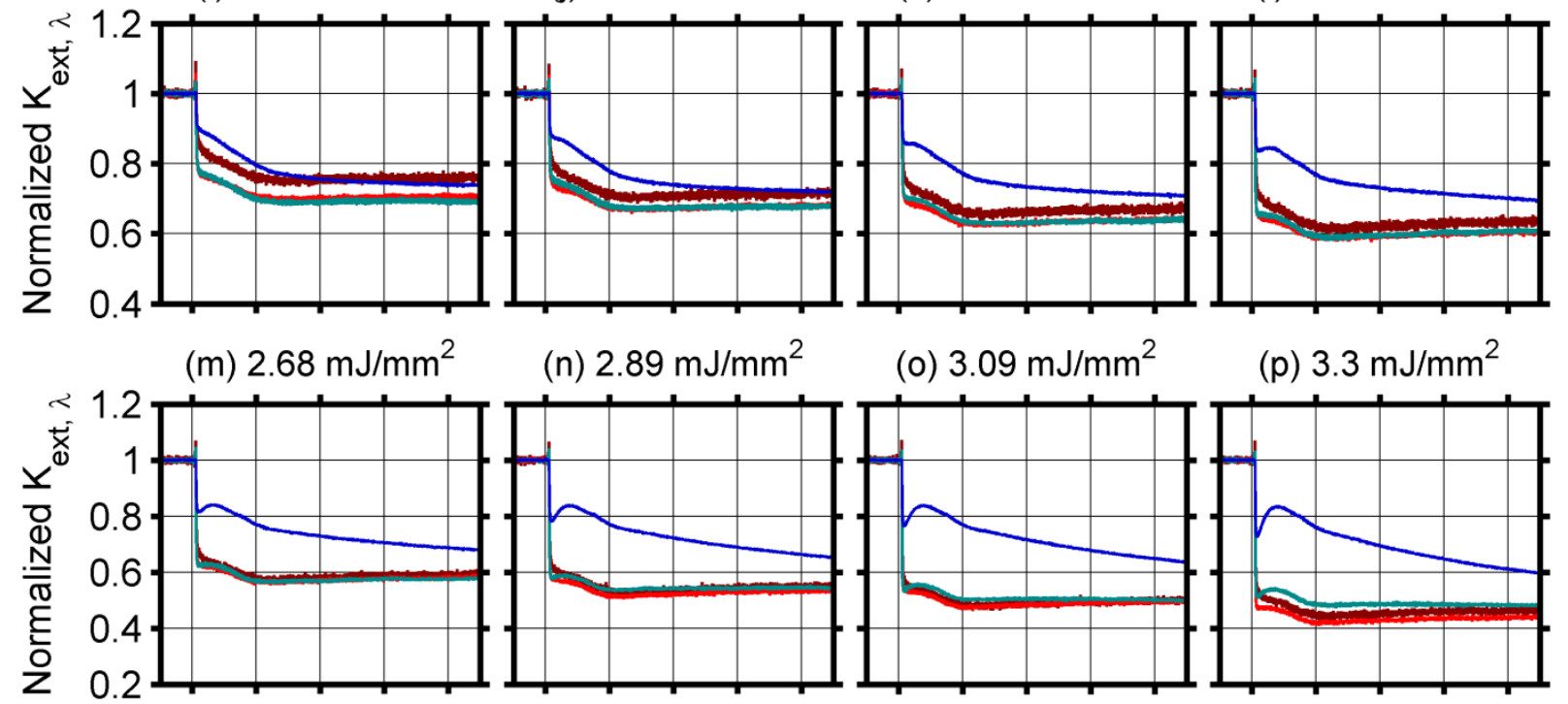

(o) $3.09 \mathrm{~mJ} / \mathrm{mm}^{2}$

(p) $3.3 \mathrm{~mJ} / \mathrm{mm}^{2}$

(q) $3.51 \mathrm{~mJ} / \mathrm{mm}^{2}$

(r) $4.12 \mathrm{~mJ} / \mathrm{mm}^{2}$
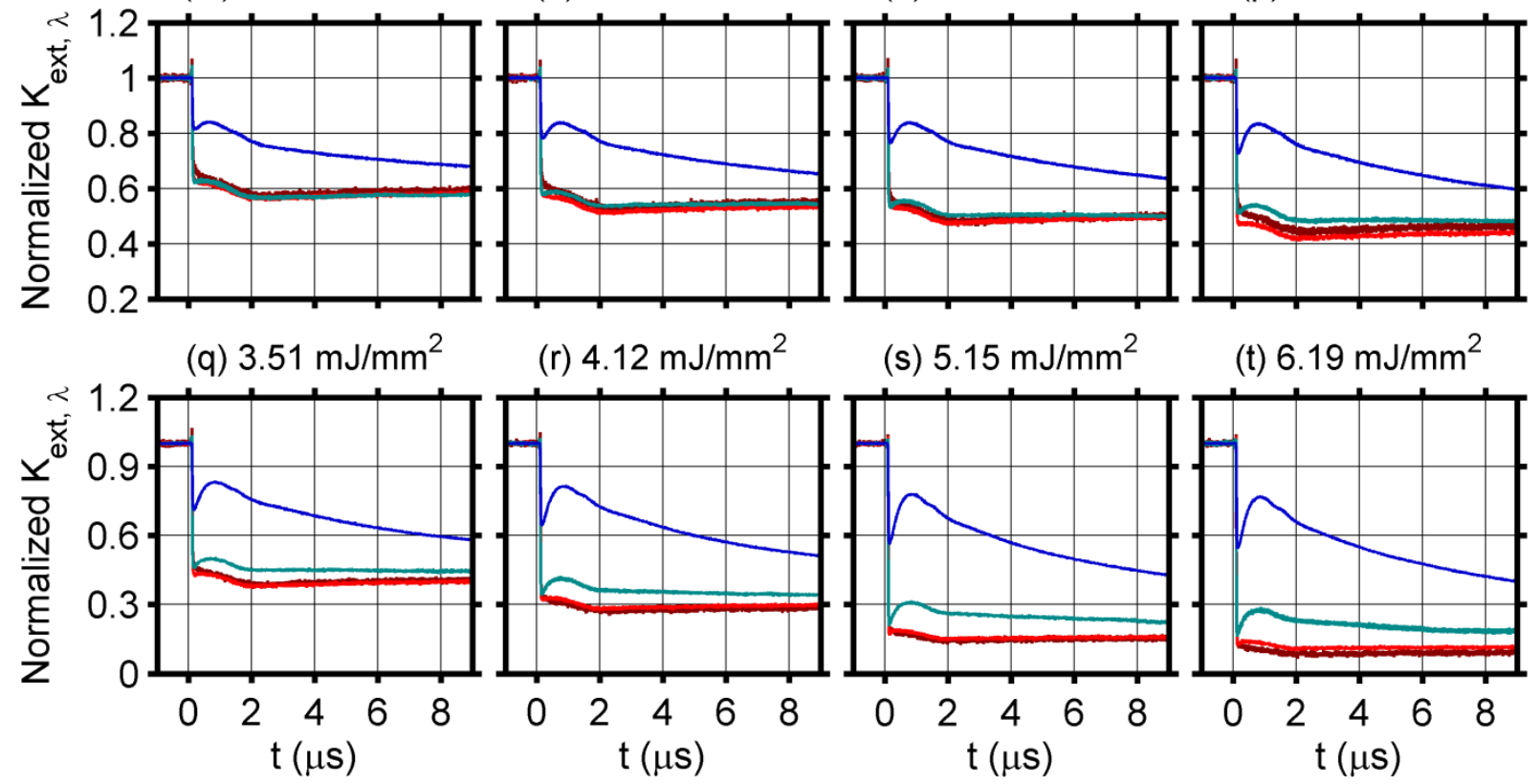

(s) $5.15 \mathrm{~mJ} / \mathrm{mm}^{2}$

(t) $6.19 \mathrm{~mJ} / \mathrm{mm}^{2}$
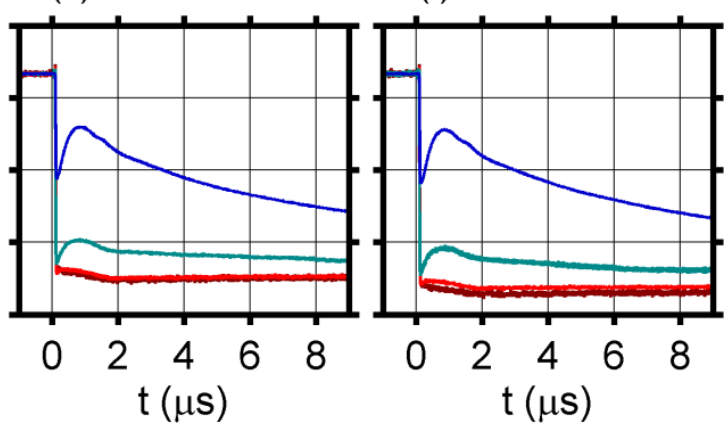

$808 \mathrm{~nm}$

$488 \mathrm{~nm}$ $405 \mathrm{~nm}$

Fig. S5 Comparing the extinction profiles measured for the diffusion flame with four different wavelengths, $\lambda_{\mathrm{cW}}=808 \mathrm{~nm}, \lambda_{\mathrm{CW}}=633 \mathrm{~nm}, \lambda_{\mathrm{CW}}=488 \mathrm{~nm}$, and $\lambda_{\mathrm{CW}}=405 \mathrm{~nm}$, from $1 \mu \mathrm{s}$ before to $9 \mu \mathrm{s}$ after the laser pulse. 
(a) $0.21 \mathrm{~mJ} / \mathrm{mm}^{2}$

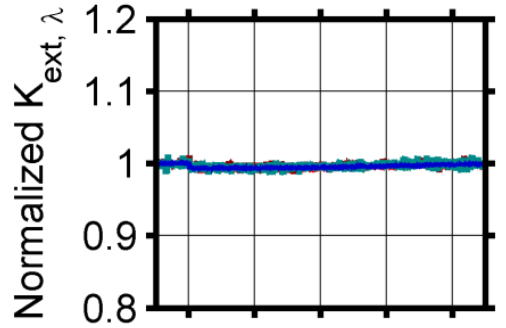

(e) $1.03 \mathrm{~mJ} / \mathrm{mm}^{2}$

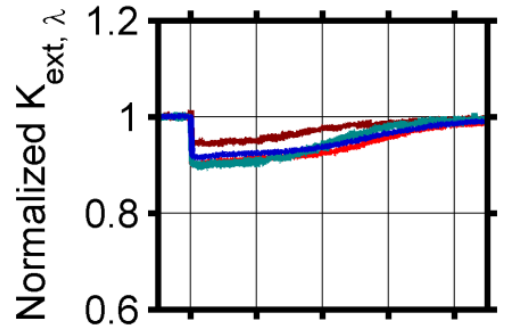

(i) $1.86 \mathrm{~mJ} / \mathrm{mm}^{2}$

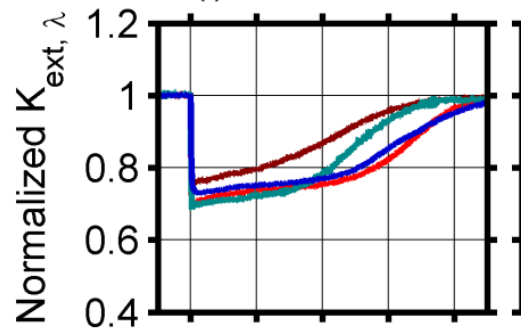

(m) $2.68 \mathrm{~mJ} / \mathrm{mm}^{2}$

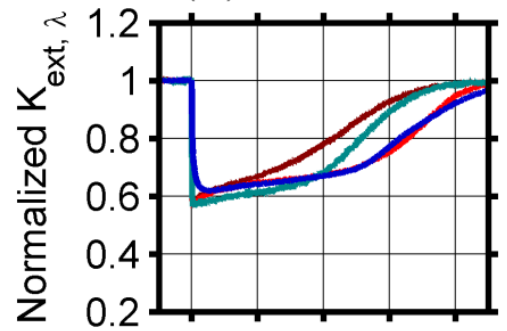

(q) $3.51 \mathrm{~mJ} / \mathrm{mm}^{2}$

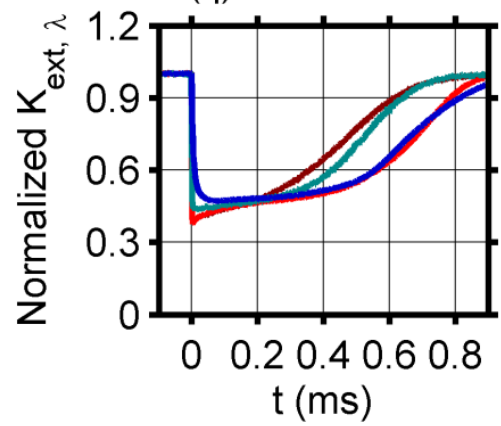

$808 \mathrm{~nm}$ (b) $0.41 \mathrm{~mJ} / \mathrm{mm}^{2}$

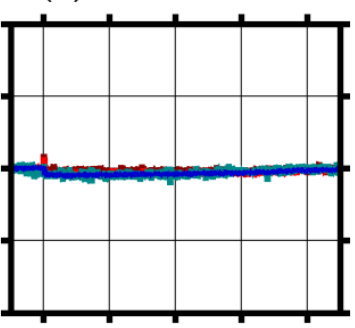

(f) $1.24 \mathrm{~mJ} / \mathrm{mm}^{2}$

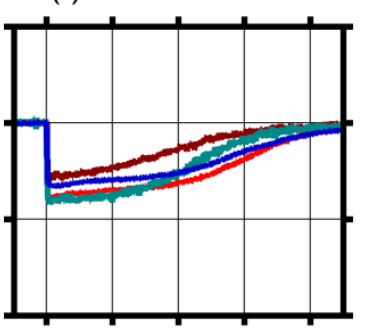

(j) $2.06 \mathrm{~mJ} / \mathrm{mm}^{2}$

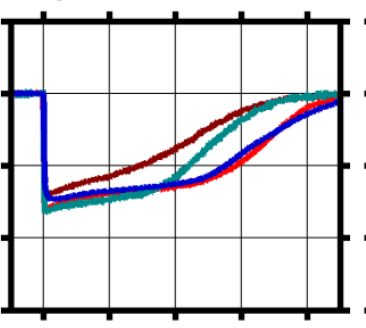

(n) $2.89 \mathrm{~mJ} / \mathrm{mm}^{2}$

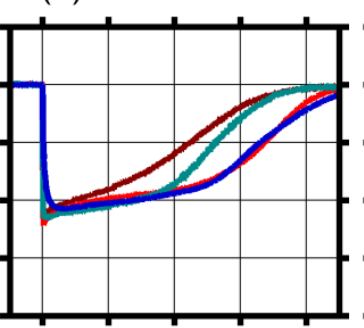

(r) $4.12 \mathrm{~mJ} / \mathrm{mm}^{2}$

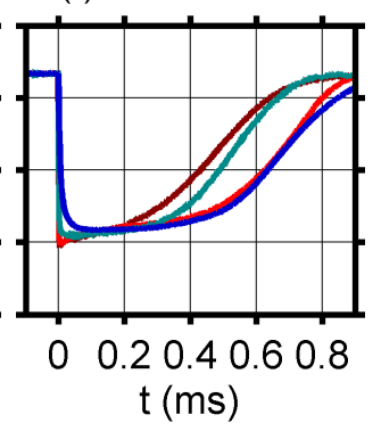

$633 \mathrm{~nm}$

(c) $0.62 \mathrm{~mJ} / \mathrm{mm}^{2}$

(d) $0.82 \mathrm{~mJ} / \mathrm{mm}^{2}$
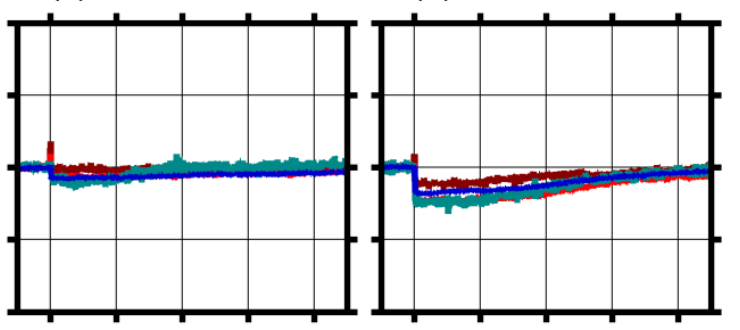

(g) $1.44 \mathrm{~mJ} / \mathrm{mm}^{2}$

(h) $1.65 \mathrm{~mJ} / \mathrm{mm}^{2}$

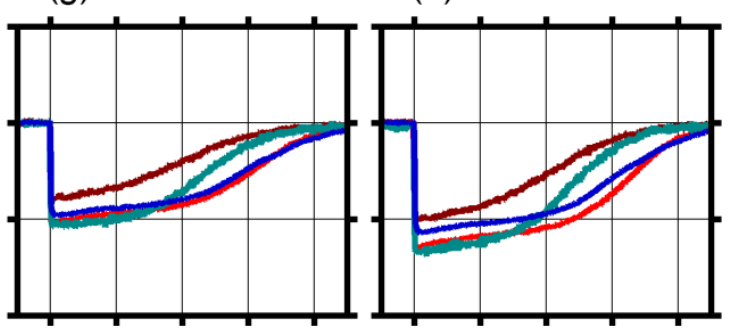

(k) $2.27 \mathrm{~mJ} / \mathrm{mm}^{2}$

(I) $2.47 \mathrm{~mJ} / \mathrm{mm}^{2}$
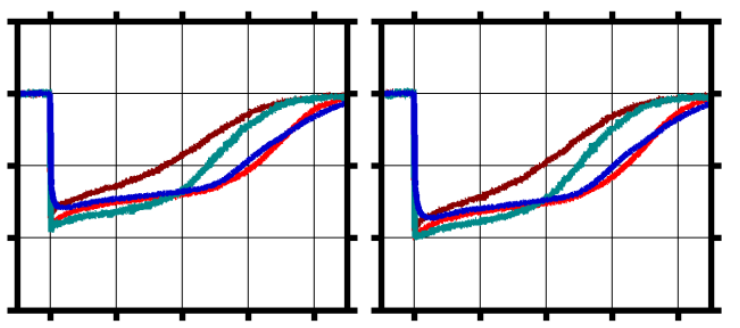

(o) $3.09 \mathrm{~mJ} / \mathrm{mm}^{2}$

(p) $3.3 \mathrm{~mJ} / \mathrm{mm}^{2}$
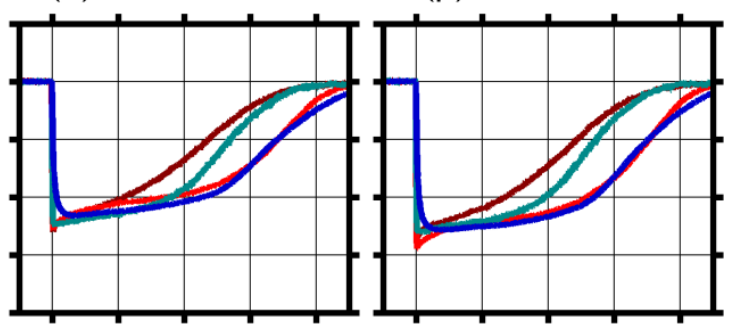

(s) $5.15 \mathrm{~mJ} / \mathrm{mm}^{2}$

(t) $6.19 \mathrm{~mJ} / \mathrm{mm}^{2}$
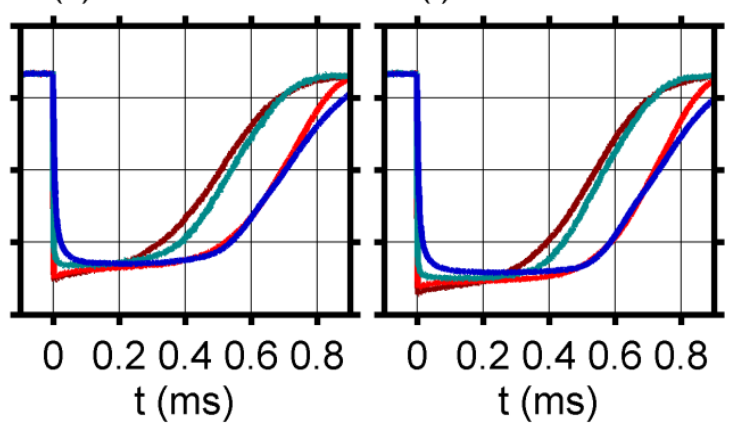

$488 \mathrm{~nm}-405 \mathrm{~nm}$

Fig. S6 Comparing the extinction profiles measured for the diffusion flame with four different wavelengths, $\lambda_{\mathrm{cW}}=808 \mathrm{~nm}, \lambda_{\mathrm{cW}}=633 \mathrm{~nm}, \lambda_{\mathrm{cW}}=488 \mathrm{~nm}$, and $\lambda_{\mathrm{cW}}=405 \mathrm{~nm}$, from $0.1 \mathrm{~ms}$ before to $0.9 \mathrm{~ms}$ after the laser pulse. 

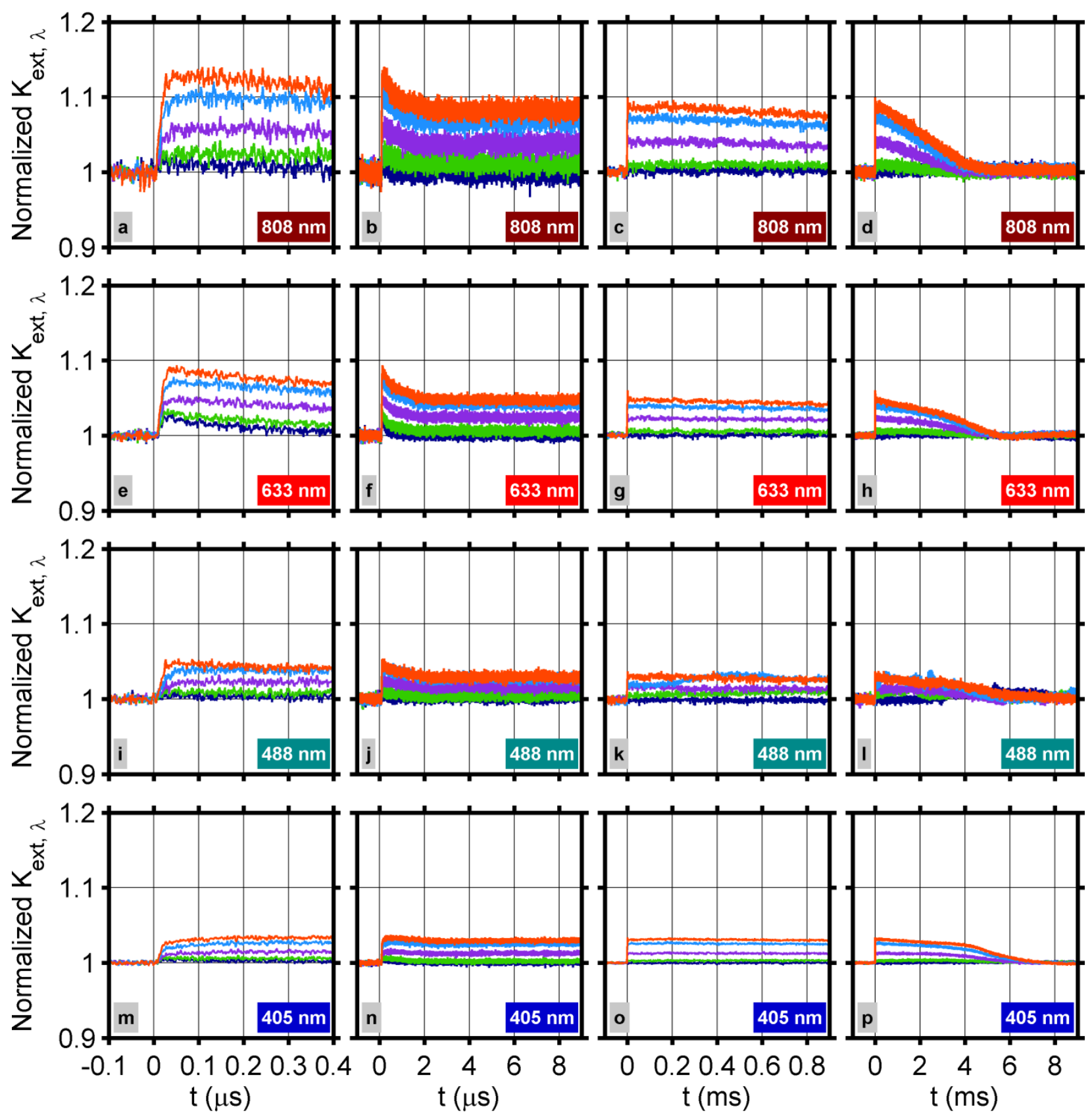

$-0.21 \mathrm{~mJ} / \mathrm{mm}^{2} \longrightarrow 0.41 \mathrm{~mJ} / \mathrm{mm}^{2} \longrightarrow 0.62 \mathrm{~mJ} / \mathrm{mm}^{2}-0.82 \mathrm{~mJ} / \mathrm{mm}^{2}-1.03 \mathrm{~mJ} / \mathrm{mm}^{2}$

Fig. $\mathbf{5 7}$ Comparing the normalized extinction coefficient profiles in the premixed flame for five different fluence leveles ranging from, $0.21 \mathrm{~mJ} / \mathrm{mm}^{2}$ to $1.03 \mathrm{~mJ} / \mathrm{mm}^{2}$, at four wavelengths and in four time windows. 

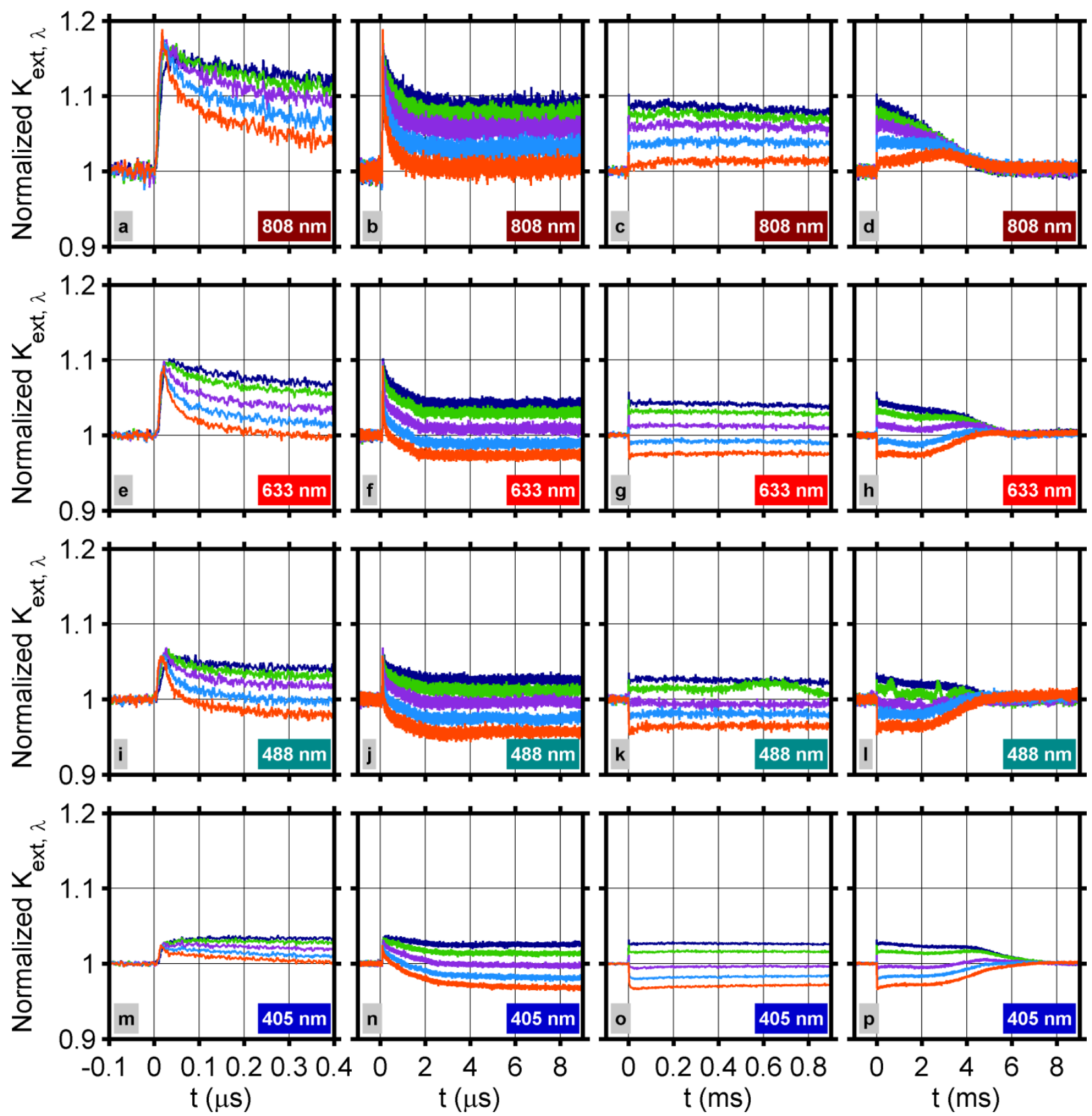

$-1.24 \mathrm{~mJ} / \mathrm{mm}^{2}$

$1.44 \mathrm{~mJ} / \mathrm{mm}^{2}$

$1.65 \mathrm{~mJ} / \mathrm{mm}^{2}-1.86 \mathrm{~mJ} / \mathrm{mm}^{2}$

$2.06 \mathrm{~mJ} / \mathrm{mm}^{2}$

Fig. $\mathbf{8 8}$ Comparing the normalized extinction coefficient profiles in the premixed flame for five different fluence leveles ranging from, $1.24 \mathrm{~mJ} / \mathrm{mm}^{2}$ to $2.06 \mathrm{~mJ} / \mathrm{mm}^{2}$, at four wavelengths and in four time windows. 

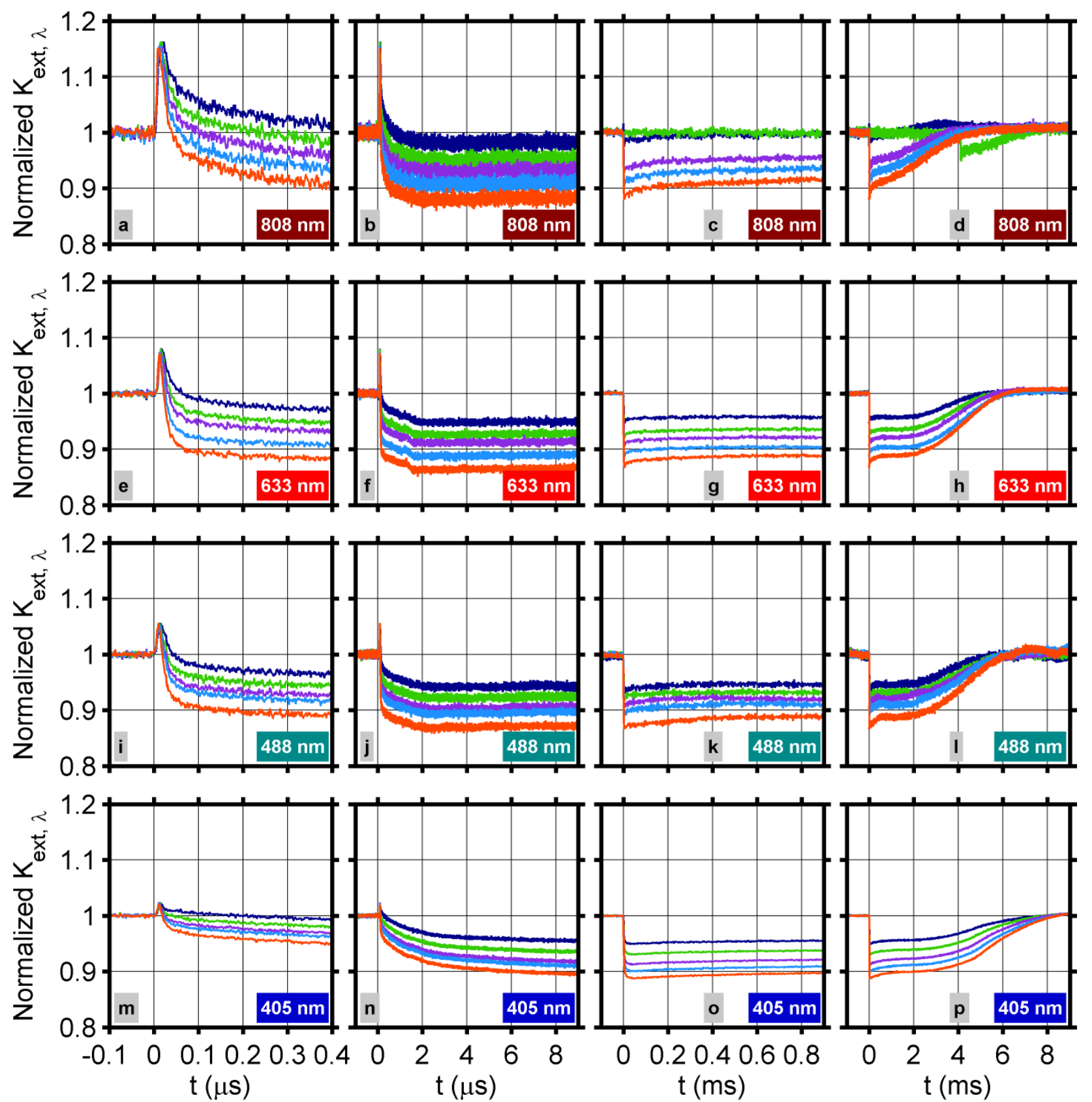

$-2.27 \mathrm{~mJ} / \mathrm{mm}^{2}-2.47 \mathrm{~mJ} / \mathrm{mm}^{2} \longrightarrow 2.68 \mathrm{~mJ} / \mathrm{mm}^{2}-2.89 \mathrm{~mJ} / \mathrm{mm}^{2}-3.09 \mathrm{~mJ} / \mathrm{mm}^{2}$

Fig. S9 Comparing the normalized extinction coefficient profiles in the premixed flame for five different fluence leveles ranging from, $2.27 \mathrm{~mJ} / \mathrm{mm}^{2}$ to $3.09 \mathrm{~mJ} / \mathrm{mm}^{2}$, at four wavelengths and in four time windows. 

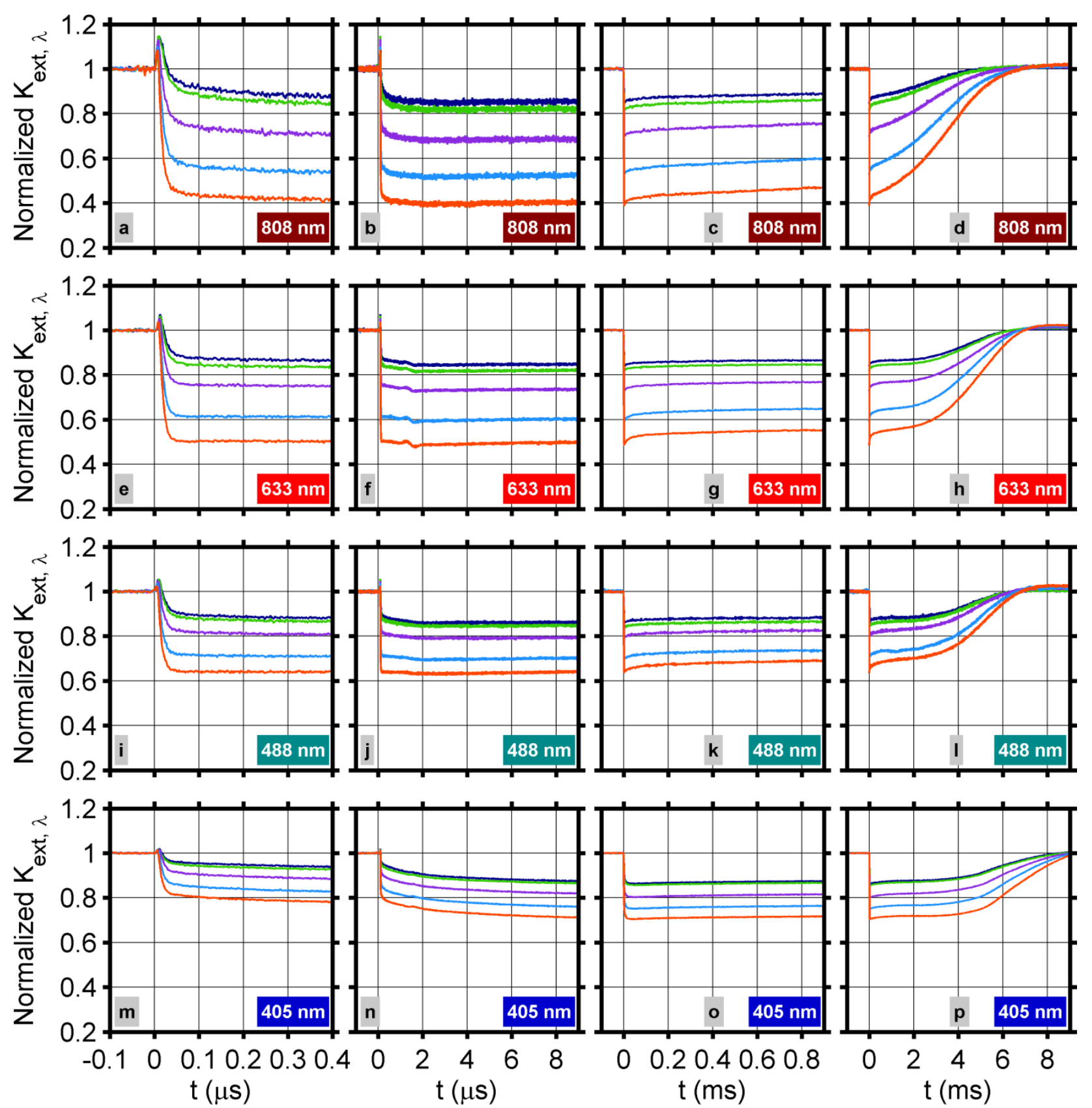

$-3.3 \mathrm{~mJ} / \mathrm{mm}^{2}$

$3.51 \mathrm{~mJ} / \mathrm{mm}^{2}$

$4.12 \mathrm{~mJ} / \mathrm{mm}^{2}-5.15 \mathrm{~mJ} / \mathrm{mm}^{2}$

$6.19 \mathrm{~mJ} / \mathrm{mm}^{2}$

Fig. S10 Comparing the normalized extinction coefficient profiles in the premixed flame for five different fluence leveles ranging from, $3.30 \mathrm{~mJ} / \mathrm{mm}^{2}$ to $6.19 \mathrm{~mJ} / \mathrm{mm}^{2}$, at four wavelengths and in four time windows. 

(a) $0.21 \mathrm{~mJ} / \mathrm{mm}^{2}$
(b) $0.41 \mathrm{~mJ} / \mathrm{mm}^{2}$
(c) $0.62 \mathrm{~mJ} / \mathrm{mm}^{2}$
(d) $0.82 \mathrm{~mJ} / \mathrm{mm}^{2}$
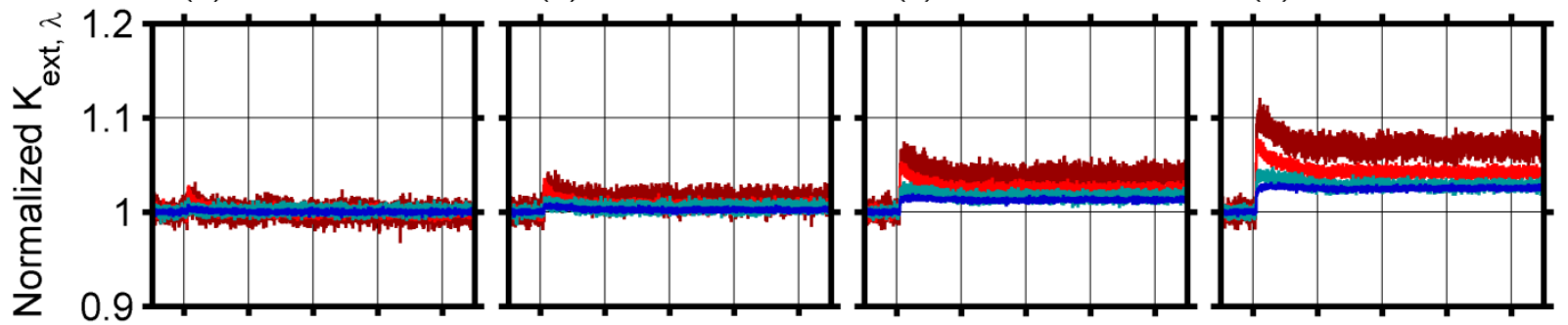

(e) $1.03 \mathrm{~mJ} / \mathrm{mm}^{2}$

(f) $1.24 \mathrm{~mJ} / \mathrm{mm}^{2}$
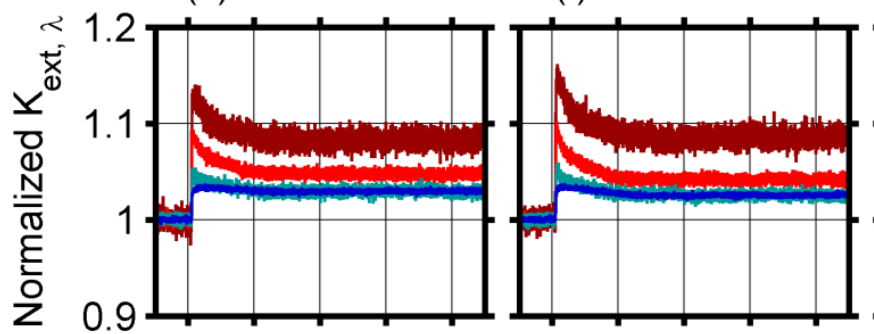

(g) $1.44 \mathrm{~mJ} / \mathrm{mm}^{2}$

(h) $1.65 \mathrm{~mJ} / \mathrm{mm}^{2}$

(i) $1.86 \mathrm{~mJ} / \mathrm{mm}^{2}$

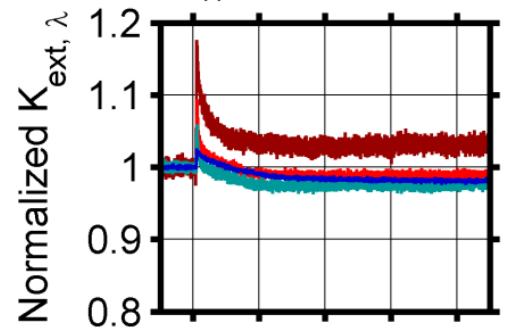

(j) $2.06 \mathrm{~mJ} / \mathrm{mm}^{2}$
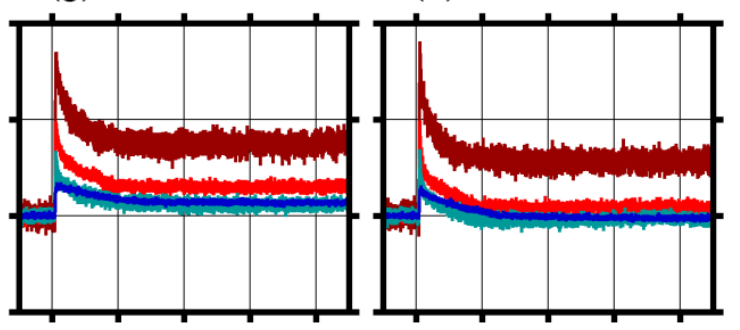

(m) $2.68 \mathrm{~mJ} / \mathrm{mm}^{2}$

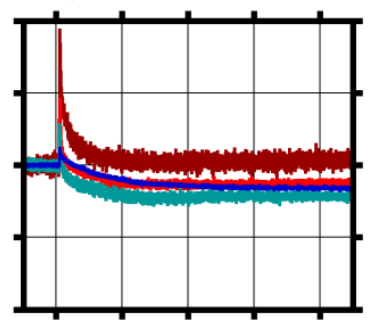

(k) $2.27 \mathrm{~mJ} / \mathrm{mm}^{2}$

(I) $2.47 \mathrm{~mJ} / \mathrm{mm}^{2}$
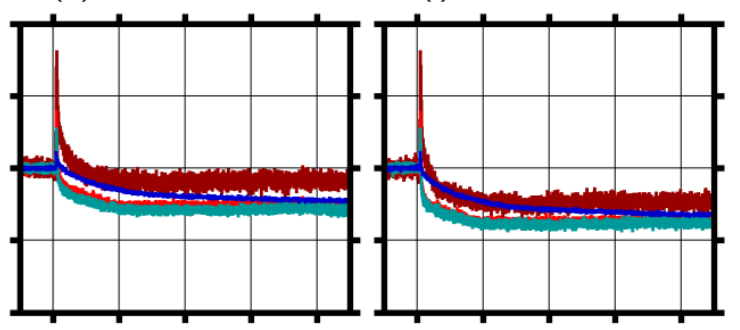

(n) $2.89 \mathrm{~mJ} / \mathrm{mm}^{2}$

(o) $3.09 \mathrm{~mJ} / \mathrm{mm}^{2}$

(p) $3.3 \mathrm{~mJ} / \mathrm{mm}^{2}$
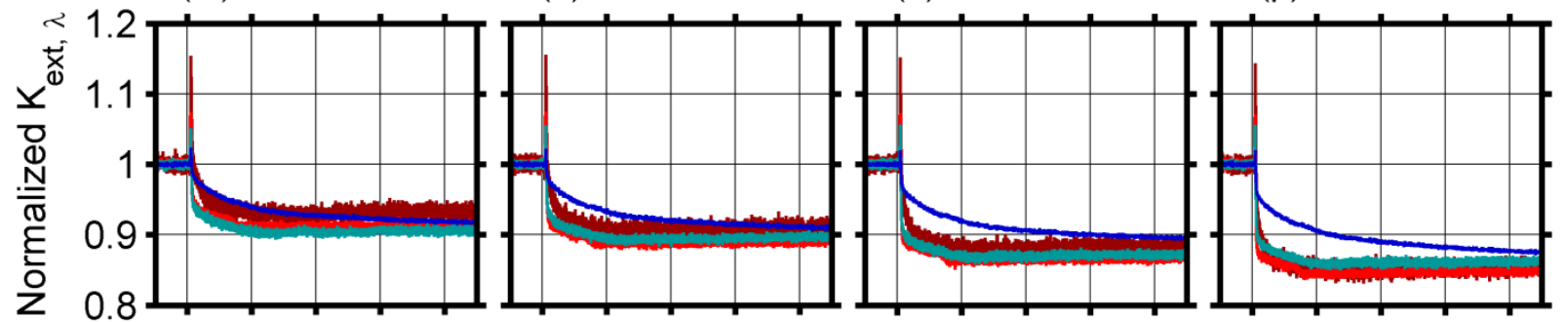

(q) $3.51 \mathrm{~mJ} / \mathrm{mm}^{2}$

(r) $4.12 \mathrm{~mJ} / \mathrm{mm}^{2}$

(s) $5.15 \mathrm{~mJ} / \mathrm{mm}^{2}$

(t) $6.19 \mathrm{~mJ} / \mathrm{mm}^{2}$
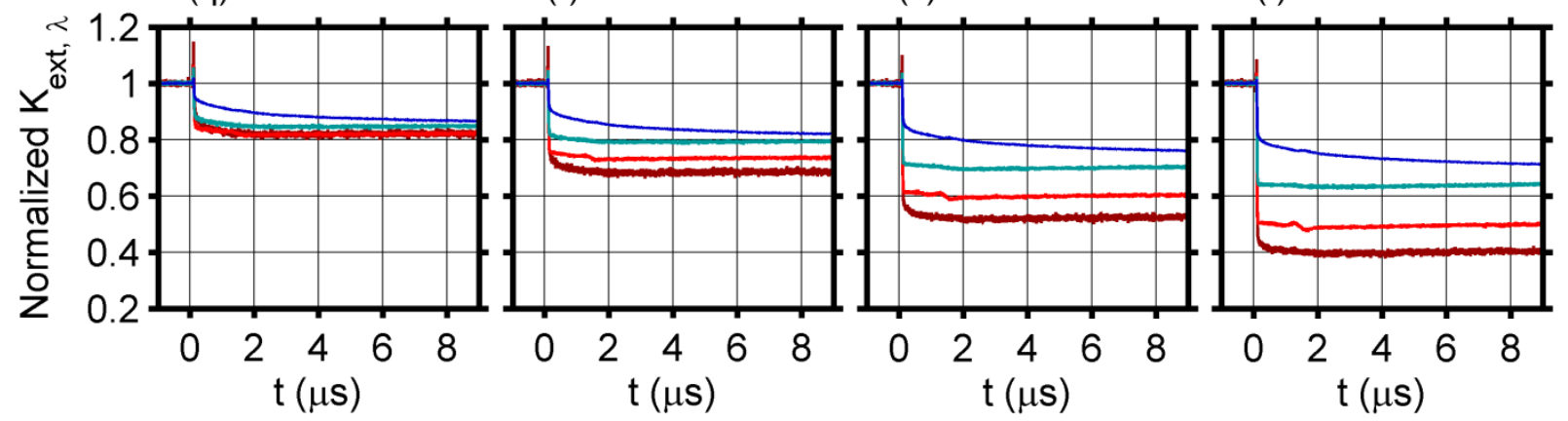

$808 \mathrm{~nm}$

$488 \mathrm{~nm}=405 \mathrm{~nm}$

Fig. S11 Comparing extinction profiles for the premixed flame at four different wavelengths from $t=-1 \mu \mathrm{s}$ to $t=9 \mu \mathrm{s}$. 

(a) $0.21 \mathrm{~mJ} / \mathrm{mm}^{2}$
(b) $0.41 \mathrm{~mJ} / \mathrm{mm}^{2}$
(c) $0.62 \mathrm{~mJ} / \mathrm{mm}^{2}$
(d) $0.82 \mathrm{~mJ} / \mathrm{mm}^{2}$
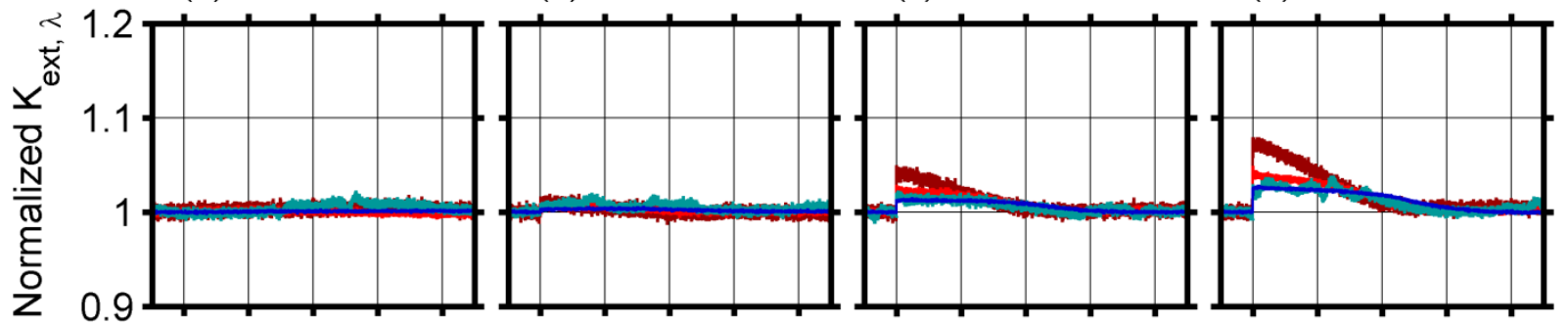

(e) $1.03 \mathrm{~mJ} / \mathrm{mm}^{2}$

(f) $1.24 \mathrm{~mJ} / \mathrm{mm}^{2}$

(g) $1.44 \mathrm{~mJ} / \mathrm{mm}^{2}$

(h) $1.65 \mathrm{~mJ} / \mathrm{mm}^{2}$
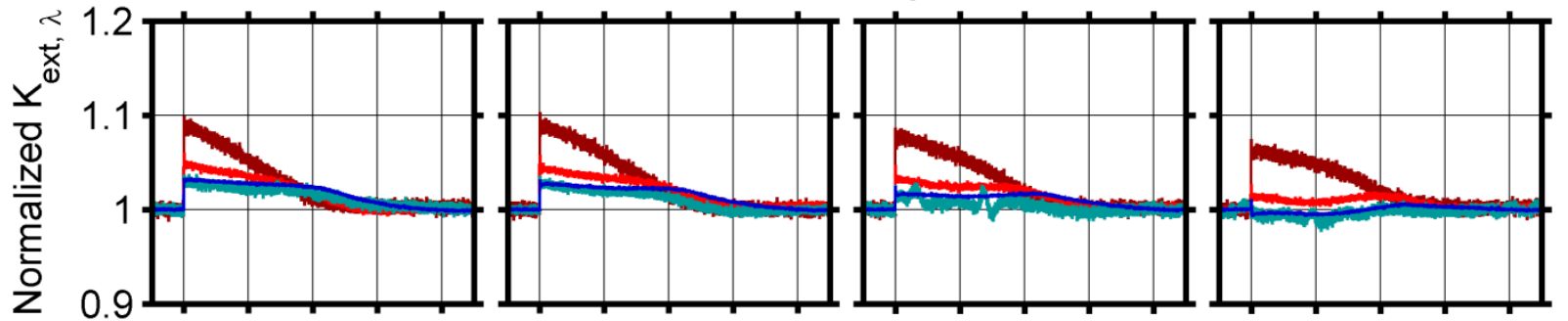

(i) $1.86 \mathrm{~mJ} / \mathrm{mm}^{2}$

(j) $2.06 \mathrm{~mJ} / \mathrm{mm}^{2}$
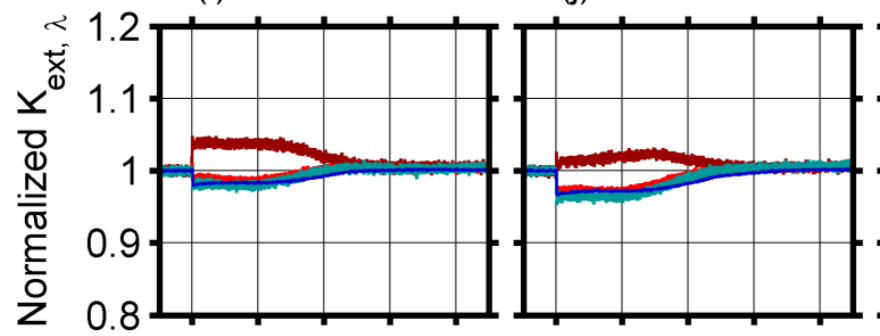

(k) $2.27 \mathrm{~mJ} / \mathrm{mm}^{2}$

(I) $2.47 \mathrm{~mJ} / \mathrm{mm}^{2}$

(m) $2.68 \mathrm{~mJ} / \mathrm{mm}^{2}$

(n) $2.89 \mathrm{~mJ} / \mathrm{mm}^{2}$
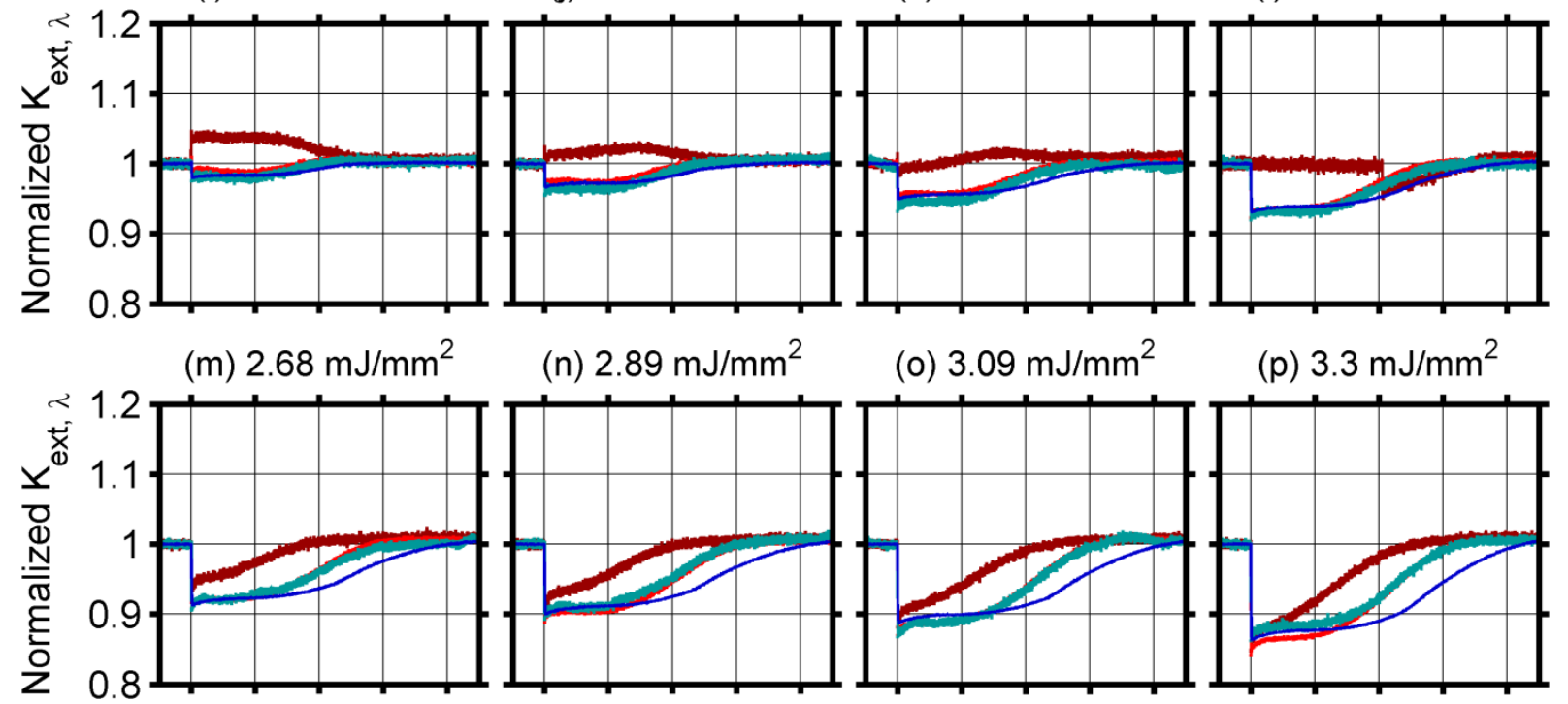

(o) $3.09 \mathrm{~mJ} / \mathrm{mm}^{2}$

(p) $3.3 \mathrm{~mJ} / \mathrm{mm}^{2}$
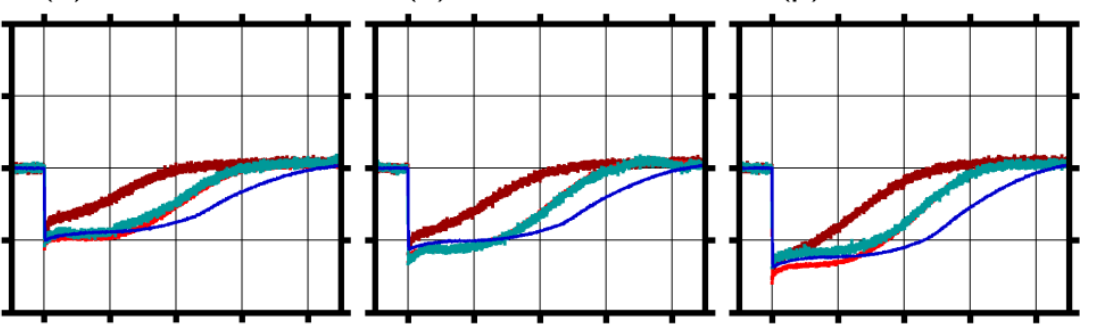

(q) $3.51 \mathrm{~mJ} / \mathrm{mm}^{2}$

(r) $4.12 \mathrm{~mJ} / \mathrm{mm}^{2}$

(s) $5.15 \mathrm{~mJ} / \mathrm{mm}^{2}$

(t) $6.19 \mathrm{~mJ} / \mathrm{mm}^{2}$
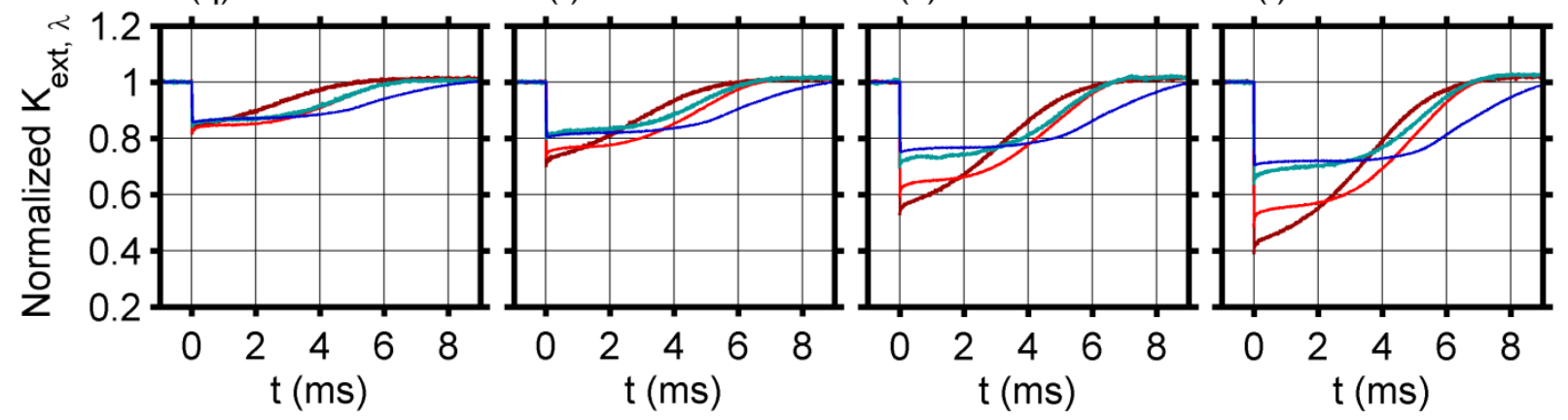

$808 \mathrm{~nm}$

$488 \mathrm{~nm}$

$405 \mathrm{~nm}$

Fig. $\mathbf{S 1 2}$ Comparing extinction profiles for the premixed flame at four different wavelengths from $t=-1 \mathrm{~ms}$ to $t=9$ ms. 

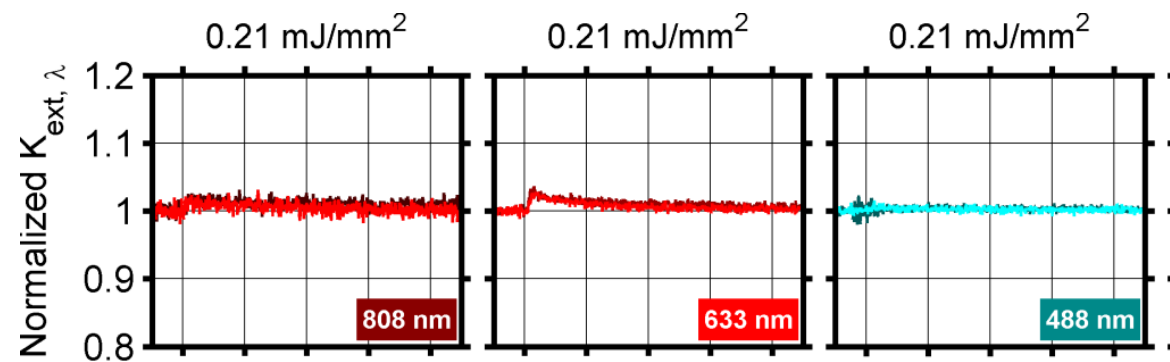

$0.21 \mathrm{~mJ} / \mathrm{mm}^{2}$

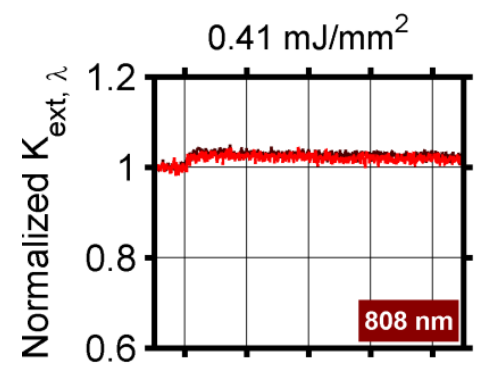

$0.41 \mathrm{~mJ} / \mathrm{mm}^{2}$

$0.41 \mathrm{~mJ} / \mathrm{mm}^{2}$
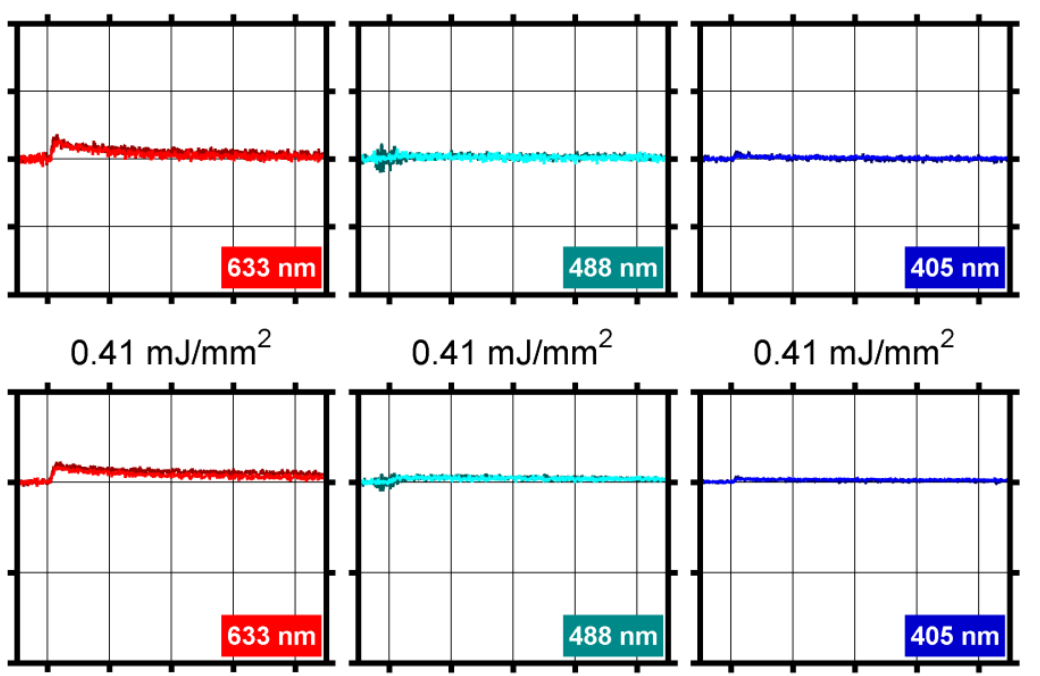

$0.41 \mathrm{~mJ} / \mathrm{mm}^{2}$

$0.62 \mathrm{~mJ} / \mathrm{mm}^{2}$

$0.62 \mathrm{~mJ} / \mathrm{mm}^{2}$

$0.62 \mathrm{~mJ} / \mathrm{mm}^{2}$
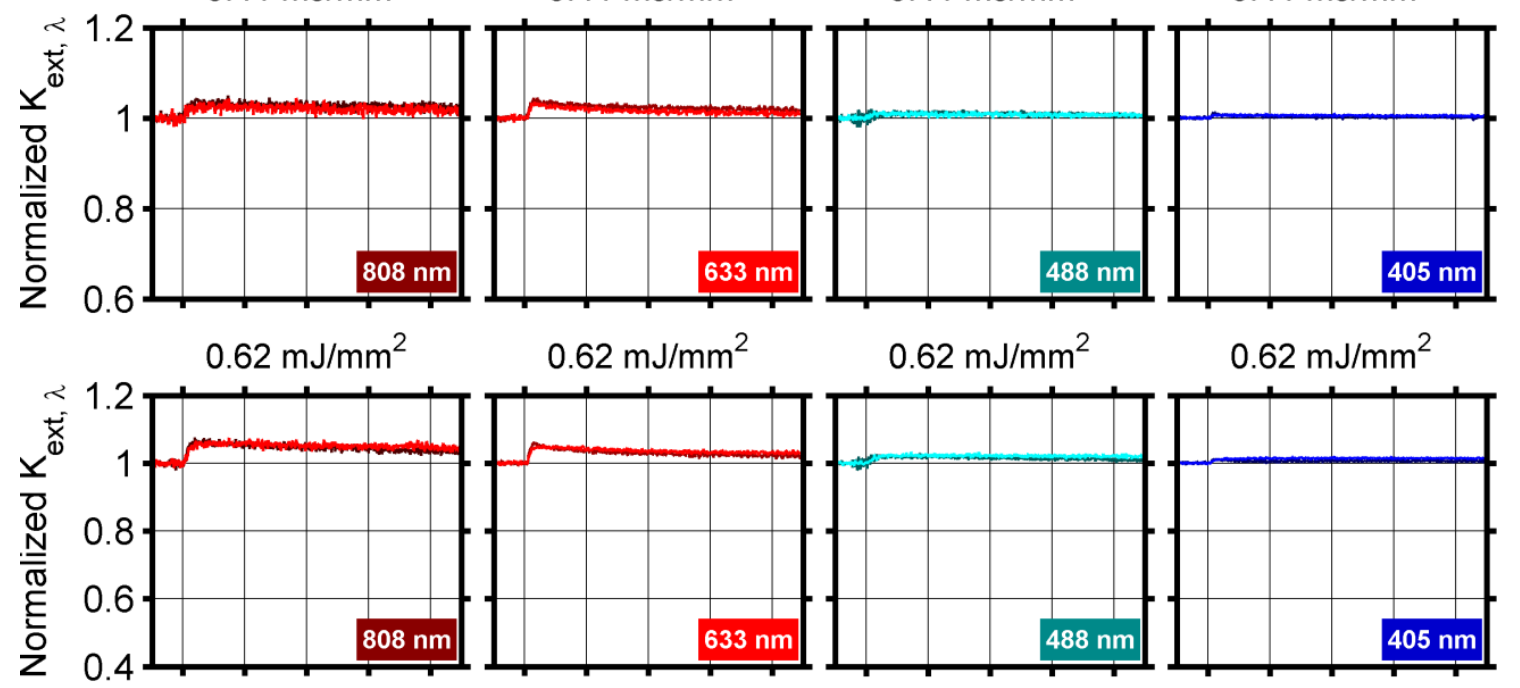

$0.62 \mathrm{~mJ} / \mathrm{mm}^{2}$

$0.82 \mathrm{~mJ} / \mathrm{mm}^{2}$

$0.82 \mathrm{~mJ} / \mathrm{mm}^{2}$

$0.82 \mathrm{~mJ} / \mathrm{mm}^{2}$
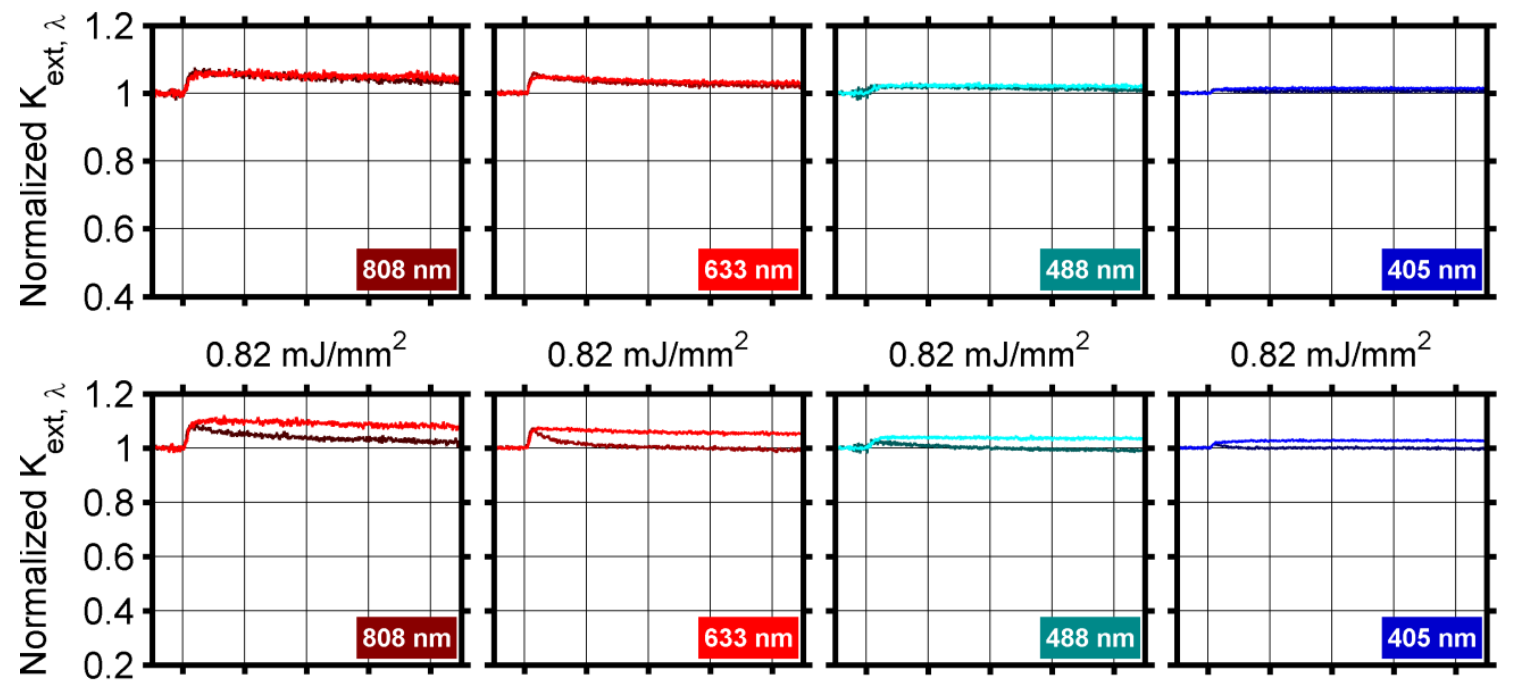

$0.82 \mathrm{~mJ} / \mathrm{mm}^{2}$
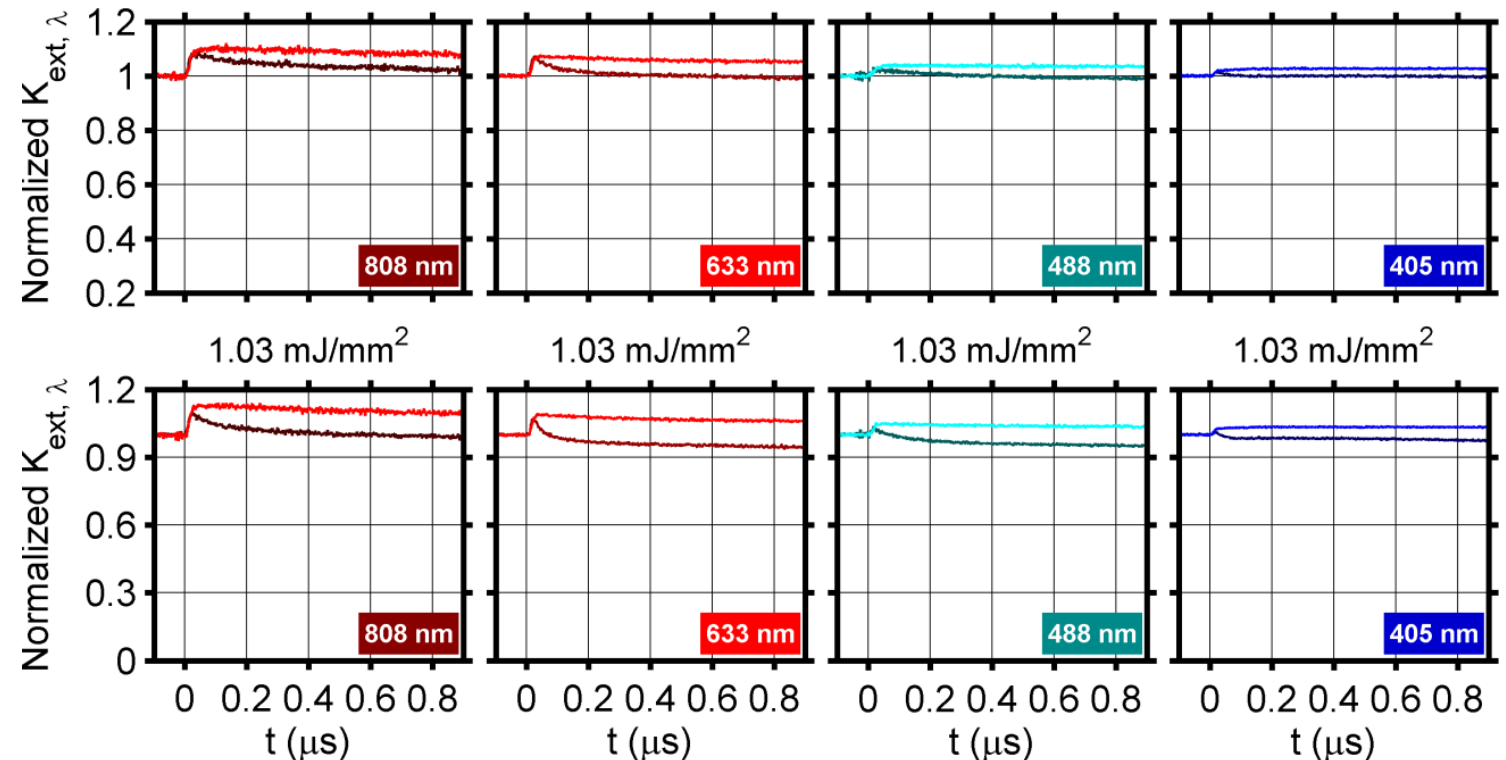

$1.03 \mathrm{~mJ} / \mathrm{mm}^{2}$

$1.03 \mathrm{~mJ} / \mathrm{mm}^{2}$

$1.03 \mathrm{~mJ} / \mathrm{mm}^{2}$
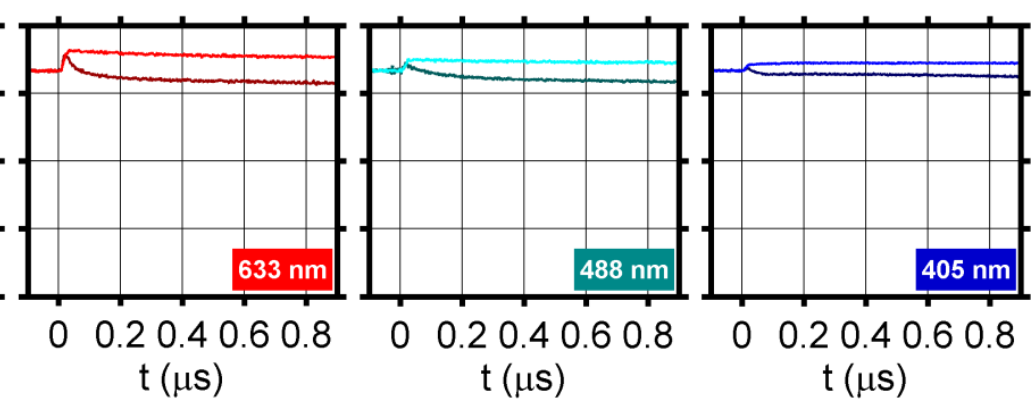

_ Diffusion flame

Diffusion flame $\mathrm{t}(\mu \mathrm{s})$

$0 \quad 0.20 .40 .60 .8$

Diffusion flame $\mathrm{t}(\mu \mathrm{s})$

Premixed flame

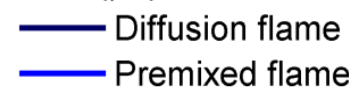

Fig. S13 Comparing extinction profiles in the diffusion and premixed flames, at four wavelengths and for fluence ranging from 0.21 to $1.03 \mathrm{~mJ} / \mathrm{mm}^{2}$, up to $\mathrm{t}=0.9 \mu \mathrm{s}$. The profiles measured in the diffusion flame are shown with darker lines and the results measured in the premixed flame are shown with the brighter lines. 

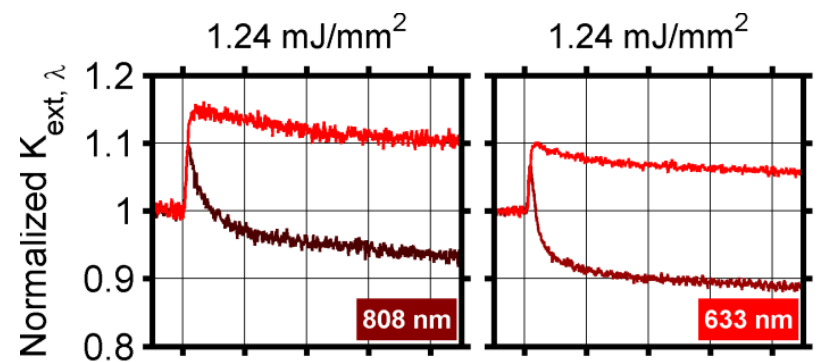

$1.24 \mathrm{~mJ} / \mathrm{mm}^{2}$

$1.24 \mathrm{~mJ} / \mathrm{mm}^{2}$

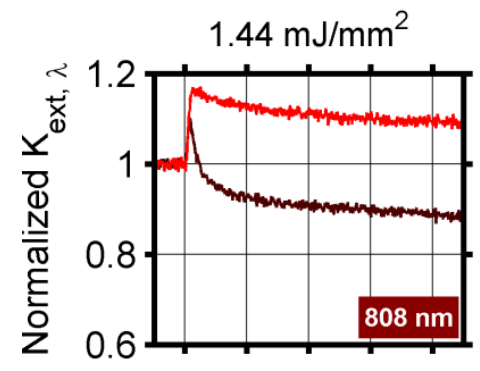

$1.44 \mathrm{~mJ} / \mathrm{mm}^{2}$
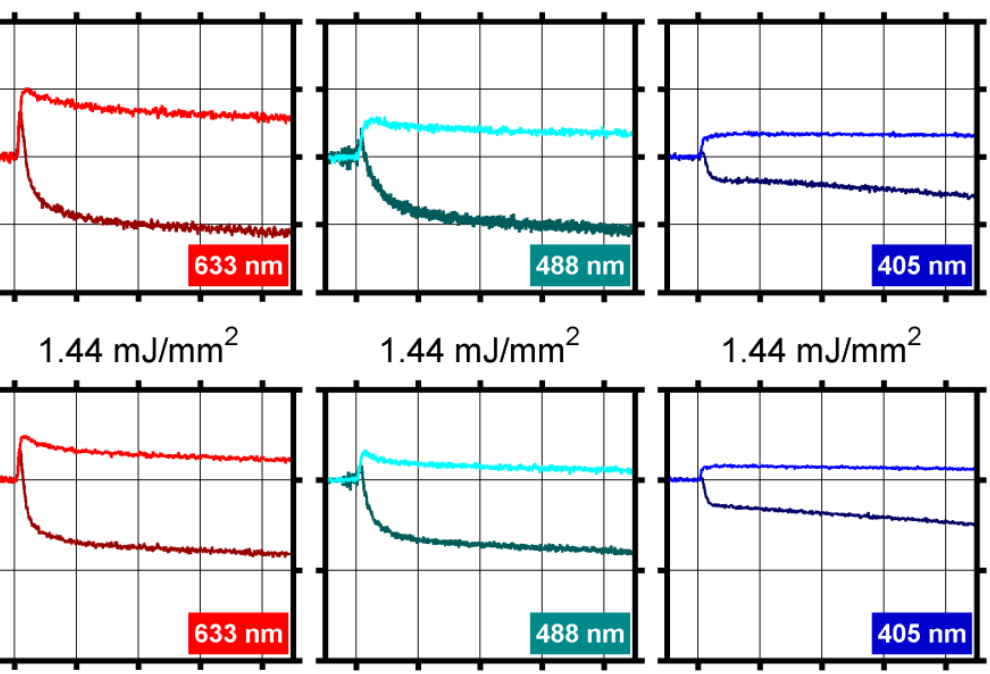

$1.44 \mathrm{~mJ} / \mathrm{mm}^{2}$

$1.44 \mathrm{~mJ} / \mathrm{mm}^{2}$
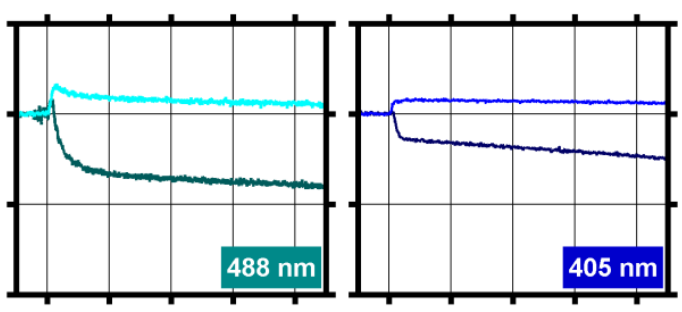

$1.65 \mathrm{~mJ} / \mathrm{mm}^{2}$

$1.65 \mathrm{~mJ} / \mathrm{mm}^{2}$

$1.65 \mathrm{~mJ} / \mathrm{mm}^{2}$

$1.65 \mathrm{~mJ} / \mathrm{mm}^{2}$
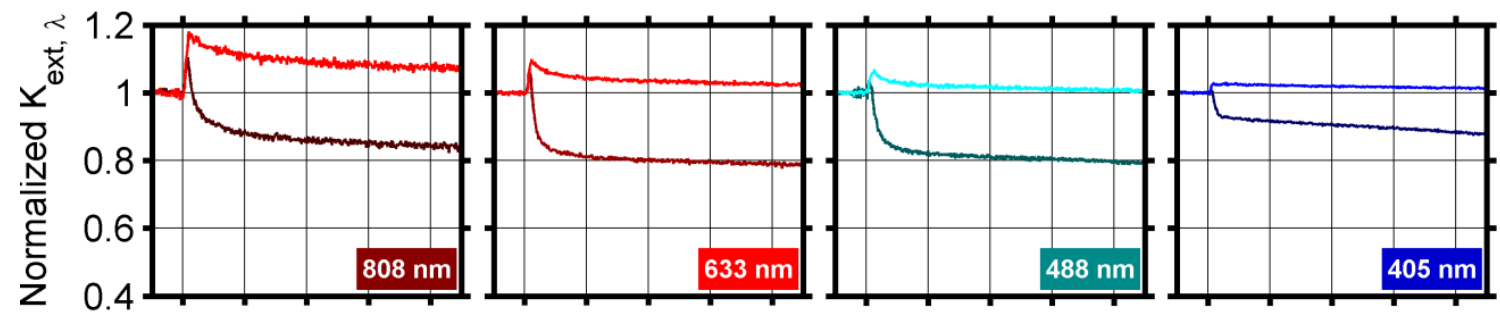

$1.86 \mathrm{~mJ} / \mathrm{mm}^{2}$

$1.86 \mathrm{~mJ} / \mathrm{mm}^{2}$

$1.86 \mathrm{~mJ} / \mathrm{mm}^{2}$

$1.86 \mathrm{~mJ} / \mathrm{mm}^{2}$
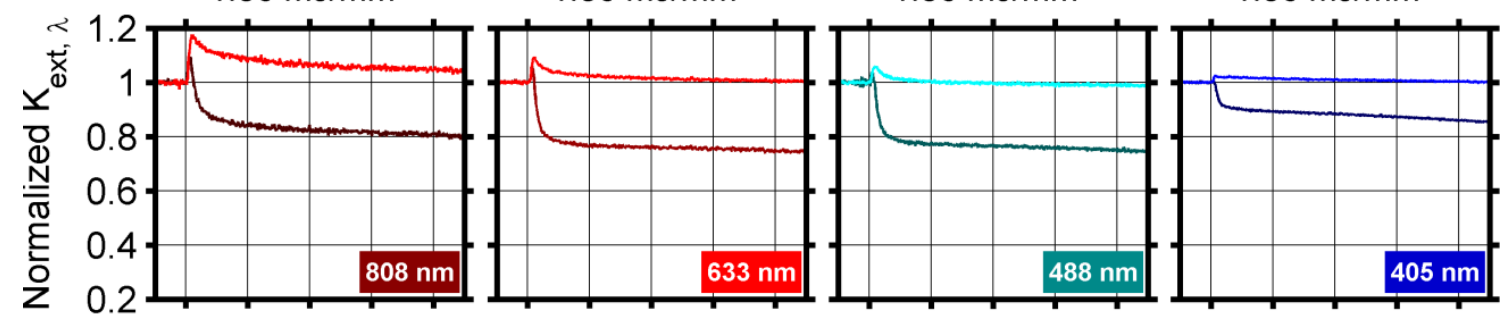

$2.06 \mathrm{~mJ} / \mathrm{mm}^{2}$

$2.06 \mathrm{~mJ} / \mathrm{mm}^{2}$

$2.06 \mathrm{~mJ} / \mathrm{mm}^{2}$

$2.06 \mathrm{~mJ} / \mathrm{mm}^{2}$
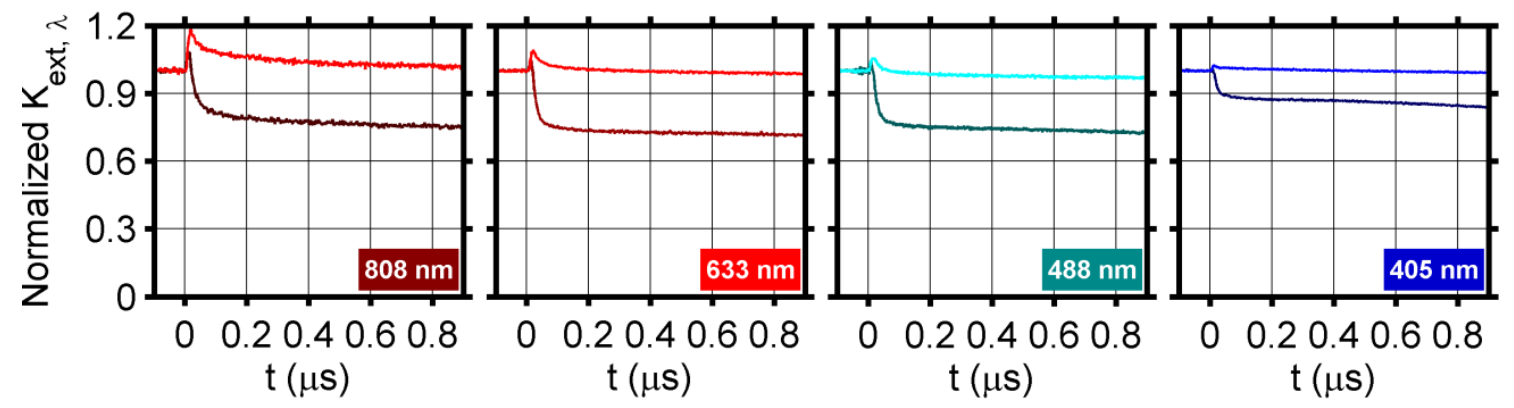

Diffusion flame
Premixed flame

Diffusion flame

- Diffusion flame Premixed flame

$\mathrm{t}(\mu \mathrm{s})$

- Diffusion flame

Fig. S14 Comparing extinction profiles in the diffusion and premixed flames, at four wavelengths and for fluence ranging from 1.24 to $2.06 \mathrm{~mJ} / \mathrm{mm}^{2}$, up to $\mathrm{t}=0.9 \mu \mathrm{s}$. The profiles measured in the diffusion flame are shown with darker lines and the results measured in the premixed flame are shown with the brighter lines. 

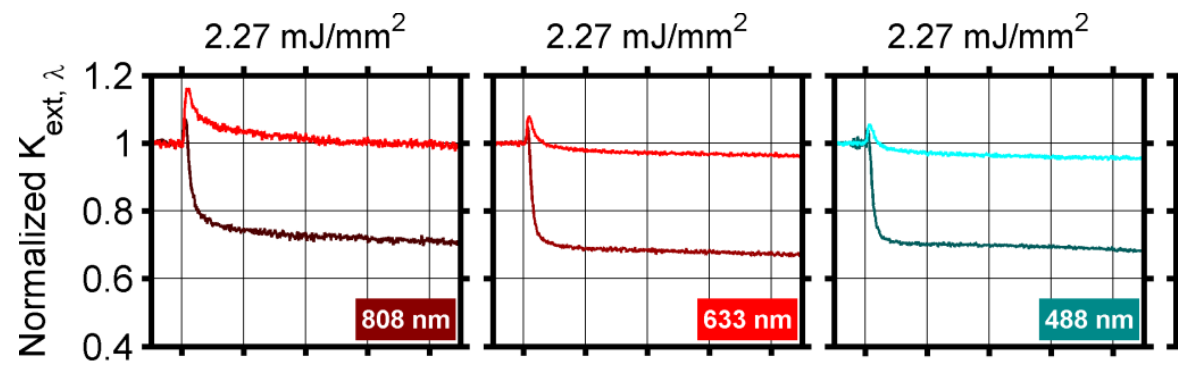

$2.27 \mathrm{~mJ} / \mathrm{mm}^{2}$
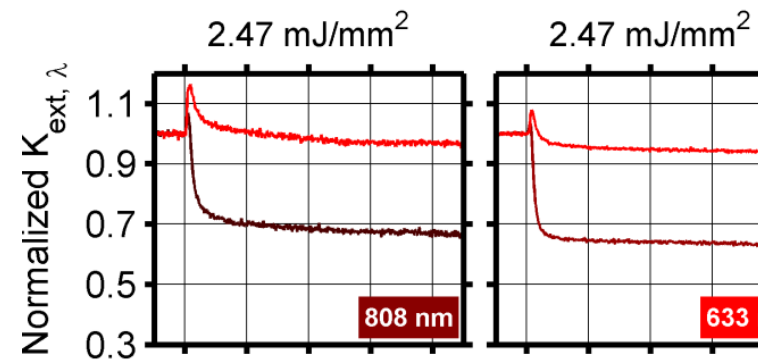

$2.47 \mathrm{~mJ} / \mathrm{mm}^{2}$
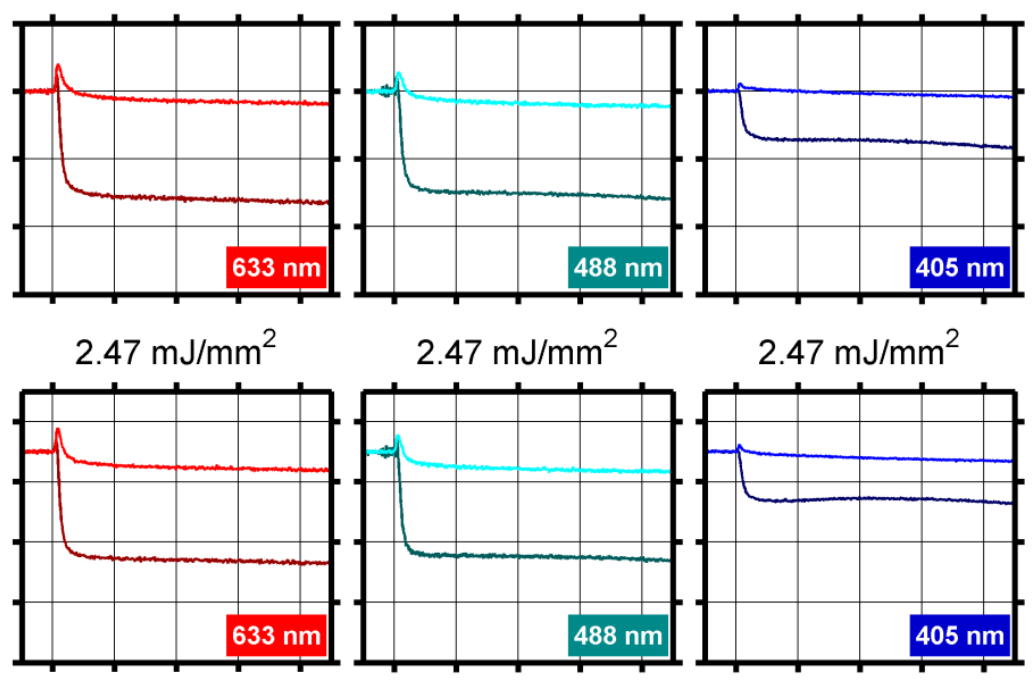

$2.47 \mathrm{~mJ} / \mathrm{mm}^{2}$

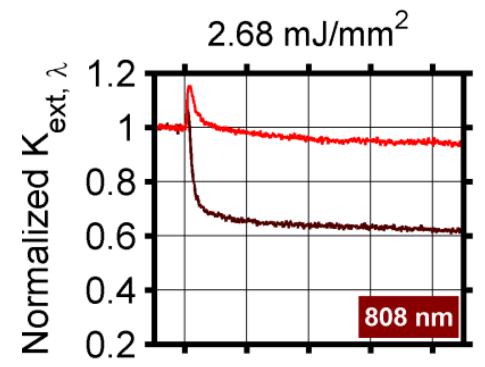

$2.68 \mathrm{~mJ} / \mathrm{mm}^{2}$

$2.68 \mathrm{~mJ} / \mathrm{mm}^{2}$
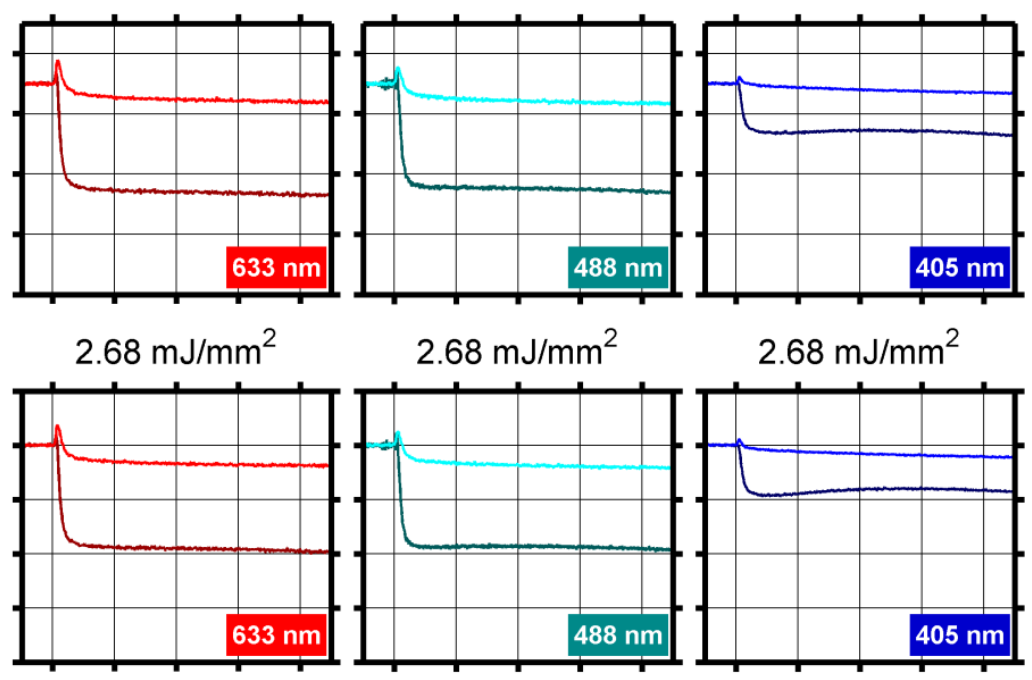

$2.68 \mathrm{~mJ} / \mathrm{mm}^{2}$

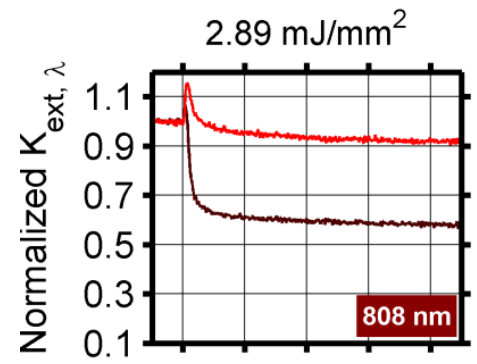

$2.89 \mathrm{~mJ} / \mathrm{mm}^{2}$

$2.89 \mathrm{~mJ} / \mathrm{mm}^{2}$
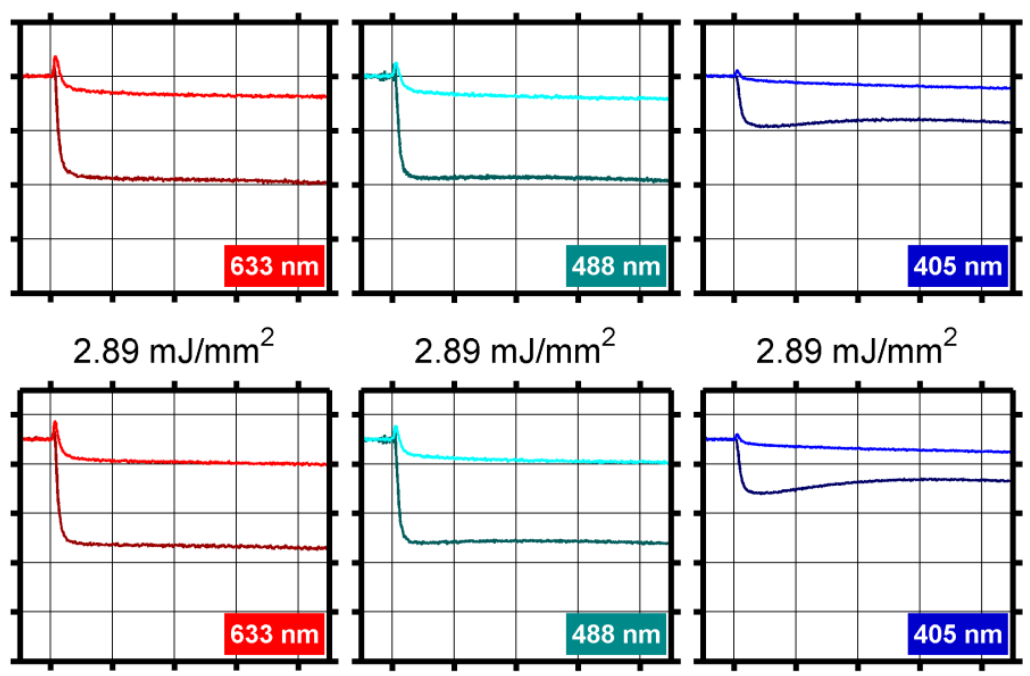

$2.89 \mathrm{~mJ} / \mathrm{mm}^{2}$

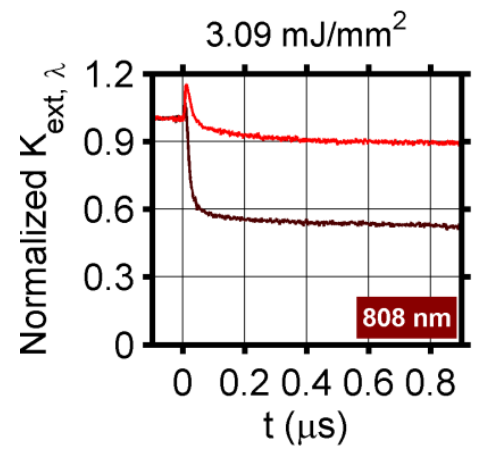

$3.09 \mathrm{~mJ} / \mathrm{mm}^{2}$

$3.09 \mathrm{~mJ} / \mathrm{mm}^{2}$
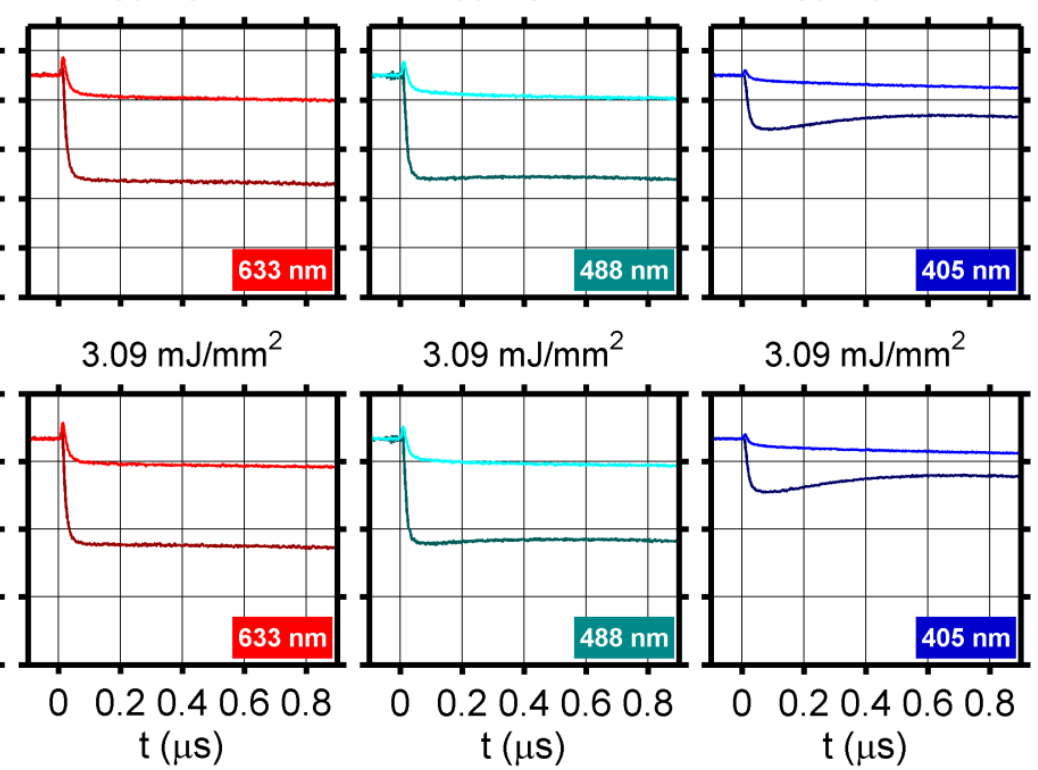

$3.09 \mathrm{~mJ} / \mathrm{mm}^{2}$

- Diffusion flame Diffusion flame

Diffusion flame

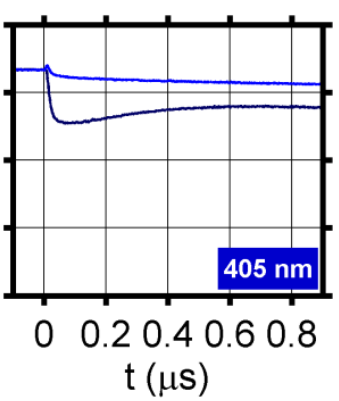

- Premixed flame

Fig. S15 Comparing extinction profiles in the diffusion and premixed flames, at four wavelengths and for fluence ranging from 2 to $3.09 \mathrm{~mJ} / \mathrm{mm}^{2}$, up to $\mathrm{t}=0.9 \mu \mathrm{s}$. The profiles measured in the diffusion flame are shown with darker lines and the results measured in the premixed flame are shown with the brighter lines. 

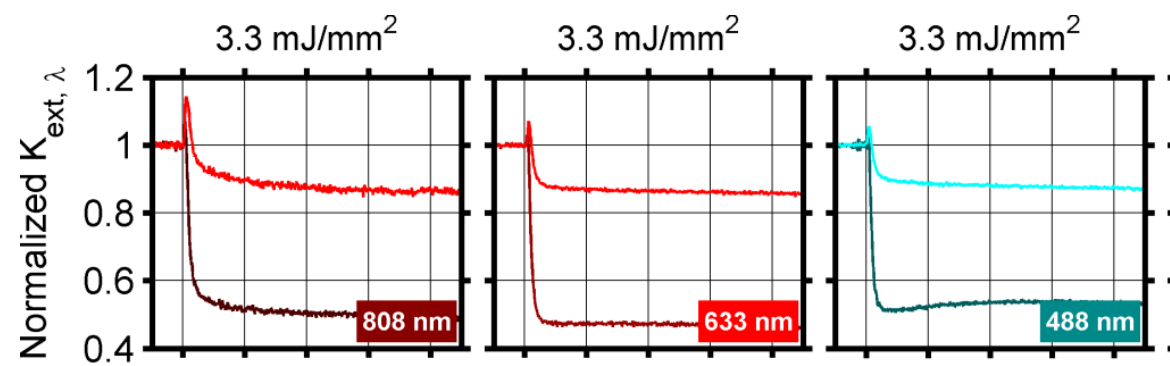

$3.3 \mathrm{~mJ} / \mathrm{mm}^{2}$

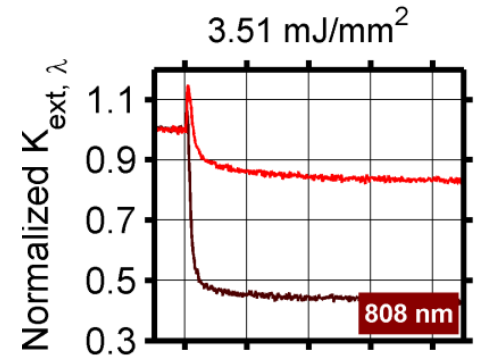

$3.51 \mathrm{~mJ} / \mathrm{mm}^{2}$

$3.51 \mathrm{~mJ} / \mathrm{mm}^{2}$
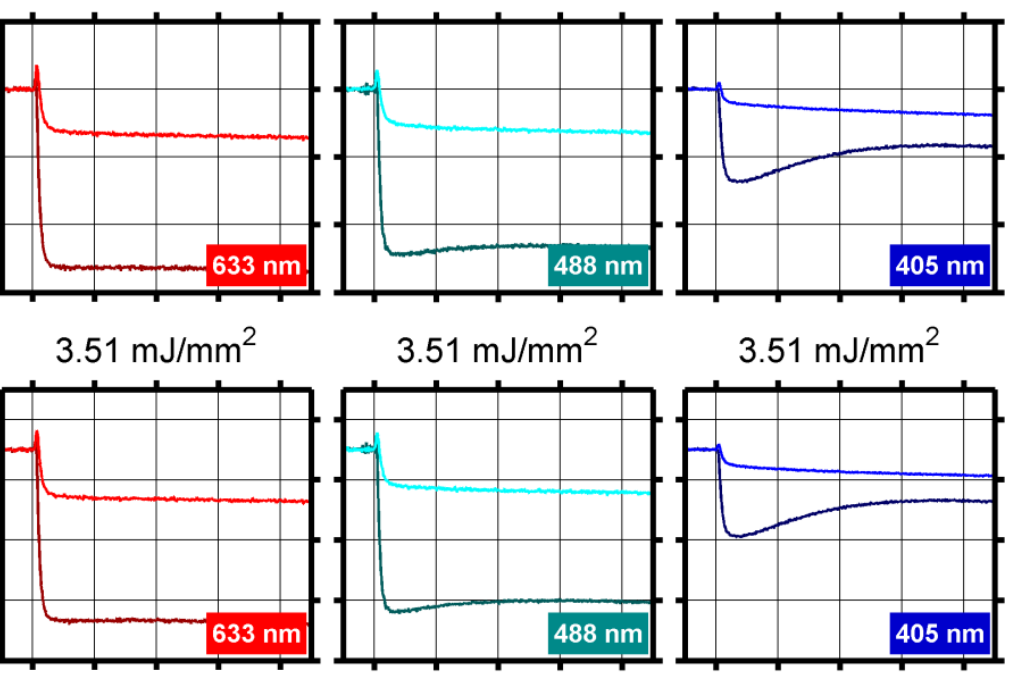

$3.51 \mathrm{~mJ} / \mathrm{mm}^{2}$

$4.12 \mathrm{~mJ} / \mathrm{mm}^{2}$

$4.12 \mathrm{~mJ} / \mathrm{mm}^{2}$

$4.12 \mathrm{~mJ} / \mathrm{mm}^{2}$
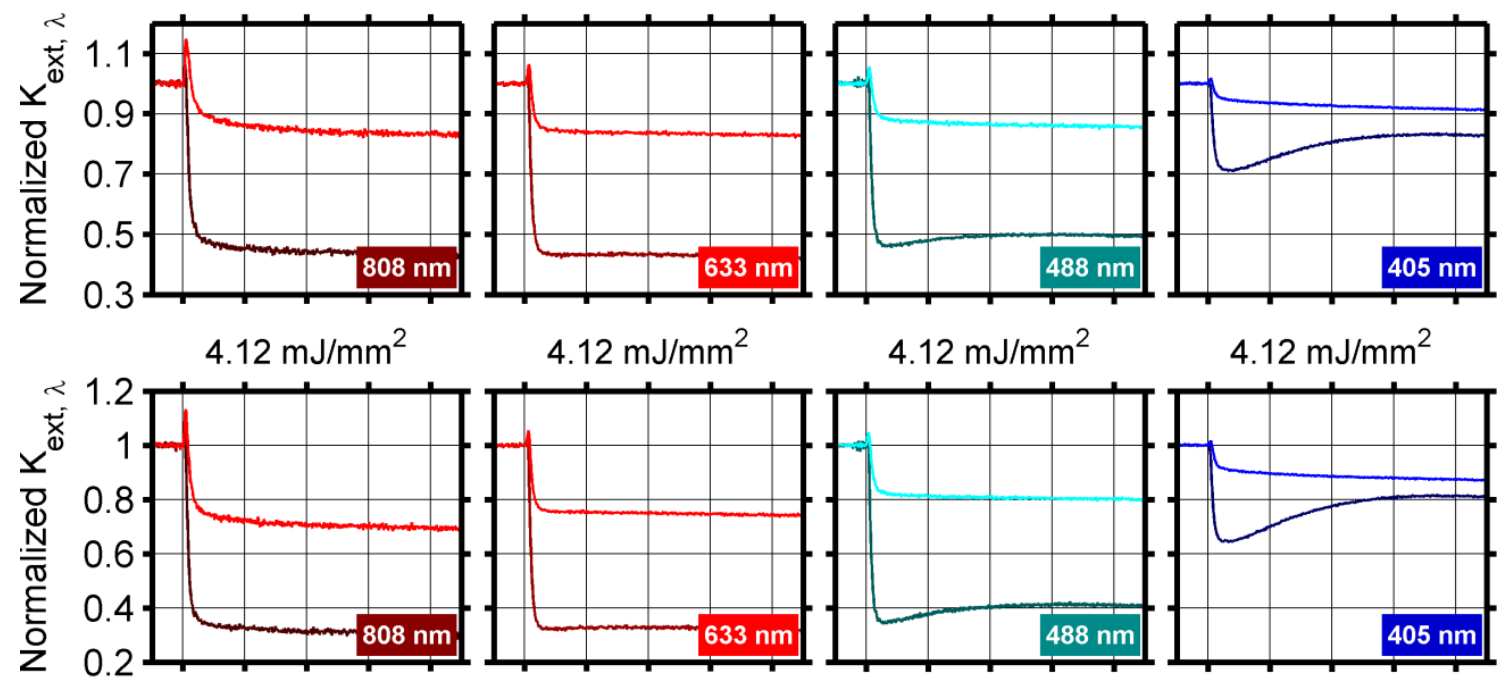

$4.12 \mathrm{~mJ} / \mathrm{mm}^{2}$

$5.15 \mathrm{~mJ} / \mathrm{mm}^{2}$

$5.15 \mathrm{~mJ} / \mathrm{mm}^{2}$
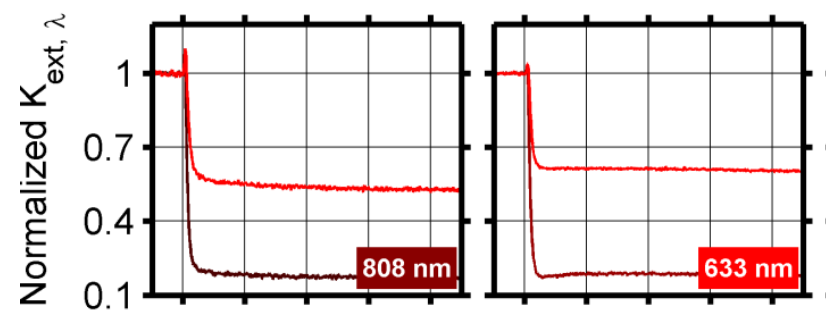

$5.15 \mathrm{~mJ} / \mathrm{mm}^{2}$

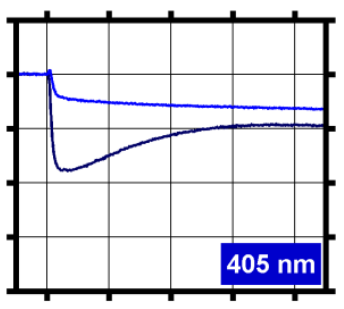

$6.19 \mathrm{~mJ} / \mathrm{mm}^{2}$

$6.19 \mathrm{~mJ} / \mathrm{mm}^{2}$

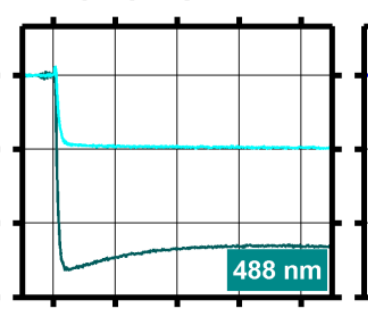

$5.15 \mathrm{~mJ} / \mathrm{mm}^{2}$
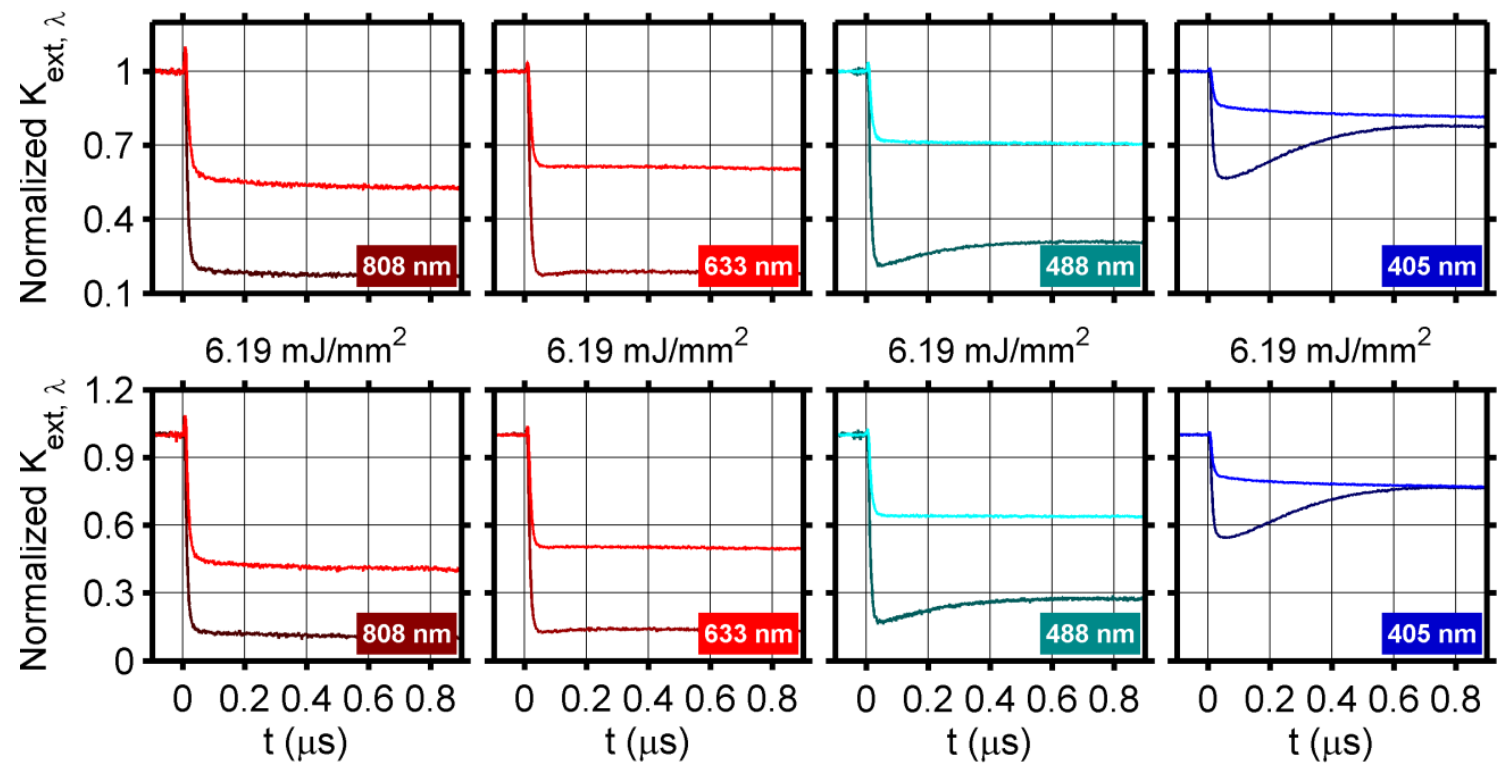

$6.19 \mathrm{~mJ} / \mathrm{mm}^{2}$

$6.19 \mathrm{~mJ} / \mathrm{mm}^{2}$

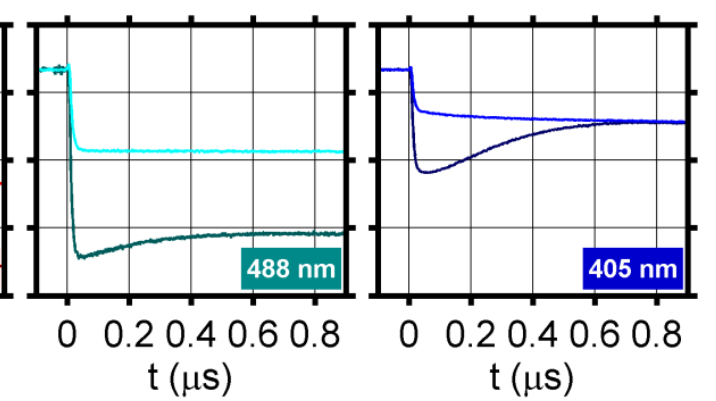

Diffusion flame

- Diffusion flame

- Diffusion flame Premixed flame

- Diffusion flame

Fig. S16 Comparing extinction profiles in the diffusion and premixed flames, at four wavelengths and for fluence ranging from 3.30 to $6.19 \mathrm{~mJ} / \mathrm{mm}^{2}$, up to $\mathrm{t}=0.9 \mu \mathrm{s}$. The profiles measured in the diffusion flame are shown with darker lines and the results measured in the premixed flame are shown with the brighter lines. 


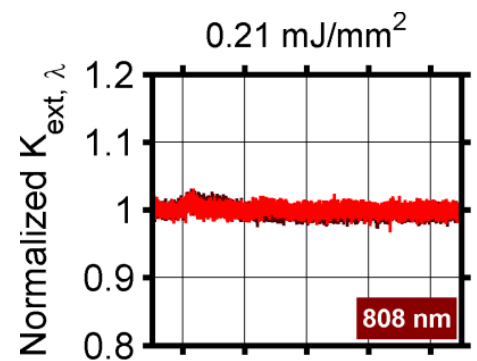

$0.21 \mathrm{~mJ} / \mathrm{mm}^{2}$

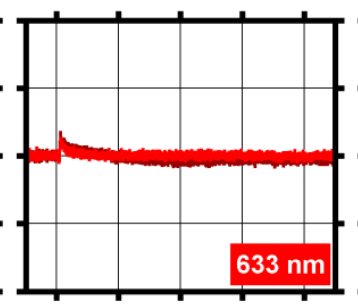

$0.41 \mathrm{~mJ} / \mathrm{mm}^{2}$

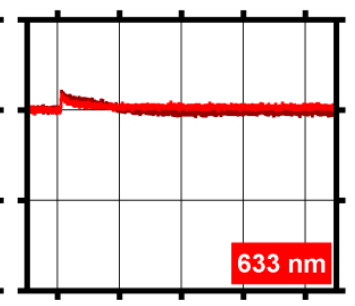

$0.62 \mathrm{~mJ} / \mathrm{mm}^{2}$

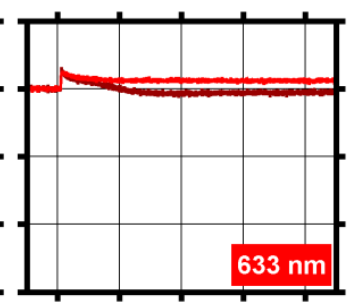

$0.82 \mathrm{~mJ} / \mathrm{mm}^{2}$

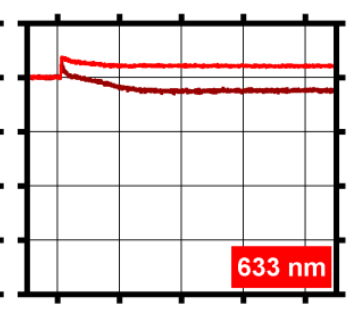

$1.03 \mathrm{~mJ} / \mathrm{mm}^{2}$

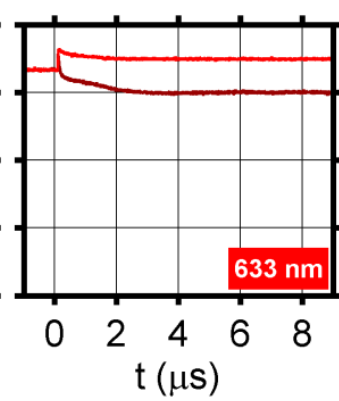

— Diffusion flame

- Premixed flame
$0.21 \mathrm{~mJ} / \mathrm{mm}^{2}$

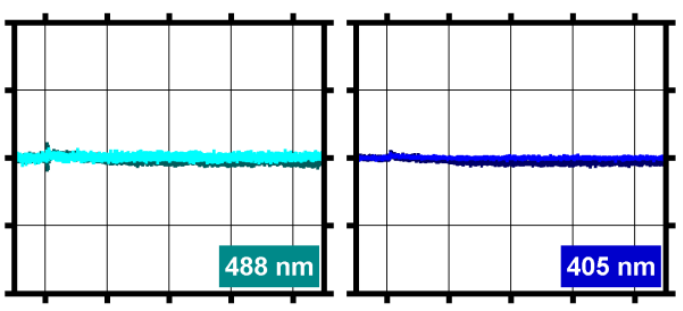

$0.41 \mathrm{~mJ} / \mathrm{mm}^{2}$

$0.41 \mathrm{~mJ} / \mathrm{mm}^{2}$

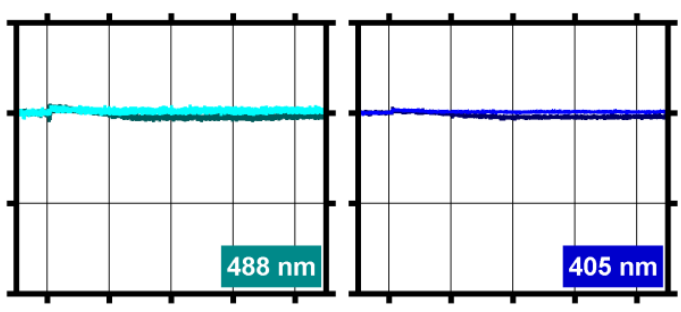

$0.62 \mathrm{~mJ} / \mathrm{mm}^{2}$

$0.62 \mathrm{~mJ} / \mathrm{mm}^{2}$

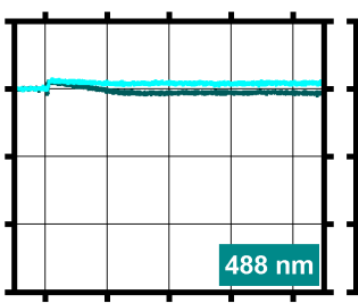

$0.82 \mathrm{~mJ} / \mathrm{mm}^{2}$

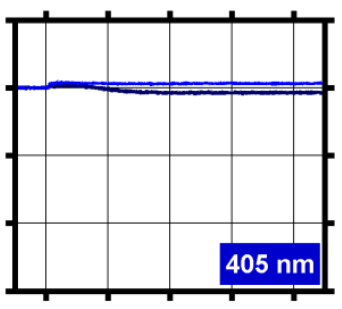

$0.82 \mathrm{~mJ} / \mathrm{mm}^{2}$

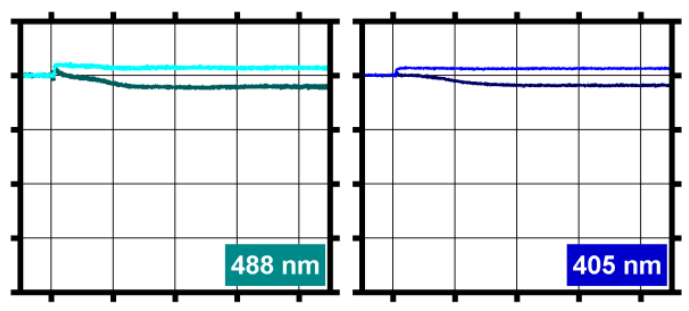

$1.03 \mathrm{~mJ} / \mathrm{mm}^{2}$

$1.03 \mathrm{~mJ} / \mathrm{mm}^{2}$

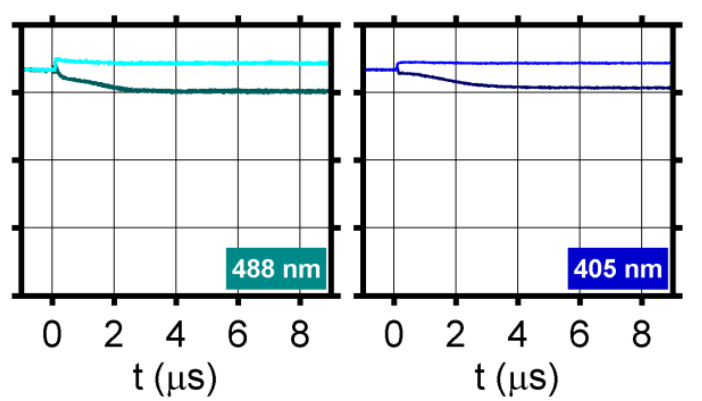

Diffusion flame

- Diffusion flame Premixed flame
- Diffusion flame - Premixed flame

Fig. S17 Comparing extinction profiles in the diffusion and premixed flames, at four wavelengths and for fluence ranging from 0.21 to $1.03 \mathrm{~mJ} / \mathrm{mm}^{2}$, up to $\mathrm{t}=9 \mu \mathrm{s}$. The profiles measured in the diffusion flame are shown with darker lines and the results measured in the premixed flame are shown with the brighter lines. 

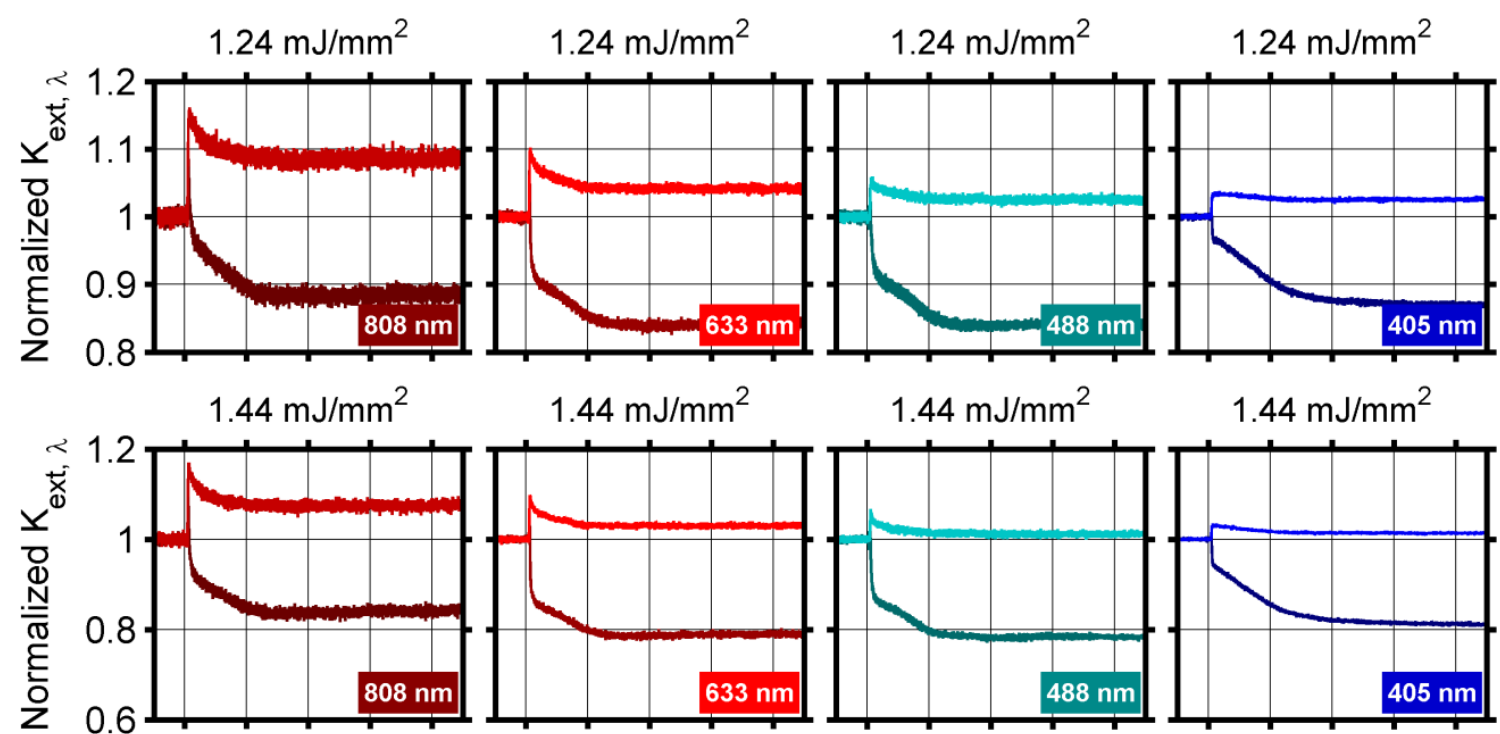

$1.44 \mathrm{~mJ} / \mathrm{mm}^{2}$
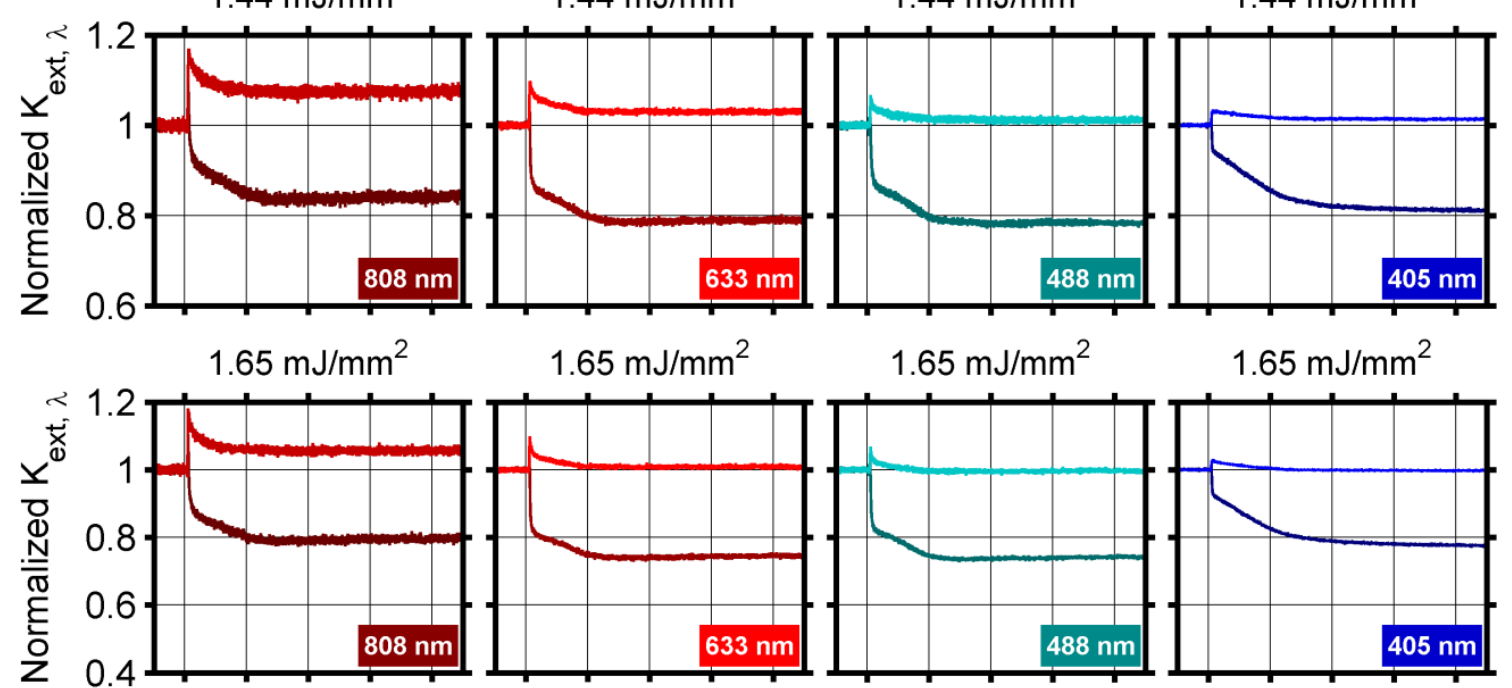

$1.65 \mathrm{~mJ} / \mathrm{mm}^{2}$
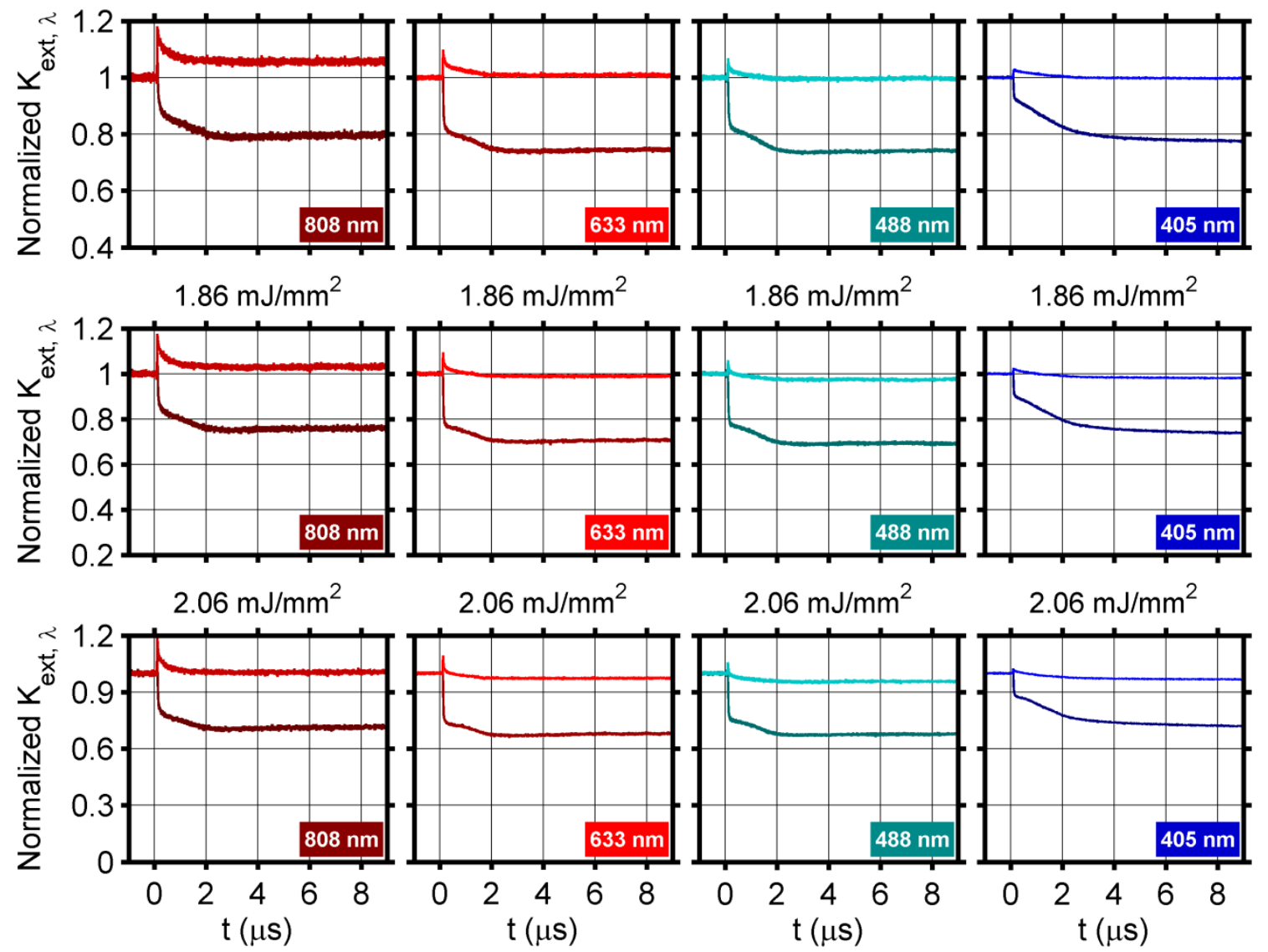

$1.86 \mathrm{~mJ} / \mathrm{mm}^{2}$

$1.86 \mathrm{~mJ} / \mathrm{mm}^{2}$
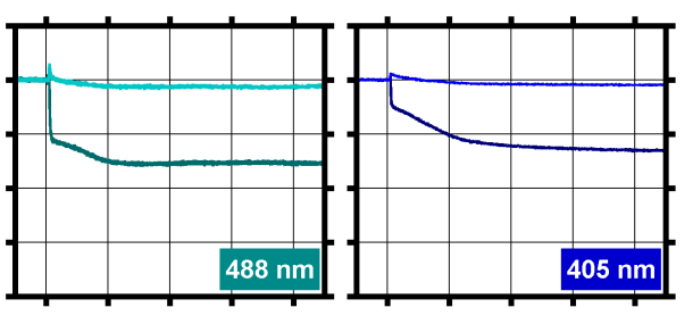

Diffusion flame Diffusion flame

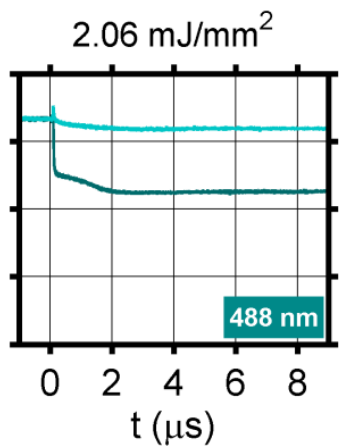

$2.06 \mathrm{~mJ} / \mathrm{mm}^{2}$

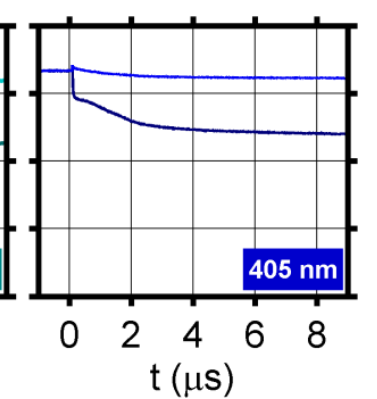

- Premixed flame Premixed flame

- Diffusion flame

- Diffusion flame Premixed flame

Fig. S18 Comparing extinction profiles in the diffusion and premixed flames, at four wavelengths and for fluence ranging from 1.24 to $2.06 \mathrm{~mJ} / \mathrm{mm}^{2}$, up to $\mathrm{t}=9 \mu \mathrm{s}$. The profiles measured in the diffusion flame are shown with darker lines and the results measured in the premixed flame are shown with the brighter lines. 

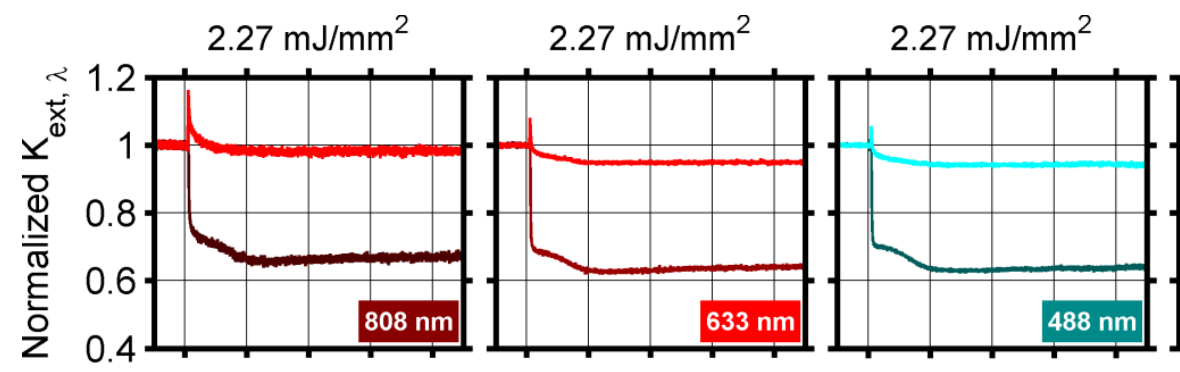

$2.27 \mathrm{~mJ} / \mathrm{mm}^{2}$
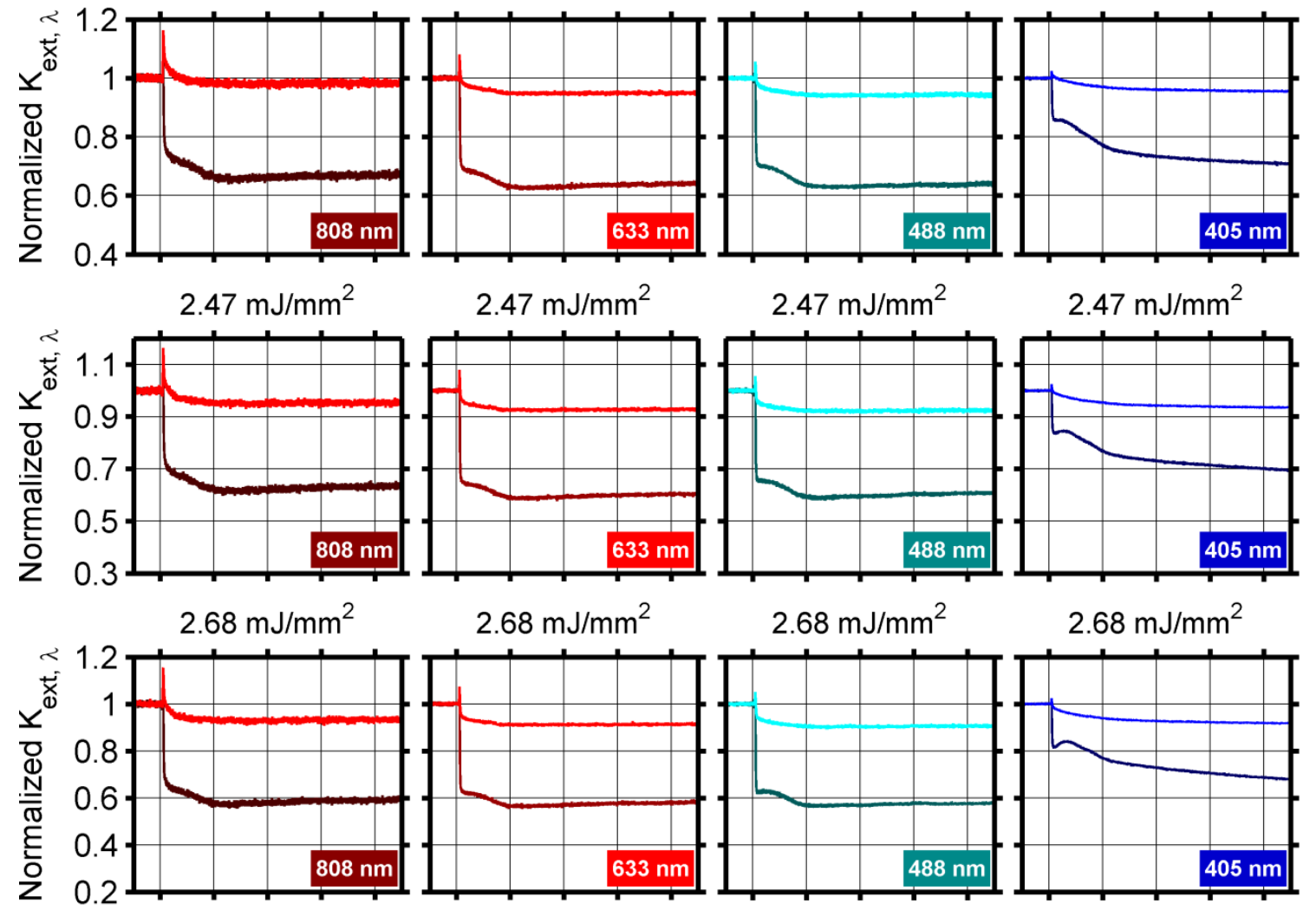

$2.47 \mathrm{~mJ} / \mathrm{mm}^{2}$
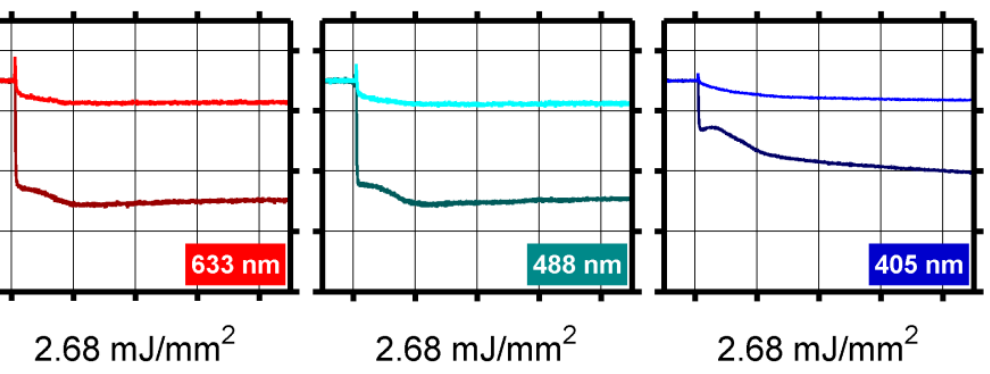

$2.68 \mathrm{~mJ} / \mathrm{mm}^{2}$
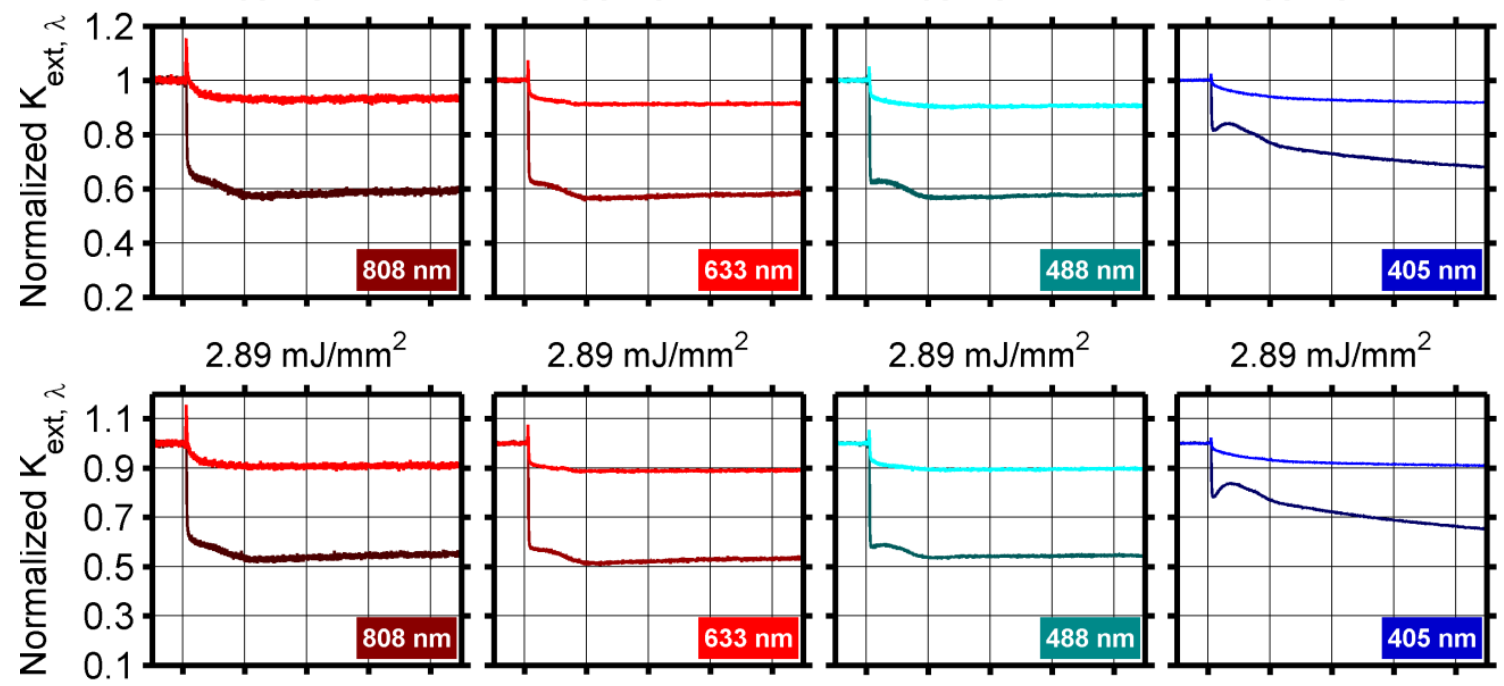

$2.89 \mathrm{~mJ} / \mathrm{mm}^{2}$
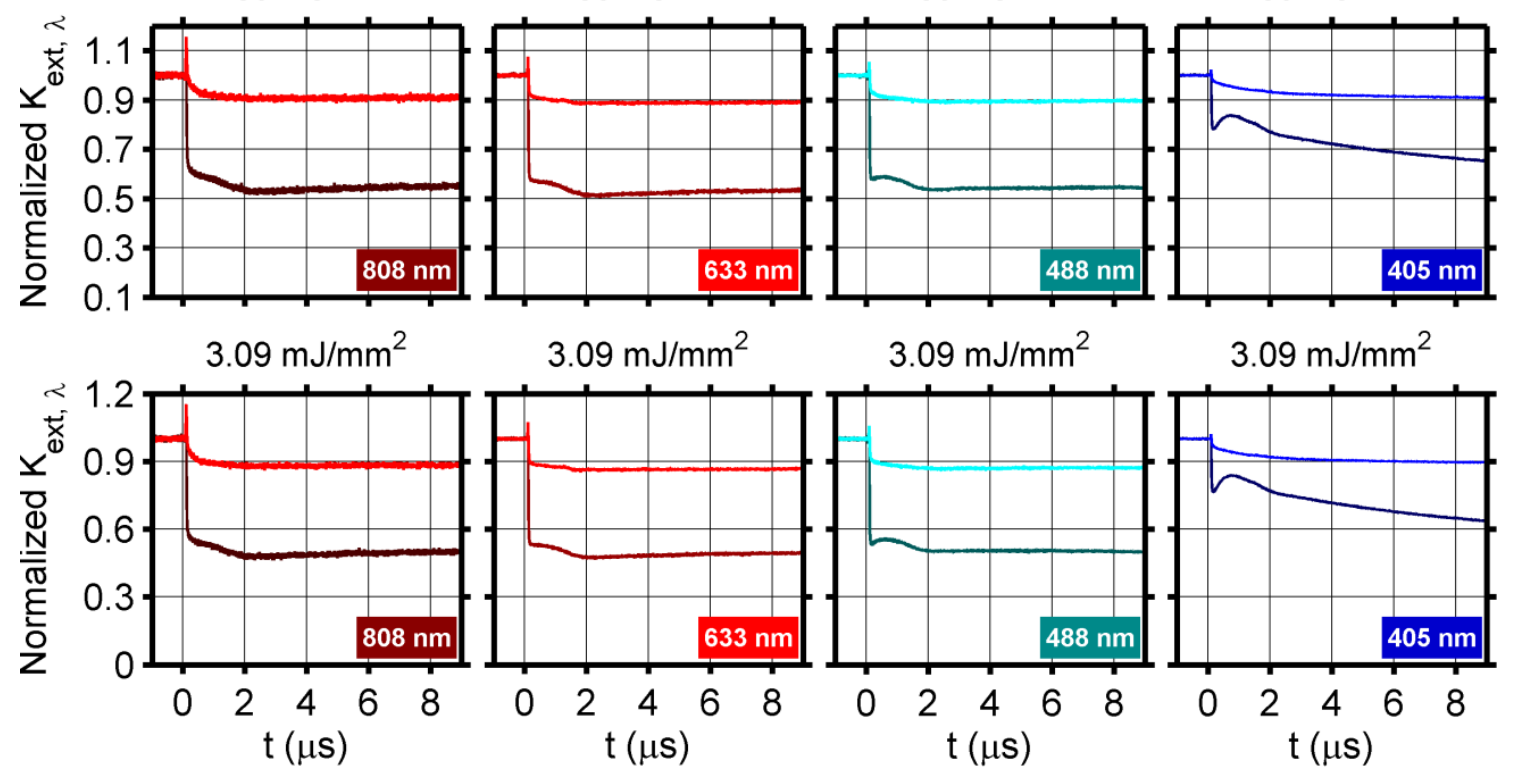

$3.09 \mathrm{~mJ} / \mathrm{mm}^{2}$

$3.09 \mathrm{~mJ} / \mathrm{mm}^{2}$

$3.09 \mathrm{~mJ} / \mathrm{mm}^{2}$
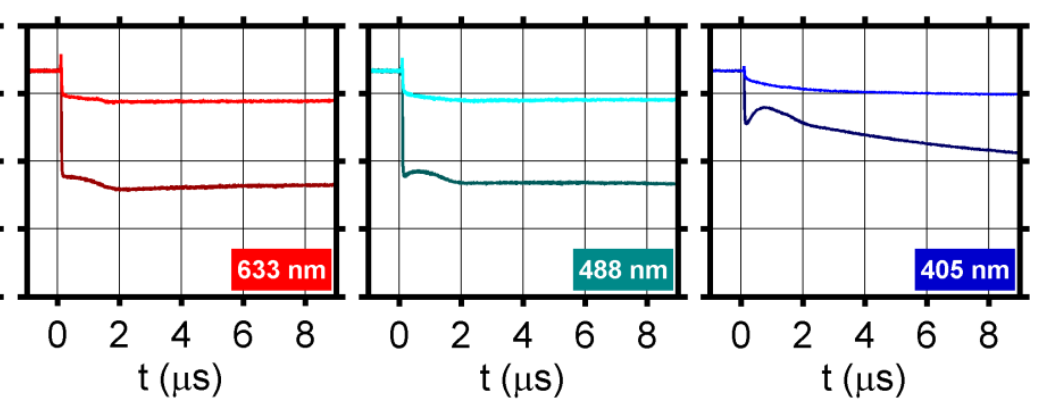

Diffusion flame

- Diffusion flame

- Diffusion flame

- Diffusion flame

Fig. S19 Comparing extinction profiles in the diffusion and premixed flames, at four wavelengths and for fluence ranging from 2 to $3.09 \mathrm{~mJ} / \mathrm{mm}^{2}$, up to $\mathrm{t}=9 \mu \mathrm{s}$. The profiles measured in the diffusion flame are shown with darker lines and the results measured in the premixed flame are shown with the brighter lines. 

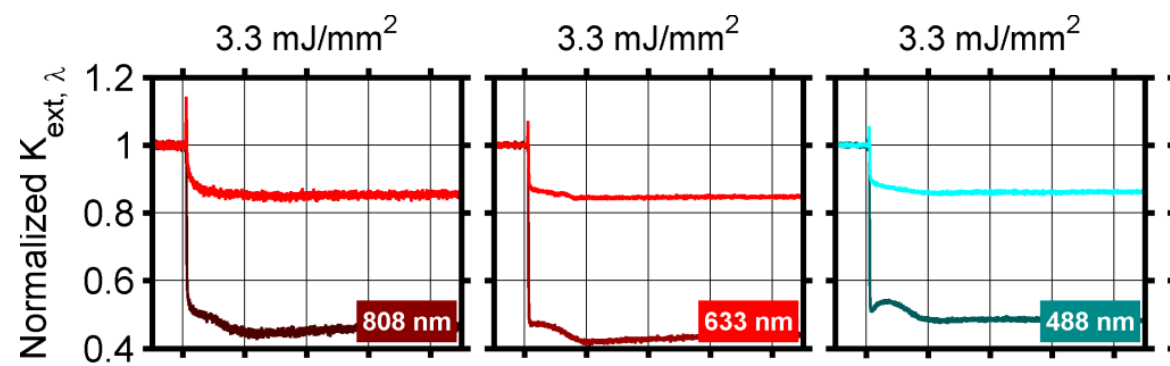

$3.3 \mathrm{~mJ} / \mathrm{mm}^{2}$

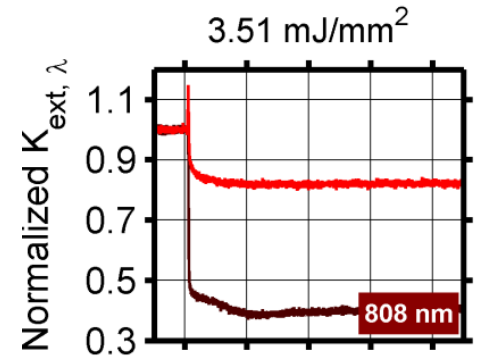

$3.51 \mathrm{~mJ} / \mathrm{mm}^{2}$

$3.51 \mathrm{~mJ} / \mathrm{mm}^{2}$
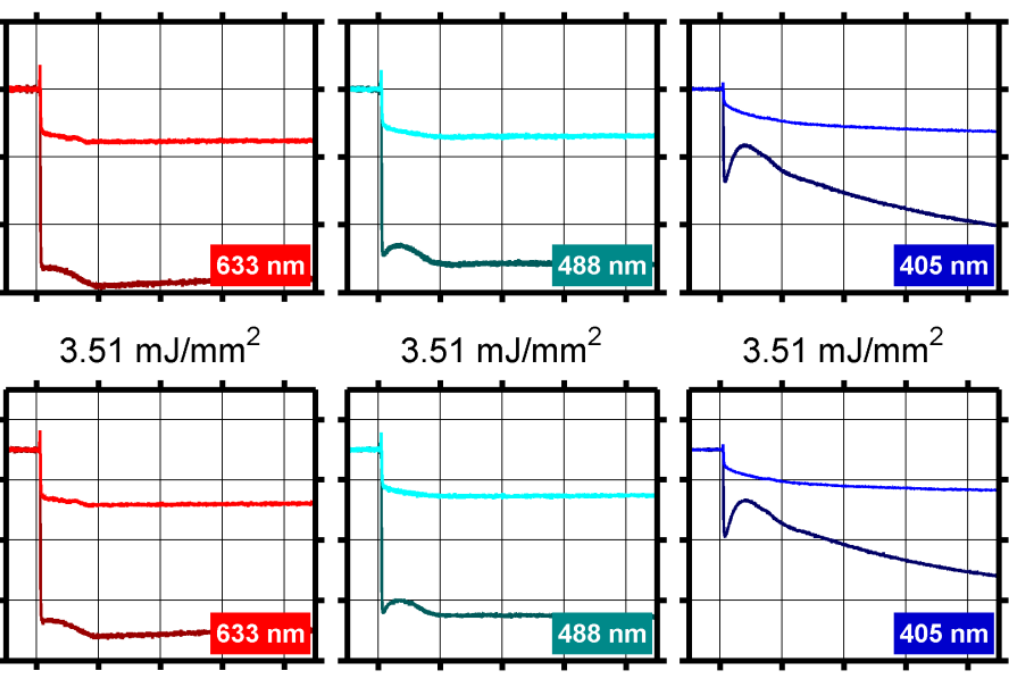

$3.51 \mathrm{~mJ} / \mathrm{mm}^{2}$

$4.12 \mathrm{~mJ} / \mathrm{mm}^{2}$

$4.12 \mathrm{~mJ} / \mathrm{mm}^{2}$

$4.12 \mathrm{~mJ} / \mathrm{mm}^{2}$
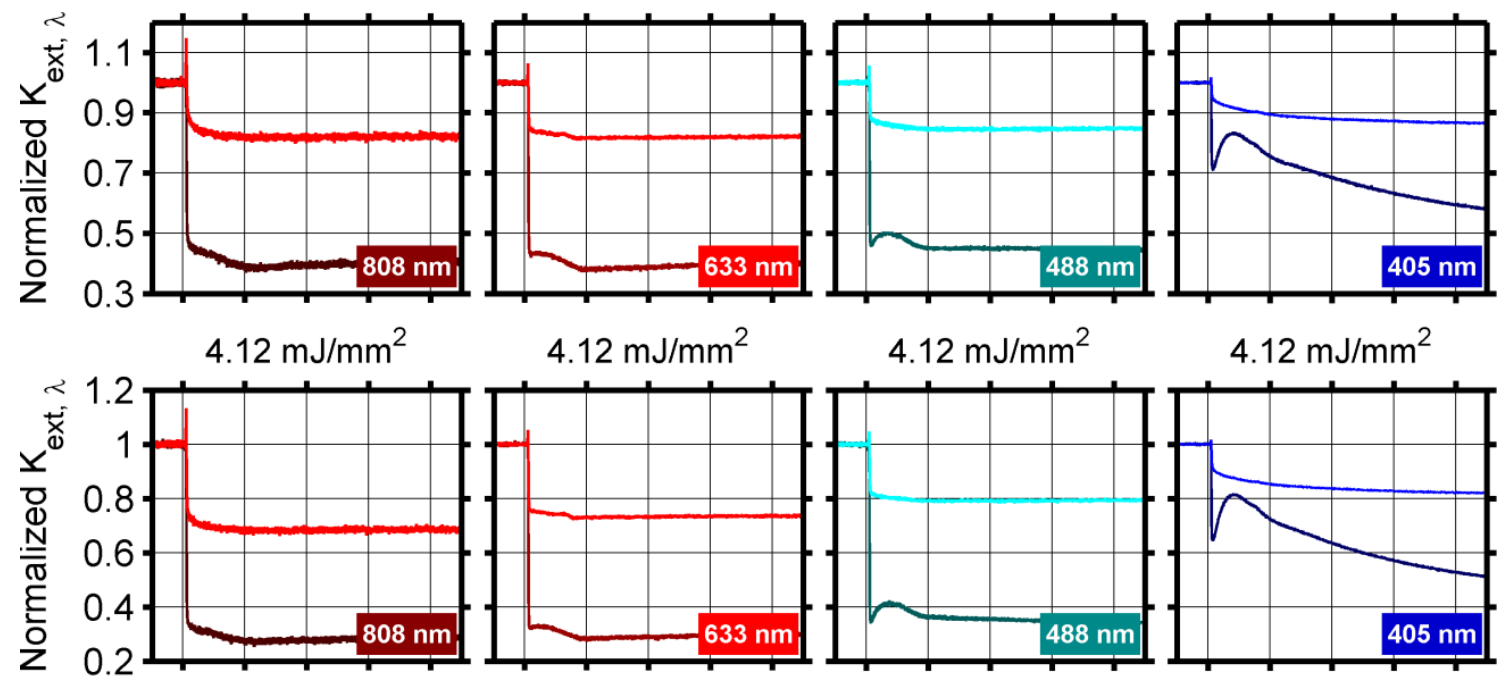

$4.12 \mathrm{~mJ} / \mathrm{mm}^{2}$

$5.15 \mathrm{~mJ} / \mathrm{mm}^{2}$

$5.15 \mathrm{~mJ} / \mathrm{mm}^{2}$
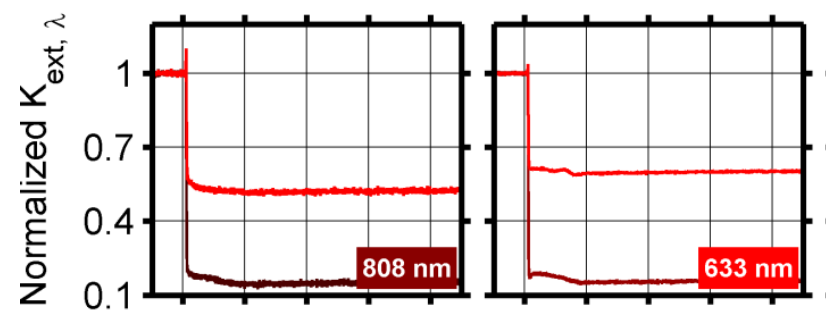

$5.15 \mathrm{~mJ} / \mathrm{mm}^{2}$

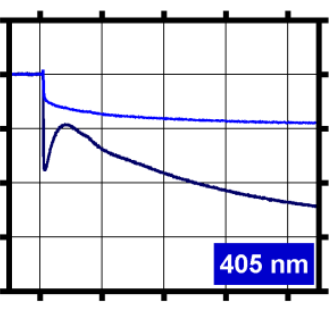

$6.19 \mathrm{~mJ} / \mathrm{mm}^{2}$

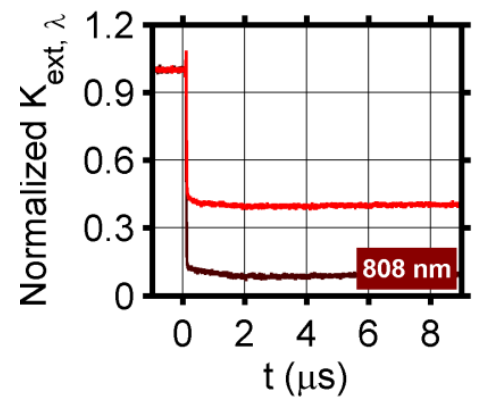

$6.19 \mathrm{~mJ} / \mathrm{mm}^{2}$

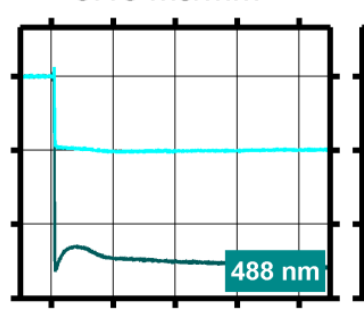

$5.15 \mathrm{~mJ} / \mathrm{mm}^{2}$

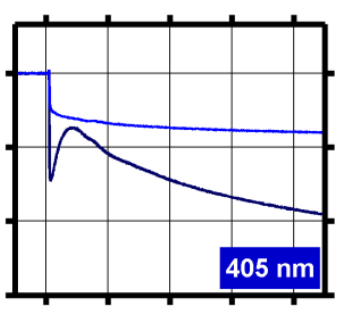

$6.19 \mathrm{~mJ} / \mathrm{mm}^{2}$

$6.19 \mathrm{~mJ} / \mathrm{mm}^{2}$
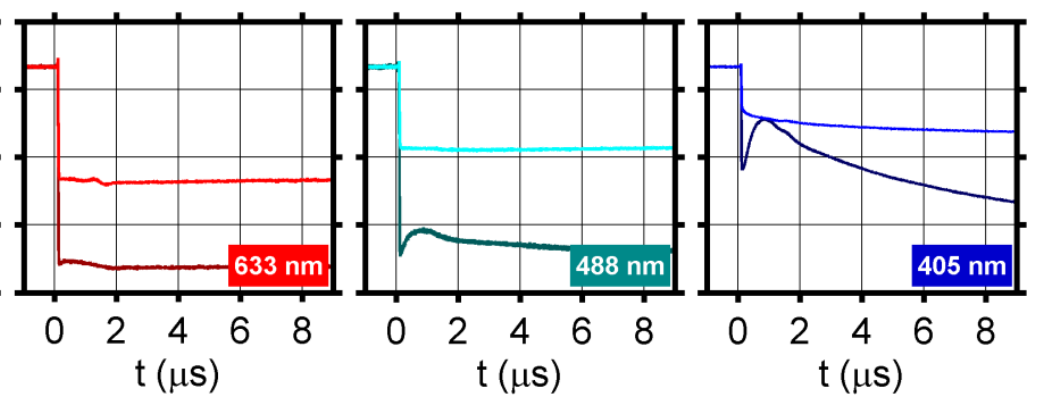

Diffusion flame

Diffusion flame

Diffusion flame $\mathrm{t}(\mu \mathrm{s})$

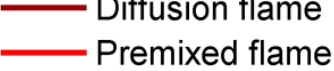
Premixed flame

- Diffusion flame

Fig. S20 Comparing extinction profiles in the diffusion and premixed flames, at four wavelengths and for fluence ranging from 3.30 to $6.19 \mathrm{~mJ} / \mathrm{mm}^{2}$, up to $\mathrm{t}=9 \mu \mathrm{s}$. The profiles measured in the diffusion flame are shown with darker lines and the results measured in the premixed flame are shown with the brighter lines. 

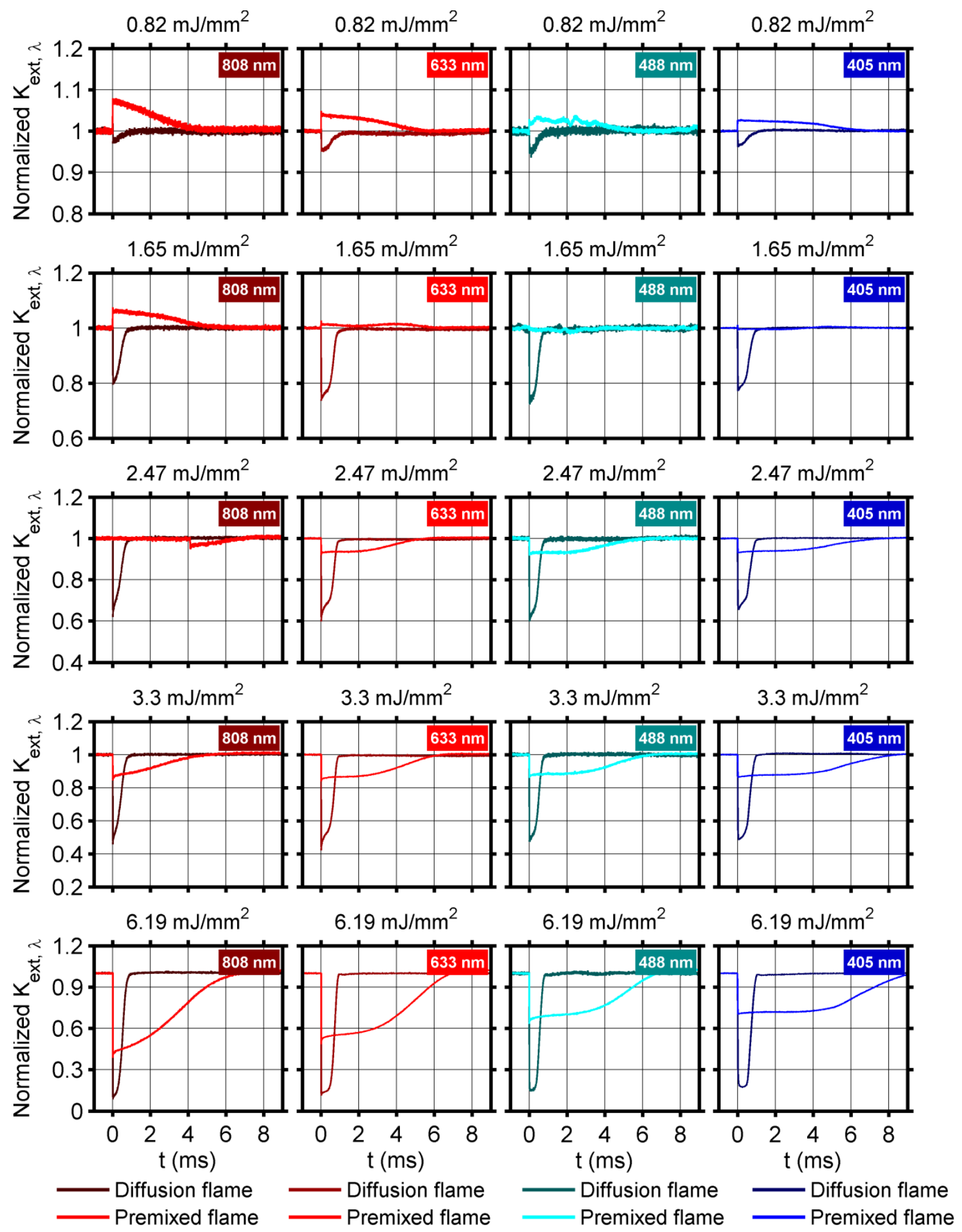

Fig. S21 Comparing extinction profiles in the diffusion and premixed flames at four wavelengths and five fluence levels, from $1 \mathrm{~ms}$ before to $9 \mathrm{~ms}$ after the laser pulse. The profiles measured in the diffusion flame are shown with darker lines and the results measured in the premixed flame are shown with the brighter lines. 